Aus der Poliklinik für Zahnärztliche Prothetik

(Prof. Dr. med. dent. R. Bürgers)

im Zentrum Zahn-, Mund- und Kieferheilkunde

der Medizinischen Fakultät der Universität Göttingen

\title{
Einfluss von Wachstumsfaktoren auf die Migration von mesenchymalen Progenitorzellen im menschlichen Kniemeniskus
}

\author{
INAUGURAL - DISSERTATION \\ zur Erlangung des Doktorgrades \\ der Medizinischen Fakultät der \\ Georg-August-Universität zu Göttingen
}

\author{
vorgelegt von \\ Claus Christian von der Burchard \\ aus Kiel
}

Göttingen 2015 
Dekan: Prof. Dr. rer. nat. H. K. Kroemer

I. Berichterstatter: $\quad$ Prof. Dr. med. N. Miosge

II. Berichterstatter: Prof. Dr. Rüdiger Behr

III. Berichterstatter:

Tag der mündlichen Prüfung: $\quad$ 16.06.2015 



\section{Inhaltsverzeichnis}

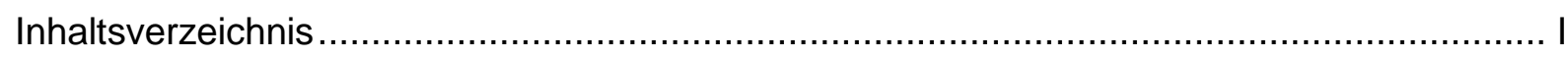

Abbildungs- und Tabellenverzeichnis ..................................................................... IV

Abkürzungsverzeichnis...........................................................................................

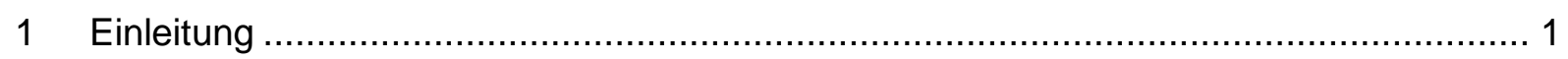

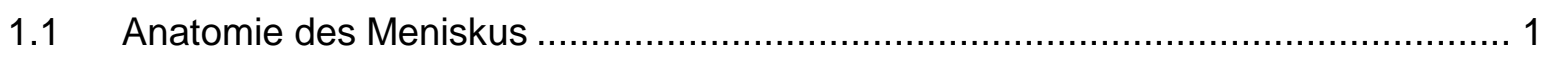

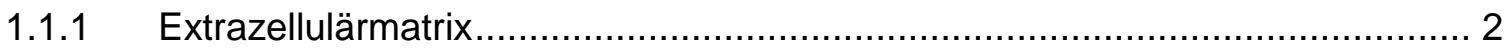

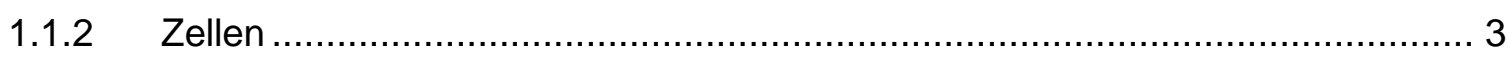

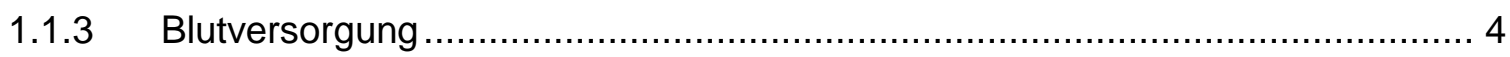

1.2 Krankheiten des Meniskus ……………………...................................... 5

1.2.1 Degenerative Erkrankungen ....................................................................

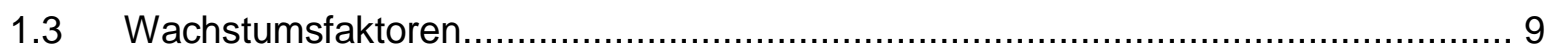

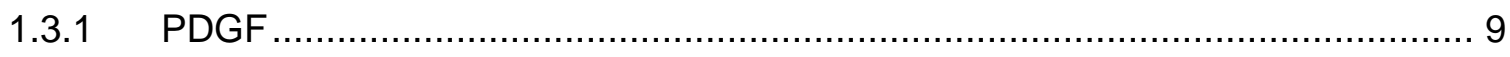

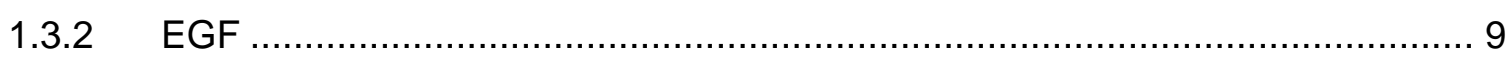

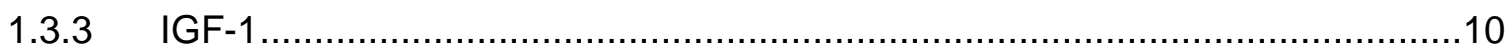

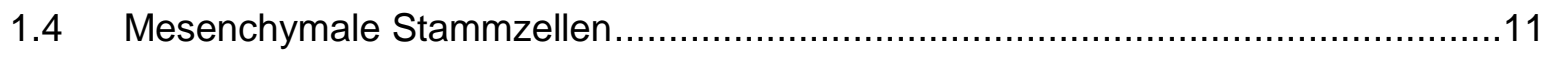

1.4.1 Mesenchymale Progenitorzellen im Meniskus ...............................................14

1.4.2 Migration von MSCs ..........................................................................15

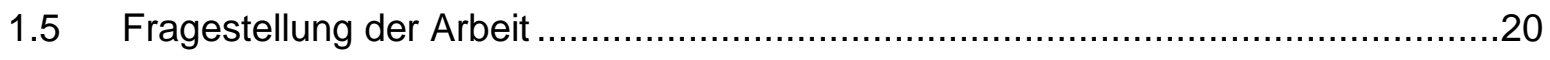

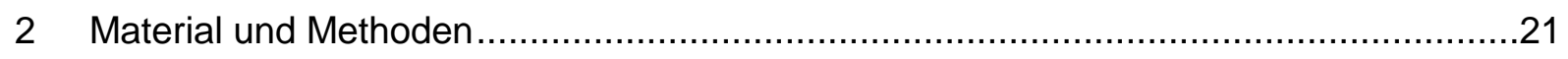

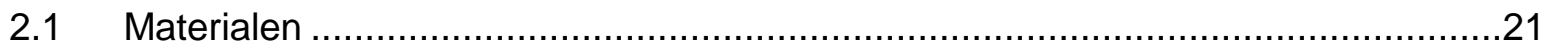

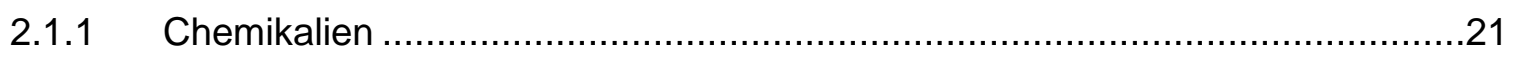

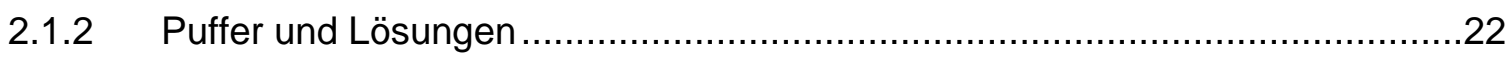

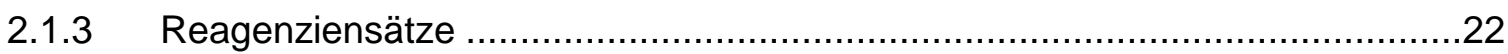

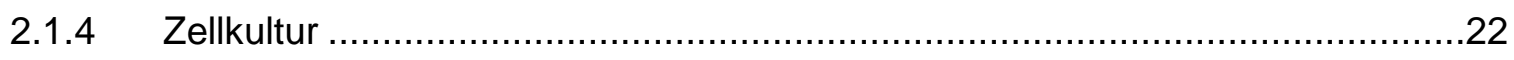

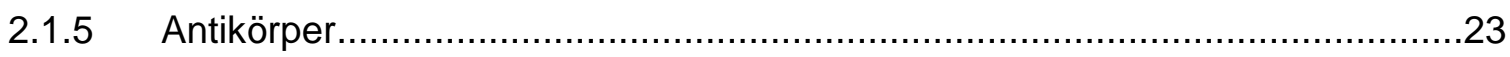

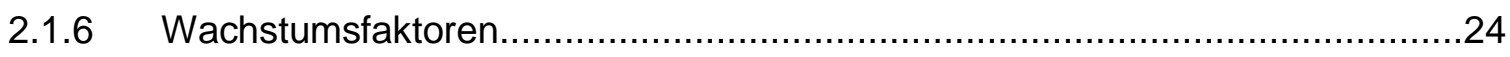

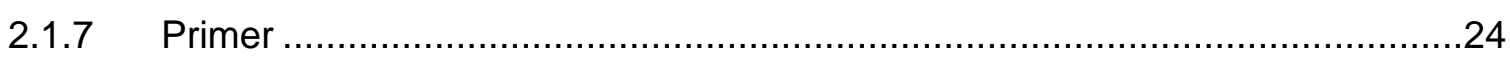




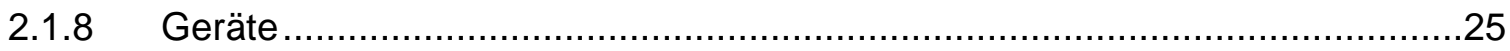

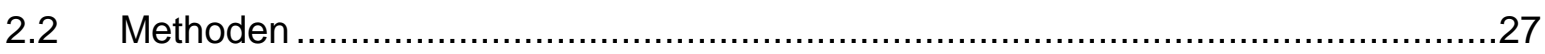

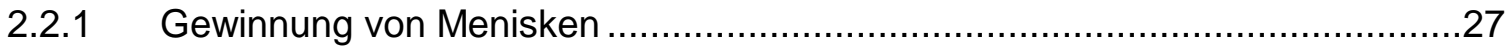

2.2.2 Gewinnung von mesenchymalen Progenitorzellen (MPCs) ..........................27

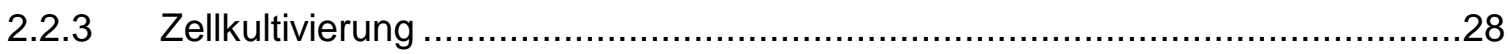

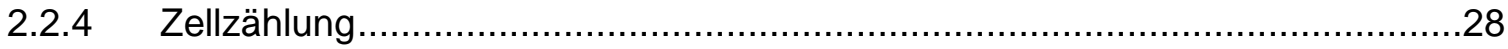

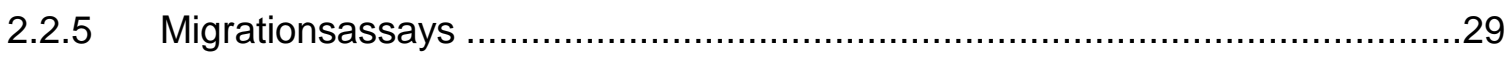

2.2.6 Quantitativer mRNA-Nachweis mithilfe von real-time RT-PCR ......................30

2.2.6.1 Durchführung der RNA-Isolation aus Zellen .......................................

2.2.6.2 Umschreiben der RNA in cDNA ....................................................

2.2.6.3 Durchführung der PCR ................................................................. 32

2.2.6.4 Standardisierung der Messwerte .....................................................32

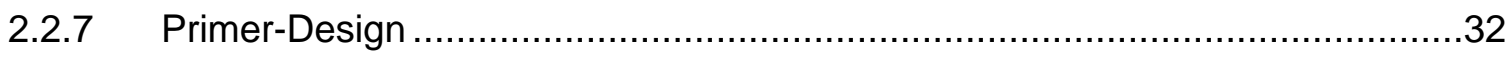

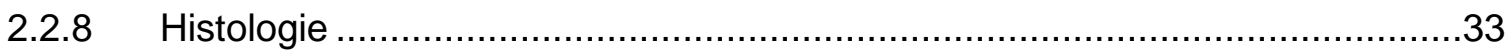

2.2.8.1 Herstellen von Paraffin-Präparaten ...................................................3

2.2.8.2 Herstellung der Schnitte im Mikrotom .....................................................34

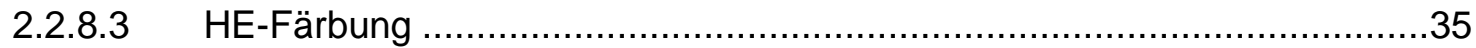

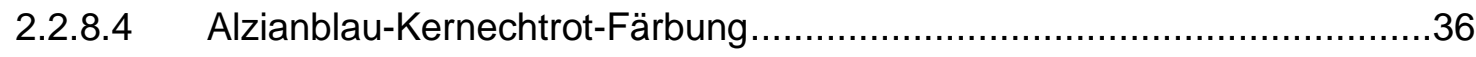

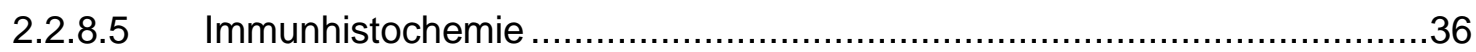

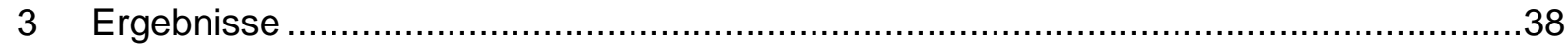

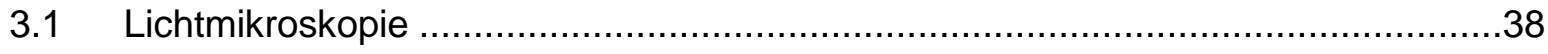

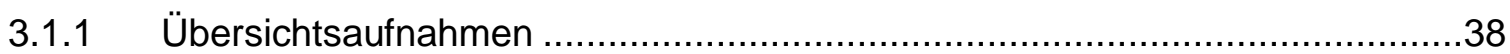

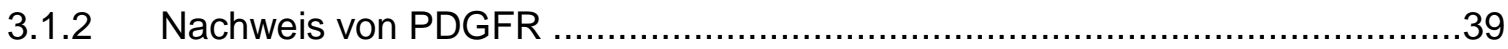

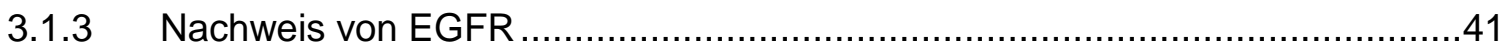

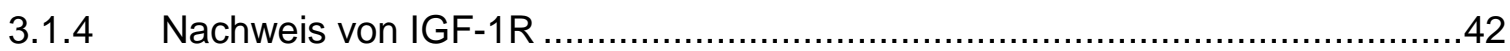

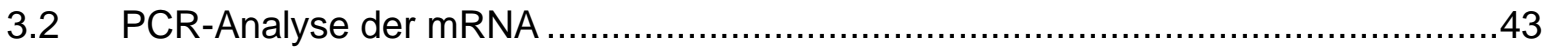

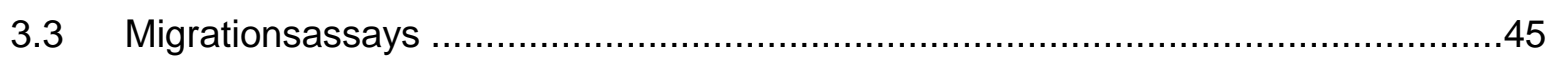

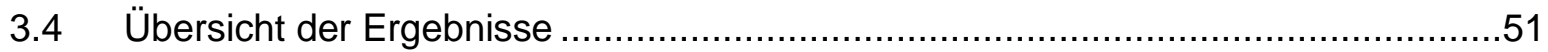

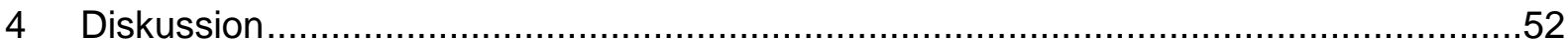

4.1 Einfluss der Wachstumsfaktoren auf die Migration .........................................52 


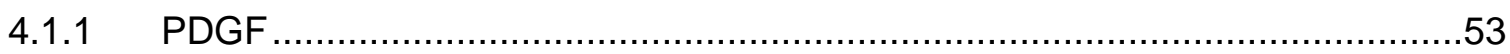

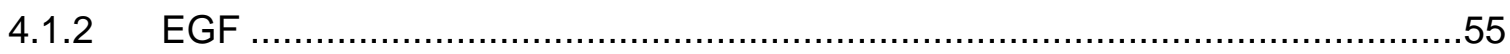

4.1.3 IGF-1

4.1.4 Zusammenhang zwischen der Inkubationszeit und dem Migrationsverhalten..58

4.2 Klinische Relevanz und weitere Forschung .................................................

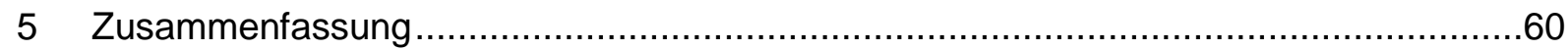

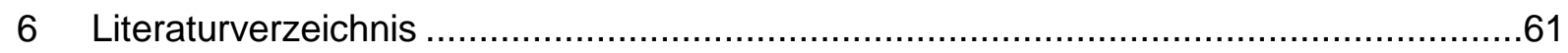




\section{Abbildungs- und Tabellenverzeichnis}

Abbildung 1: Übersicht über die Bandstrukturen der Menisken......................................... 2

Abbildung 2: Schema der Zellen im Meniskus. ........................................................ 4

Abbildung 3: Skizze der Zellmigration.................................................................. 18

Abbildung 4: Skizze der Einzeilung des Meniskus in Zonen. .........................................28

Abbildung 5: Schnitt der Oberfläche eines Meniskus, Alzianblau-Kernechtrot-Färbung........38

Abbildung 6: Schnitt durch die Innenzone des Meniskus, Immunhistochemie für PDGFR ....40

Abbildung 7: Schnitt durch die Innenzone des Meniskus, Immunhistochemie für EGFR .......41

Abbildung 8: Schnitt durch die Innenzone des Meniskus, Immunhistochemie für IGF-1R ....42

Abbildung 9: Relativer mRNA-Gehalt für PDGFR ......................................................43

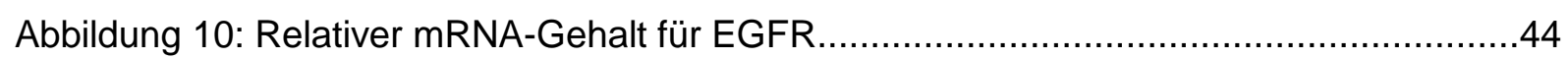

Abbildung 11: Relativer mRNA-Gehalt für IGF-1R ................................................44

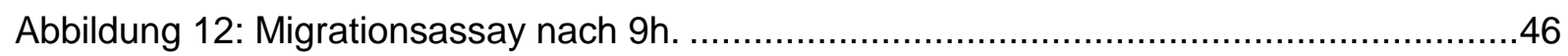

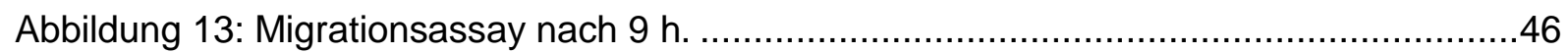

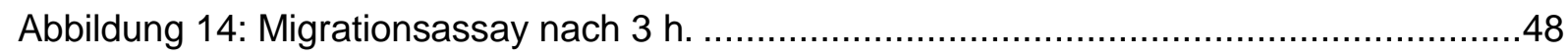

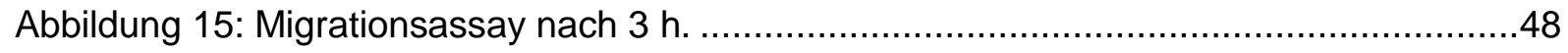

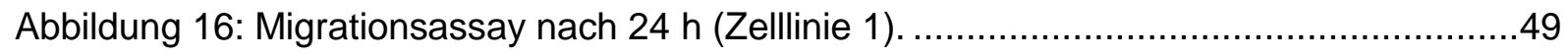

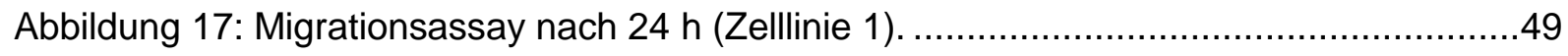

Abbildung 18: Migrationsassay nach $24 \mathrm{~h}$ (Zelllinie 2). ...............................................50

Abbildung 19: Migrationsassay nach $24 \mathrm{~h}$ (Zelllinie 2). ................................................50

Abbildung 20: Einfluss von PDGF auf die Migration von Chondrozyten. .............................54

Tabelle 1: Liste der verwendeten Chemikalien ........................................................21

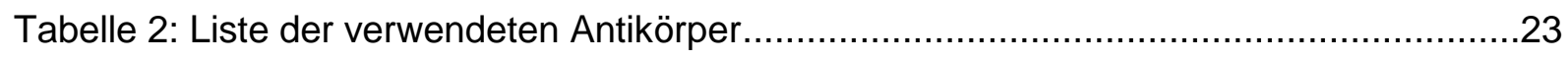

Tabelle 3: Liste der verwendeten Wachstumsfaktoren.....................................................24

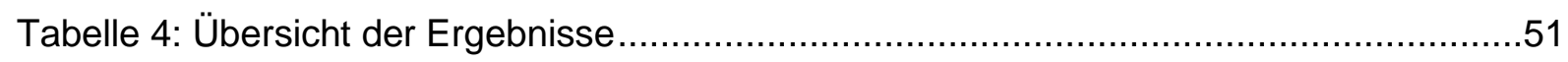

Tabelle 5: Übersicht über den Einfluss von verschiedenen Wachstumsfaktoren auf die Zellmigration 


\section{Abkürzungsverzeichnis}

\begin{tabular}{|c|c|}
\hline ATP & Adenosintriphosphat \\
\hline $\mathrm{BCP}$ & basic calcium phosphate \\
\hline BM-MSC & bone marrow mesenchymal stem cell \\
\hline BMP & bone morphogenetic protein \\
\hline BSA & bovines Serumalbumin \\
\hline CD & cluster of differentiation \\
\hline CPC & chondrogene Progenitorzelle \\
\hline DMEM & Dulbecco's Modified Eagle's Medium \\
\hline DNA & Desoxyribonukleinsäure (deoxyribonucleic acid) \\
\hline EDTA & Ethylendiamintetraessigsäure \\
\hline EGF & endothelial growth factor \\
\hline EGFR & endothelial growth factor receptor \\
\hline EZM & Extrazellulärmatrix \\
\hline FCS & fetal calf serum \\
\hline G & Erdbeschleunigung \\
\hline $\mathrm{GH}$ & Somatotropin = Wachstumshormon (growth hormone) \\
\hline $\mathrm{h}$ & Stunde \\
\hline $\mathrm{HE}$ & Hämatoxylin-Eosin \\
\hline IGF-1 & insulin-like growth factor 1 \\
\hline IGF-1R & insulin-like growth factor 1 receptor \\
\hline IL & Interleukin \\
\hline ISCT & International Society for Cellular Therapy \\
\hline MMP & Matrixmetalloprotease \\
\hline MPC & meniscal progenitor cell \\
\hline mRNA & messenger RNA \\
\hline MSC & mesenchymale Stammzelle \\
\hline $\mathrm{NCBI}$ & National Center for Biotechnology Information \\
\hline PBS & phosphate buffered saline \\
\hline PCR & Polymerasekettenreaktion (polymerase chain reaction) \\
\hline PDGF & platelet-derived growth factor \\
\hline PDGFR & platelet-derived growth factor receptor \\
\hline $\mathrm{PIP}_{3}$ & Phosphatidylinositol-3,4,5-Trisphosphat \\
\hline RNA & Ribonukleinsäure (ribonucleic acid) \\
\hline RT-PCR & reverse transcriptase polymerase chain reaction \\
\hline
\end{tabular}


TERT

TGF

TNF- $\alpha$

VEGF telomerase reverse transcriptase

Transforming growth factor

Tumornekrosefaktor $\alpha$

vascular endothelial growth factor 


\section{Einleitung}

\subsection{Anatomie des Meniskus}

Unter Kniemenisken versteht man die im Kniegelenk enthaltenen konkav-konvexen bindegewebigen Strukturen zwischen Tibia und Femur. Ihre hauptsächliche Aufgabe besteht darin, die „Inkongruenz von Femur und Tibia auszugleichen“ und damit die gleichmäßige Verteilung des Gelenkdruckes sicherzustellen (Walker und Erkman 1975, Petersen und Tillmann 1999).

In der Literatur werden die Kniemenisken häufig als halbmondförmig beschrieben, bei genauerer Betrachtung zeigen sie sich im Längsschnitt jedoch eher als konkav-konvex bzw. cförmig. Im Querschnitt sind die Menisken keilförmig aufgebaut und gleichen somit die lateralen Rundungen der Femurkondyle aus.

Pro Kniegelenk finden sich jeweils zwei Menisken, ein lateraler und ein medialer Meniskus, die zusammen etwa $70 \%$ der Kontaktfläche des Gelenkes bedecken (Fukubayashi und Kurosawa 1980). Der mediale Meniskus ist dabei mit einer durchschnittlichen Länge von 45,7 $\pm 5.0 \mathrm{~mm}$ ein wenig größer als der laterale Meniskus mit einer durchschnittlichen Länge von 35,7 \pm 3,7 mm (McDermott et al. 2004). Die Menisken sind jeweils an den Seitenrändern mit der Gelenkkapsel verbunden, außerdem verfügt der mediale Meniskus über eine feste Verbindung zum medialen Seitenband (Beaufils und Verdonk 2010).

Die Menisken können im Längsschnitt in Vorderhorn, Körper und Hinterhorn unterteilt werden. Vorder- und Hinterhorn sind an ihren Enden über verlängerte Kollagenfasern aus dem Meniskuskörper in der Area intercondylaris anterior bzw. posterior am Tibiaplateau verankert (Beaufils und Verdonk 2010, Schünke et al. 2007). Zusätzlich besteht mit dem Ligamentum transversum genus eine Verbindung zwischen den beiden Vorderhörnern der Menisken (Nelson und LaPrade 2000).

Des Weiteren findet sich noch eine variable Aufhängung des Hinterhorns der lateralen Menisken am medialen Femurkondylus. Dabei treten als Varianten das häufigere hinter dem hinteren Kreuzband verlaufende Ligamentum meniscofemorale posterius (Ligamentum Wrisberg) und das seltenere vor dem hinteren Kreuzband verlaufende Ligamentum meniscofemorale anterius (Ligamentum Humphrey) auf (Wan und Felle 1995). Die Funktion dieser Bänder wird teilweise unterschiedlich bewertet, am häufigsten wird ihnen eine zusätzliche Begrenzung der hinteren tibiofemoralen Verschiebung zugeschrieben (u.a. Kusayama et al. 1994). 
Während der Bewegung des Kniegelenkes entsteht durch diese Aufhängung eine kombinierte Roll- und Gleitbewegung, wobei sich die femorotibiale Kontaktfläche und damit auch die Lage der Menisken mit zunehmender Flexion nach hinten verlagert (Yao et al. 2008). Dabei ist die Bewegung des medialen Meniskus durch die weiter auseinanderstehende und dadurch straffere Aufhängung geringer (Schünke 2007).

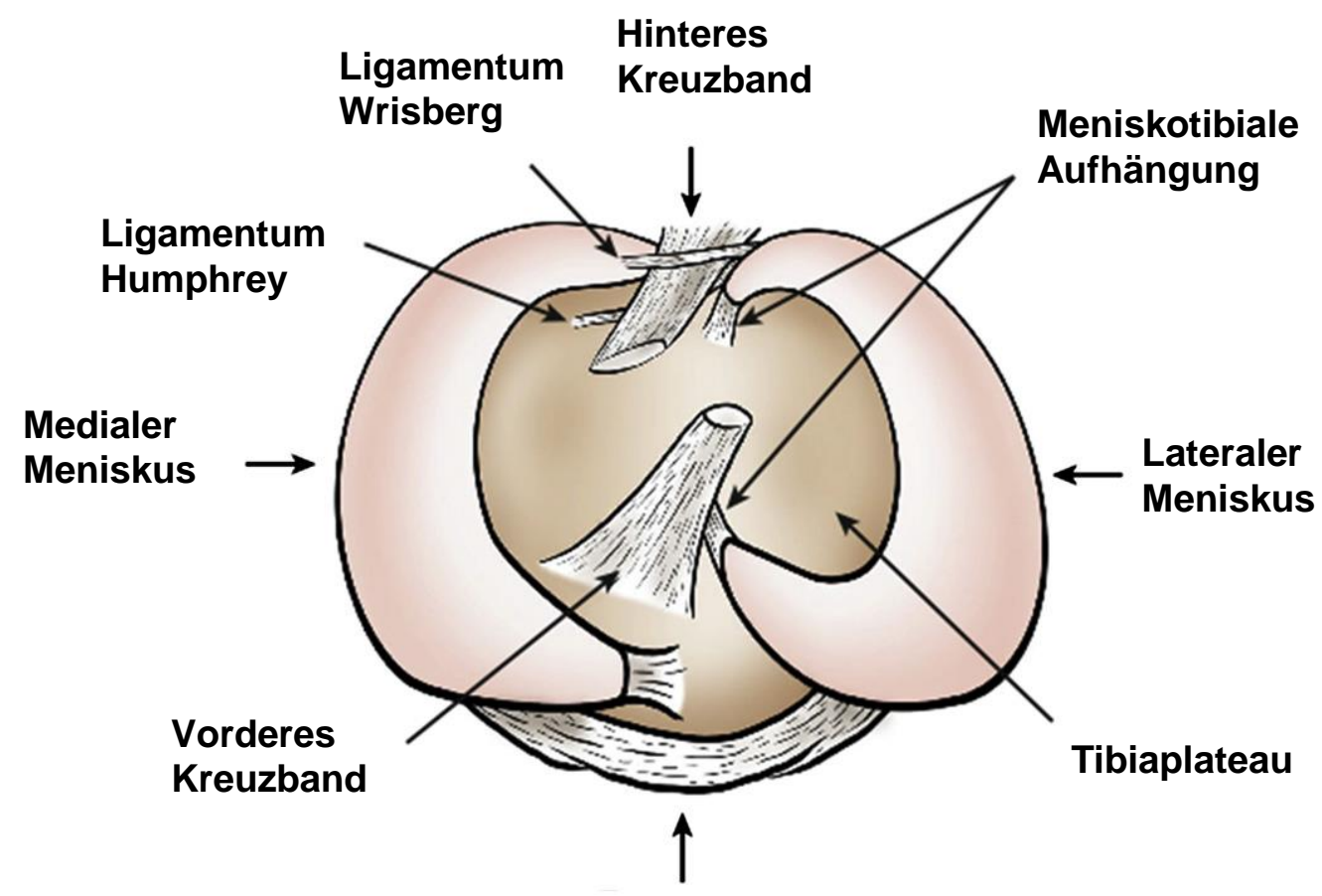

Ligamentum transversum genus

Abbildung 1: Übersicht über die Bandstrukturen der Menisken. Modifiziert nach Makris et al. 2011, S. 7413

\subsubsection{Extrazellulärmatrix}

Der Meniskus besteht zu etwa $72 \%$ aus Wasser, $22 \%$ aus Kollagen, 0,8 \% Glykosaminoglykanen und $0.12 \%$ DNA (Herwig et al. 1984), die Trockenmasse besteht zu $78 \%$ aus Kollagen und $8 \%$ nicht-kollagenösem Protein (Ingman et al. 1974).

$80 \%$ des Kollagens bestehen dabei aus Kollagen Typ I, der Rest aus den Typen II, III und IV (boviner Meniskus, Cheung 1987). In der inneren Zone des Meniskus findet sich hingegen eine andere Verteilung: 60 \% Kollagen Typ II, 40 \% Kollagen Typ I.

Bezüglich der Ausrichtung der Kollagenfibrillen gibt es detaillierte Untersuchungen durch Petersen und Tillmann (1999). Diese unterteilen die Kollagenfibrillen in 3 unterschiedliche Schichten: Oberflächlich findet sich zunächst ein etwa $10 \mu \mathrm{m}$ dickes Netzwerk von Fibrillen ohne bevorzugte Ausrichtung. An der tibialen und femoralen Oberfläche folgt darauf eine lamellenartig aufgebaute Schicht, in der sich Faserbündel netzartig überkreuzen. Die Dicke 
dieser Schicht beträgt $150 \mu \mathrm{m}$ und nimmt nach innen ab. Der zentrale Hauptteil besteht aus $120 \mu \mathrm{m}$ dicken Fibrillen, welche zirkulär angeordnet sind. Diese werden von lamellenartigen Faserzügen in radiärer Richtung durchbrochen, denen eine Verhinderung der longitudinalen Splittung zugeschrieben wird (Bullough et al. 1970).

Der Meniskus wird dem Faserknorpel zugerechnet, wobei die äußere Zirkumferenz auch als straffes Bindegewebe gewertet wird (Petersen und Tillmann 1999).

\subsubsection{Zellen}

Ghadially et al. beschrieben 1983 drei verschiedene Zelltypen im Meniskus: Chondrozyten, Fibroblasten und Zellen mit einem intermediären Phänotyp. Diese Zuteilung unternahmen die Autoren anhand der Zellform und der An- oder Abwesenheit einer territorialen Matrix. Gleichzeitig unterteilten sie die Chondrozyten noch in die spindelförmigen Chondrozyten an den Meniskusoberflächen und die eher rund-ovalen Chondrozyten der inneren Schichten. Später wurde der Terminus Chondrozyt aufgrund der Unterscheidung zwischen hyalinem Knorpel und Faserknorpel zu Fibrochondrozyt präzisiert (McDevitt und Webber 1990).

Inzwischen hat sich in der Literatur folgende Einteilung der Zellen etabliert (u.a. Ghadially et al. 1983; Hoberg et al. 2006; Beaufils und Verdonk 2010; Makris et al. 2011):

1. Fibrochondrozyten: Fibrochondrozyten besitzen eine runde oder ovale Form und synthetisieren hauptsächlich Kollagen Typ I. Sie sind der häufigste Zelltyp im inneren und mittleren Meniskusdrittel. Verglichen mit den fibroblastenähnlichen Zellen (s.u.) weisen sie eine höhere mechanische Steifigkeit auf (Sanchez-Adams und Athanasiou 2012). Das Gebiet ihres Hauptvorkommens wird in dieser Arbeit als innere Zone bezeichnet.

2. Fibroblasten-ähnliche Zellen: Diese Zellen finden sich im äußeren Meniskusdrittel und weisen keine perizelluläre Matrix auf. Im Gegensatz zu den Fibrochondrozyten sind diese Zellen untereinander mit gap junctions verbunden (Hellio Le Graverand et al. 2001). Das Gebiet ihres Hauptvorkommens wird in dieser Arbeit als äußere Zone bezeichnet. 
3. Zellen der oberflächlichen Zone: Diese spindelförmigen Zellen finden sich lediglich direkt unter den Meniskusoberflächen. Nach Ansicht vieler Autoren finden sich besonders in dieser Zone Stammzellen (Beaufils und Verdonk 2010). Das Gebiet ihres Hauptvorkommens wird in dieser Arbeit als oberflächliche bzw. superfizielle Zone bezeichnet.

Entsprechend dieser Einteilung untersuchen viele Autoren die Zellen der inneren, äußeren und oberflächlichen Zone getrennt. Auch in dieser Arbeit wurden die Menisken anhand der verschiedenen Zonen unterteilt.

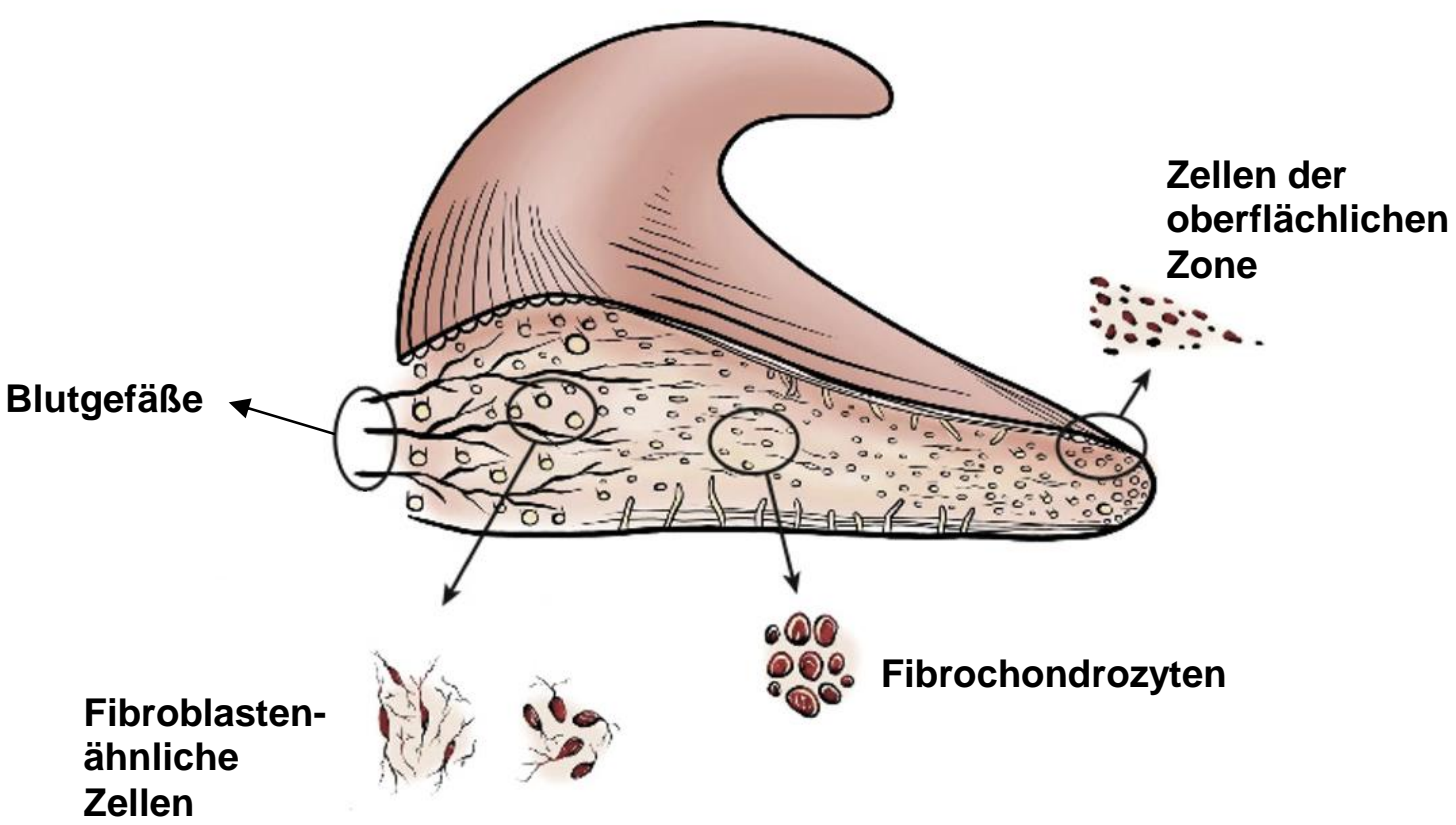

Abbildung 2: Schema der Zellen im Meniskus. Modifiziert nach Makris et al. 2011, S. 7413

\subsubsection{Blutversorgung}

Die Blutversorgung der Menisken erfolgt über die Gelenkkapsel und den hieraus entspringenden Arteriae geniculatae inferiores mediales et laterales sowie den Arteriae geniculatae mediales (Arnoczky und Warren 1982). Petersen und Tillmann haben 1995 gezeigt, dass zum Zeitpunkt der Geburt zwar der gesamte Meniskus vaskularisiert ist, diese Vaskularisation jedoch schon ab der frühen Kindheit zu großen Teilen verschwindet und im Erwachsenenalter nur noch in den äußeren Meniskusanteilen vorliegt.

Für den erwachsenen menschlichen Meniskus hat sich daher das Modell der Aufteilung der Vaskularisierung in 3 Zonen etabliert (Makris et al. 2011): Eine reichlich durchblutete äußere rote Zone, eine weniger durchblutete mittlere rot-weiße-Zone und eine avaskuläre innere weiße Zone. Bei Erwachsenen ist das Ausmaß der Vaskularisierung interindividuell unter- 
schiedlich, das Ausmaß der Eindringtiefe der Gefäße wird meist mit 10-30 \% der Meniskusbreite (Arnoczky und Warren 1982) angegeben.

\subsection{Krankheiten des Meniskus}

Für den Meniskus ist eine Reihe von Erkrankungen bekannt. Diese beinhalten kongenitale Anomalien, Traumata, Entzündungen, metabolische Störungen, degenerative Erkrankungen und Neoplasien, wobei klinisch die traumatischen Erkrankungen die wichtigste Rolle einnehmen (Hough und Webber 1990).

Tatsächlich ist das Kniegelenk das am häufigsten verletzte Gelenk bei jüngeren Patienten, und $15 \%$ aller Knieverletzungen gehen mit Meniskusverletzungen assoziiert (Vrancken et al. 2013). Gefürchtet sind insbesondere Meniskusrisse, die um ein Mehrfaches häufiger am medialen als am lateralen Meniskus vorkommen (Hough und Webber 1990). Diese Risse sind in der Regel vertikal und longitudinal ausgerichtet (Vrancken et al. 2013) und heilen lediglich in der peripheren vaskulären Region (Hough und Webber 1990). Die meisten Patienten mit einem Riss der inneren avaskulären Region werden nach wie vor mit einer partiellen, subtotalen oder totalen Meniskusentfernung therapiert und sind damit für die Entwicklung einer Arthrose prädisponiert (Haddad et al. 2013). Von diesen traumatischen Rissen abzugrenzen sind degenerative Meniskusrisse, die in der Regel horizontal verlaufen und eng mit der Arthrose verbunden sind (Noble und Hamblen 1975).

In dieser Arbeit soll hauptsächlich auf degenerative Meniskuserkrankungen eingegangen werden.

\subsubsection{Degenerative Erkrankungen}

Arthrose (englisch: osteoarthritis, kurz $O A$ ) ist die häufigste Gelenkserkrankung von Erwachsenen weltweit (Felson 1988) und betrifft vor allen Dingen die Knie, die Hüfte sowie die Hände (Michael et al. 2010). In einer Prävalenzstudie innerhalb der Bundesrepublik Deutschland zeigte eine Befragung von 18- bis 79-Jährigen, dass 27,7 \% angaben, an Arthrose mindestens einer Gelenksregion zu leiden (Schneider et al. 2005). Die Autoren schätzen die daraus resultierenden Kosten allein innerhalb der Bundesrepublik auf 3,5 bis 5,4 Milliarden Euro pro Jahr ein.

Die Arthrose ist eine degenerative Erkrankung, welche das gesamte Gelenk betrifft (Felson et al. 2000). Dieser Prozess beinhaltet die progressive Destruktion von hyalinem Knorpel mit gleichzeitigen Schäden des darunterliegenden Knochens, aber eben auch die Erkrankung der Weichteile im und um das Gelenk, namentlich Synovium, Ligamente, Muskulatur und Menisken. Die genaue Definition der Arthrose ist jedoch gleich mehrfach schwierig: 
Zum einen ist nämlich unklar, ob Arthrose wirklich eine einzige Erkrankung ist, oder verschiedene Störungen mit einem ähnlichen finalen gemeinsamen Weg (Felson et al. 2000). Für Letzteres sprechen laut diesen Autoren unterschiedliche Gründe:

1. Arthrosen verschiedener Lokalisationen unterscheiden sich in ihren Risikofaktoren.

2. Bei einer generalisierten Arthrose könnte es sich um eine eigene Erkrankung handeln, bei der genetische Faktoren wichtiger sind als lokale, mechanische Faktoren.

3. Die Unterscheidung zwischen primärer und sekundärer Arthrose, die weiter unten genauer erläutert wird.

4. Zumindest für die Hüftarthrose gibt es unterschiedliche Formen, namentlich die hypertrophe und atrophe Form, die wiederum mit unterschiedlichen Skeletterkrankungen assoziiert sind.

Zum anderen ist unklar, ab wann von einer Arthrose zu sprechen ist. Die etabliertesten Diagnosekriterien beruhen entweder auf einer radiologischen oder einer klinischen Evaluation (Petersson und Jacobsson 2002). Gleichzeitig gibt es jedoch erhebliche Unstimmigkeiten sowohl zwischen diesen Kriterien untereinander als auch zwischen Kriterien und dem subjektiven Schmerzgefühl des Patienten (Hannan et al. 2000).

Die klassische Einteilung der Arthrose unterscheidet zwischen einer primären, idiopathischen und verschiedenen sekundären Formen (Michael et al. 2010). Die primäre Form ist demnach eine anlagebedingte, nicht mit bestimmten Vorerkrankungen assoziierte Störung des Gelenkknorpels mit einer daraus resultierenden verminderten Belastbarkeit. Die sekundären Formen umfassen posttraumatische bzw. postoperative Zustände, kongenitale Malformationen und Dysplasien, Malpositionen (Varus- und Valgusstellungen), aseptische Knochennekrosen sowie Patienten mit verschiedenen metabolischen und endokrinen Erkrankungen (Michael et al. 2010). Gleichzeitig gibt es jedoch Autoren, die schon seit langem an dieser Klassifikation zweifeln und die davon ausgehen, dass jeder Arthrose eine (zuweilen unbekannte) Erkrankung vorausgeht (Solomon 1976, Mitchell und Cruess 1977).

Gut bekannt sind verschiedene Risikofaktoren für die Ausbildung einer Arthrose. Dabei wird zwischen endogenen und exogenen Risikofaktoren unterschieden. Wie bei einer degenerativen Erkrankung nicht anders zu erwarten, ist das Alter dabei der wichtigste Risikofaktor (Schneider et al. 2005). Ebenso zeigen sich unterschiedliche Ausprägungen der Arthrose zwischen den Geschlechtern sowie beim weiblichen Geschlecht Unterschiede in der Prävalenz zwischen prä- und postmenopausalen Frauen (Felson et al. 2000, Michael et al. 2010). Zwillingsstudien konnten einen wichtigen genetischen Einfluss nachweisen (Spector et al. 1996). Ebenso konnten Unterschiede zwischen Angehörigen verschiedener Ethnien gezeigt werden (Anderson und Felson 1988). Als exogene Risikofaktoren gelten Traumata 
und Operationen (Michael et al. 2010), Übergewicht (Grotle et al. 2008), Tabakkonsum und ungesunde Ernährung sowie mangelnde sportliche Belastung (Schneider et al. 2005). Schließlich zeigten sich einige berufliche Tätigkeiten als wichtiger Risikofaktor, insbesondere Tätigkeiten mit hoher Kniebelastung wie z.B. bei Fliesen- und Teppichlegern (Jensen et al. 2000). Für den Alkoholkonsum konnte hingegen keine signifikante Risikoveränderung nachgewiesen werden (Schneider et al. 2005).

Während eine Arthrose klinisch inapparent verlaufen kann (Hannan et al. 2000), äußert sich die Erkrankung für viele Patienten vor allen Dingen in ausgeprägten Schmerzen. Interessanterweise ist die genaue Ursache und Pathogenese dieses Schmerzes nicht verstanden (Felson et al. 2000). Weitere klinische Symptome sind unter anderem Gelenksteifigkeit, Bewegungseinschränkungen, Krepitationen sowie verstärkte Hitze- und Kälteempfindlichkeit (Michael et al. 2010).

Pathophysiologisch beginnt die Arthrose mit einem zunehmenden Verlust von hyalinem Knorpel (Buckwalter und Mankin 1997). Dies hat verschiedene Folgen: Zum einen kommt es $\mathrm{zu}$ einer Sklerose des subchondralen Knochens mit Ausbildung von Knochenzysten und marginalen Osteophyten, zum anderen versucht der Körper verschiedene Reparaturmechanismen in Gang zu setzen. Michael et al. beschreiben 2010, dass die vom Körper initiierten Reparaturmechanismen im Anfangsstadium durch gesteigerte Stimulation von Chondrozyten wirksam sind, es jedoch in Folge einer Überstrapazierung der Chondrozyten im Verlauf zu einer Degradation der Knorpelmatrix kommt. Dabei scheinen auch verschiedene Zytokine, insbesondere IL-1 und TNF- $\alpha$, eine Rolle zu spielen, unter anderem durch Aktivierung von knorpelabbauenden MMPs (Matrixmetalloproteasen) (Goldring und Goldring 2004). Der genaue zeitliche Ablauf dieser Mechanismen ist nicht ganz geklärt, einige Autoren vermuten, dass die subchondrale Knochenschädigung der Knorpelschädigung vorausgeht und diese sogar initiiert (Radin und Rose 1986). Histologisch zeigt sich in frühen Stadien eine Ausfransung der superfiziellen Zone des Knorpels mit einhergehendem Proteoglykanverlust, Umbauten im subchondralen Knochen sowie Einwachsen von Gefäßen in den Knorpel (Buckwalter und Mankin 1997). Im zeitlichen Verlauf kommt es dann zu einer zunehmenden Knorpeldegeneration, bis schließlich der nekrotische Knochen freiliegt.

Im Kniegelenk scheint der Meniskus eine entscheidende Rolle in der Arthrose zu spielen. Schon Fairbank beschrieb 1948, dass die Meniskektomie zu radiologischen Veränderungen des Gelenkspaltes führe. Trotzdem blieb die Meniskektomie lange das operative Standardverfahren bei Meniskusverletzungen. 1987 beschrieben Jørgensen et al., dass diese Therapie mit jahrelanger Verzögerung zu einer Gonarthrose führe, weshalb die Meniskektomie heutzutage in der Regel nicht mehr durchgeführt wird. Heute ist bekannt, dass selbst kleinere Meniskusschäden zu einer gesteigerten Belastung des Knorpels führen und somit Risi- 
kofaktor für die Ausbildung der Arthrose sind (Englund et al. 2009). Gleichzeitig führen die Knorpelschäden und der freiliegende Knochen ihrerseits zu einer Schädigung des Meniskus. In welcher zeitlichen Abfolge diese Schädigungen liegen und welche Schädigung die andere mehr beeinflusst, ist dabei interessanterweise nicht geklärt.

Christoforakis et al. zeigten 2005 in einer prospektiven Fallstudie, dass degenerative Risse im Meniskus Knorpelschäden begünstigen. Snoeker et al. vergleichen wiederum 2013 in einer Metaanalyse die Risikofaktoren für Risse im Meniskus. Dabei fällt auf, dass die Risikofaktoren für degenerative Meniskusrisse denen der Arthrose auffallend ähneln: Alter gröBer als 60 Jahre, Adipositas, kniendes oder hockendes Arbeiten und das Tragen schwerer Lasten.

Eine weitere Komorbidität zwischen Meniskus und Arthrose liegt in der Kalzifizierung. Sun und Mauerhan zeigen 2012 in ihrem Review, dass sowohl der Knorpel als auch die Menisken bei Arthrosepatienten kalzifizieren. Bei Arthrosepatienten können in der Synovialflüssigkeit verschiedene Kristalle nachgewiesen werden, im Wesentlichen basische BCP-Kristalle (basic calcium phosphate crystals, Kalziumphosphatkristalle) und CPPD-Kristalle (calcium pyrophosphate dihydrate crystals, Kalziumpyrophosphatdihydratkristalle). Zwar ist unklar, ob diese Kristalle Grund, Exazerbator oder Folge der Arthrose sind, aber es konnten Kristalle in Studien mit Elektronenmikroskopen in $100 \%$ der Synovialflüssigkeiten von Arthrosepatienten nachgewiesen werden (Nero et al. 2006). Fuerst et al. konnten 2009 auch in 100\% der Knorpel von Arthrose-Patienten Kristalle nachweisen sowie die Tatsache, dass die Chondrozyten selbst die Kristalle bilden, während Chondrozyten aus gesundem Gewebe dieses Verhalten nicht aufwiesen. Sun und Mauerhan berichten 2012 weiter, dass eine starke Korrelation zwischen der Kalzifikation von Menisken und Knorpel bestehe. Demnach sei in jedem Fall einer Knorpelkalzifikation auch eine Meniskuskalzifikation nachweisbar, darüber hinaus sei bei Vorhandensein von Meniskuskalzifikationen auch eine signifikant höhere Prävalenz von Knorpelläsionen zu finden. Ebenso berichten die Autoren, dass in eigenen Experimenten sämtliche Meniskusproben von Arthrosepatienten kalzifiziert waren, während dies in der Kontrollgruppe nicht der Fall war, sowie dass die Meniskuszellen von Arthrosepatienten eine signifikant höhere Mineralproduktion in vitro aufwiesen als die Zellen der Kontrollgruppe.

All diese Erkenntnisse legen den Schluss nahe, dass degenerative Meniskusschäden und Arthrose des Kniegelenkes nah miteinander verwandt sind bzw. dass degenerative Meniskusschäden eventuell sogar als integraler Bestandteil einer Kniegelenksarthrose angesehen werden können. 


\subsection{Wachstumsfaktoren}

\subsubsection{PDGF}

Die Familie der platelet-derived growth factors (PDGF) ist seit den 1970er-Jahren bekannt und besteht nach heutigem Kenntnisstand aus fünf Subtypen (Fredriksson et al. 2004). Dabei besteht der Wachstumsfaktor jeweils aus einem durch Disulfidbrücken verbundenen Dimer aus zwei Polypeptidketten. Dabei sind seit langem die Proteinketten PDGF-A und PDGF-B bekannt, während erst später die weiteren Proteinketten PDGF-C ( $\mathrm{Li}$ et al. 2000) und PDGF-D (Bergsten et al. 2001) entdeckt wurden. Während für die klassischen Proteinketten PDGF-A und -B sowohl Homo- als auch Heterodimere beschrieben wurden, sind für die neueren C- und D-Ketten bisher nur Homodimere bekannt, so dass sich daher folgende fünf Subtypen ergeben: PDGF-AA, PDGF-AB, PDGF-BB, PDGF-CC und PDGF-DD (Fredriksson et al. 2004).

Für diese fünf Subtypen sind zwei verschiedene Rezeptoren bekannt: PDGFR $\alpha$ (platelet derived growth factor receptor $\alpha$ ) kann PDGF-AA, -AB, -BB und -CC binden, PDGFR $\beta$ bindet PDGF-BB und -DD. Es wurde zusätzlich noch eine Rezeptordimer-Form namens PDGFRa beschrieben, deren Funktion und Relevanz jedoch unklar ist (Fredriksson et al. 2004). Alle Rezeptorformen zeichnet ihre intrinsische Tyrosin-Kinase-Aktivität aus, welche eine intrazelluläre Signalkaskade auslöst, die unter anderem auf die Genexpression, die Differenzierung, das Wachstum sowie die Migration der Zelle Auswirkungen hat (Williams 1989). Durch den Einfluss auf die Migration besonders mesenchymaler Zellen erhält PDGF eine wichtige Funktion bei der Wundheilung, indem es bei Gewebsverletzungen ausgestoßen wird und somit mesenchymale Zellen rekrutiert (Schmidt et al. 2006).

\subsubsection{EGF}

EGF (epidermal growth factor) ist ein einkettiges Polypeptid (Savage et al. 1972), welches zusammen mit einigen anderen strukturell ähnlichen Proteinen die Gruppe der EGF-ähnlichen Moleküle bildet (Carpenter und Cohen 1990). Dieser Gruppe ist eine hohe Bindung an den EGFR (epidermal growth factor receptor) und somit eine ähnliche Wirkung gemeinsam. Wichtigstes weiteres Mitglied ist TGF- $\alpha$ (transforming growth factor $\alpha$ ). EGFR ist eine Rezeptortyrosinkinase und Teil der erbB-Familie, eine Familie aus ähnlichen Rezeptortyrosinkinasen (Herbst 2004).

Die Stimulation von EGFR bewirkt Zellproliferation und verhindert Apoptose (Herbst 2004). EGF spielt außerdem eine wichtige Rolle bei verschiedenen Tumoren, da die Stimulation von EGFR ebenfalls das Tumorwachstum, die Beweglichkeit und Adhäsion sowie Metastasierung fördert (Engebraaten et al. 1993, Herbst 2004). Außerdem fördert die Stimulierung des 
EGFR die Bildung von VEGF (vascular endothelial growth factor), das wiederum die Angiogenese fördert (Goldman et al. 1993). Nicht zuletzt ist für EGF ein positiver Effekt auf die Migration von MSCs beschrieben (Ponte et al. 2007, Bhargava et al. 1999).

\subsubsection{IGF-1}

IGF-1 (insulin-like growth factor 1) bildet zusammen mit IGF-2 die Familie der insulinähnlichen Wachstumsfaktoren. Wie der Name bereits aussagt, besteht für beide Wachstumsfaktoren genomisch eine hohe, nämlich ca. 50-prozentige Homologie zu Insulin (Stewart und Rotwein 1996). Im Gegensatz zu Insulin zirkulieren diese Moleküle jedoch nicht frei, sondern werden an IGFBPs (insulin-like growth factor binding proteins) gebunden, eine Familie aus derzeit sechs bekannten verschiedenen kleinen Proteinen, denen unter anderem eine Verlängerung der Plasmahalbwertszeit und eine Beeinflussung der metabolischen Effekte der IGFs zugeschrieben wird (Stewart und Rotwein 1996). IGF-1 wird hauptsächlich in der Leber gebildet, prinzipiell scheinen jedoch die meisten Zellen im Körper IGF-1 produzieren zu können (Heemskerk et al. 1999).

IGF-1 werden insbesondere anabole Effekte zugeschrieben. Diese beinhalten auf zellulärer Ebene Zellwachstum und -überleben, Proliferation, Differenzierung und metabolische Effekte (Hede et al. 2012, Stewart und Rotwein 1996), ebenso konnten Auswirkungen auf die Zellmigration beobachtet werden (Ponte et al. 2007). Für den Organismus spielt IGF-1 eine wichtige Rolle für die pränatale Entwicklung (Baker et al. 1993), weiterhin ist es integraler Bestandteil des postnatalen Wachstums, indem es die wachstumsfördernde Funktion des Somatotropins (GH, growth hormon) vermittelt (Stewart und Rotwein 1996). IGF-1 spielt eine wichtige Funktion in der angeborenen und erworbenen Immunität (Heemskerk et al. 1999). Bei Sepsis oder Traumata hingegen kommt es zu einer Abnahme der IGF-1-Konzentration bzw. -Funktion (durch erhöhte Bindung und Inaktivierung durch IGFBPs), so dass katabole Prozesse überwiegen (Heemskerk et al. 1999). Ähnlich werden auch bei der Arthrose viele katabole Mechanismen mit IGF-1 in Zusammenhang gebracht. IGF-1 spielt im Knorpel eine wichtige Rolle bei der Gewebshomöostase und Proteoglykan-Produktion. Bei Arthrosepatienten zeigen sich lokal zwar erhöhte IGF-1-Konzentrationen, trotzdem jedoch eine verminderte Reagibilität der Zellen auf das IGF-1, die nach heutigem Kenntnisstand am ehesten durch IGFBP-Hochregulation zu erklären ist (Martel-Pelletier et al. 1998, Schmidt et al. 2006).

Die Wirkung des IGF-1 wird über den IGF-1-Rezeptor (IGF-1R, insulin-like growth factor 1 receptor) vermittelt, welcher eine Tyrosinkinase ist und wiederum eine hohe Analogie zum Insulinrezeptor aufweist (Stewart und Rotwein 1996). 


\subsection{Mesenchymale Stammzellen}

Wegen ihrer einzigartigen Fähigkeit, sich in verschiedene Gewebe zu entwickeln und sich unbegrenzt zu teilen, wurden Stammzellen ausgiebig erforscht. Mit zunehmender Forschung zeigte sich jedoch, dass der Begriff Stammzelle lediglich ein Überbegriff für eine sehr breit gefächerte Anzahl verschiedener Zellpopulationen ist, wodurch es zu einer Kontroverse um die Definition des Begriffs an sich gekommen ist. Watt und Hogan definierten 2000 den Begriff Stammzelle wie folgt: „Stammzellen sind Zellen mit der Kapazität für unlimitierte oder verlängerte Selbsterneuerung, die mindestens einen Typ von hoch-differenzierten Abkömmlingen produzieren kann. Üblicherweise gibt es zwischen der Stammzelle und ihrem terminal differenzierten Nachkömmling eine dazwischenliegende Population aus gezielten Progenitorzellen mit limitierter proliferativer Kapazität und eingeschränktem Differenzierungspotential [...]“. Diese Arbeit folgt dieser Definition, jedoch sei erwähnt, dass insbesondere die Unterscheidung zwischen Stamm- und Progenitorzellen in der Literatur sehr uneinheitlich bzw. gar nicht vorgenommen wird.

1970 beschrieb der russische Forscher Friedenstein erstmals eine fibroblastenähnliche Zellpopulation im Knochenmark von Meerschweinchen, welche gut an Plastik haftet und in vitro klonale Kolonien formt (Friedenstein et al. 1970). Ähnliche Zellpopulationen wurden später in verschiedensten Geweben gefunden, des Weiteren konnte nachgewiesen werden, dass sich diese Zellpopulationen in verschiedene mesodermale Zelltypen differenzieren lassen, vor allen Dingen in Osteoblasten, Adipozyten und Chondroblasten (Pittenger et al. 1999, Murray et al. 2014). Caplan etablierte daher 1991 für diese Zellpopulationen den Begriff der mesenchymalen Stammzelle (MSC, mesenchymal stem cell), welcher seither in der Literatur gut etabliert ist.

Um die teilweise unterschiedlichen Definitionen von MSCs verschiedener Autoren zu unterbinden, definierte die internationale Gesellschaft für Zelltherapie (International Society for Cellular Therapy, ISCT) 2006 in einem Positionspapier folgende Mindestanforderungen an MSCs (Dominici et al. 2006):

MSCs

- müssen an Plastik festhaften.

- müssen die Oberflächenmarker CD105, CD73 und CD90 exprimieren.

- dürfen nicht die Oberflächenmarker CD45, CD34, CD14, CD11b, CD79a, CD19 und HLA-DR exprimieren.

- müssen in vitro ein multipotentes Differenzierungspotential in Osteoblasten, Adipozyten und Chondroblasten aufweisen. 
Neben diesen Mindestanforderungen gibt es noch diverse weitere Antigene, die üblicherweise von MSCs exprimiert werden. Eine gute Übersicht geben Murray et al. in ihrem Paper aus dem Jahr 2014. Gleichzeitig werfen dieselben Autoren die Frage auf, ob es sich bei den Zellen nach der ISCT-Definition nicht um reine Artefakte der Zellkultur ohne exaktes Korrelat in vivo handelt.

Trotz der vielen Forschungsarbeiten zu MSCs ist nämlich „die Ontogenese dieser Zellen, ihre anatomische Lokalisation oder ihre natürlichen Rolle in der Gewebshomöostase, -physiologie oder -pathologie wenig verstanden“ (Murray et al. 2014). Schofield prägte 1978 erstmals den Begriff der Nische für die anatomische Lokalisation von Stammzellen. Dabei handelt es sich um eine von stromalen „Nischenzellen“ kreierte Mikroumgebung mit bestimmten Wachstumsfaktoren, u.a. BMPs (bone morphogenetic protein), die das Wachstum kontrollieren und die Differenzierung verhindern (Ohlstein et al. 2004). Ebenfalls scheint der WntSignalweg eine zentrale Rolle in der Regulierung der Stammzellproliferation zu spielen (Pinto et al. 2003). Song und Xie beschrieben 2002, dass Adhäsionen mit der Umgebung die Zellen fest in ihrer Nische verankern. Während vor allen Dingen für die am besten erforschten hämatopoietischen Stammzellen die Nische relativ gut erforscht ist (Wilson und Trumpp 2006), gibt es bezüglich der mesenchymalen Stammzellen viele Unklarheiten.

In jüngerer Vergangenheit werden zunehmend häufig Perizyten als möglicher Ursprungsort für MSCs angenommen (Murray et al. 2014). Für diese Hypothese spricht, dass das Genexpressionsmuster von CD146-positiven Perizyten dem von MSCs auffallend ähnelt und Differentiation dieser Zellen in Osteoblasten, Adipozyten und Chondroblasten gezeigt werden konnte (Covas et al. 2008, Crisan et al. 2008). Bouacida et al. zeigten 2012, dass Perizyten in verschiedene mesodermale Zellen differenzieren können, Olson und Soriano identifizierten 2011 PDGFRß als wesentlichen Regulator. Ebenso erklärt das quasi ubiquitäre Vorkommen von Gefäßen die Präsenz von MSCs in verschiedensten unterschiedlichen Geweben (Crisan et al. 2008). Nichtsdestotrotz bleiben diese Beobachtungen bisher lediglich eine Theorie.

Wie bereits beschrieben verfügen MSCs über ein großes Differenzierungspotential. Für die Differenzierung in verschiedene Gewebe gibt es gut etablierte Protokolle, die über spezifische Kombinationen von Biomolekülen als Zusatz zum Medium in der Zellkultur eine Differenzierung in verschiedene Gewebe ermöglichen. So lässt sich beispielsweise durch den Zusatz von 3-Isobutyl-1-Methylxanthin und Insulin eine Differenzierung zu Adipozyten, durch den Zusatz von Dexamethason, $\beta$-Glycerophosphat (BGP) und Ascorbinsäure eine Differenzierung zu Osteoblasten und durch Zusatz von TGF- $\beta$ und verschiedener bone morphogenetic proteins (BMPs) eine Differenzierung zu Chondroblasten erreichen (Kolf et al. 2007, Murray et al. 2014). Hierbei ist zu beachten, dass für die stabile Kultur von Chondro- 
blasten eine 3D-Kultur notwendig ist, wie sie häufig durch Alginatkugeln hergestellt wird (Häuselmann et al. 1994) Darüber hinaus wurden für MSCs jedoch auch noch diverse andere Differenzierungsmöglichkeiten nachgewiesen, u.a. zu Sehnen, Muskulatur und Knochenmarksstroma (Pittenger et al. 1999).

Für MSCs ist ein immunmodulatorischer Effekt beschrieben, welcher unter anderem durch parakrine Sekretion von Biomolekülen den Heilungsprozess von verletztem Gewebe unterstützen kann (Caplan und Dennis 2006). Als wichtige Bestandteile dieser parakrinen Sekretion wurden unter anderem IL-10, Interferon-y und die Indolamin-2,3-Dioxygenase identifiziert (Jui et al. 2012). Des Weiteren wird die Immunmodulation durch T-Zell-Regulation vermittelt: Demnach scheinen MSCs die T-Zell-Proliferation zu hemmen und somit die Immunreaktionen zu verringern (Kuo et al. 2011). Ähnlich wurde für MSCs auch eine signifikante Reduktion der Lymphozytenaktivierung beschrieben (Sarugaser et al. 2009). Nicht zuletzt auch wegen dieser immunmodulatorischen Funktion sind die MSCs ein beliebtes Forschungsobjekt.

Neben dieser immunmodulatorischen Funktion scheint die parakrine Sekretion auch andere wichtige Aufgaben zu erfüllen. Kinnaird et al. zeigten 2004, dass MSCs Angiogenese induzieren können. Dabei konnten die Autoren zeigen, dass diese Funktion zum einen auf bekannten Zytokinen bzw. Wachstumsfaktoren, namentlich vascular endothelial growth factor (VEGF), basic fibroblast growth factor (bFGF), placental growth factor (PIGF) und monocyte chemoattractant protein-1 (MCP-1), beruht. Insbesondere für VEGF ist die angiogenetische Potenz bereits lange bekannt (Leung et al. 1989). Zum anderen konnten die Autoren jedoch zeigen, dass auch andere, eventuell noch unidentifizierte Zytokine zur Angiogenese beitragen. Des Weiteren scheinen MSCs parakrin auch antiapoptotische Eigenschaften zu vermitteln (Gnecchi et al. 2005).

Auch im Knochenmark scheinen MSCs eine wichtige Rolle zu spielen. So konnte gezeigt werden, dass multipotente stromale Zellen im Knochenmark die Hämatopoiese unterstützen (Simmons und Torok-Storb 1991). Weitere Autoren berichten, dass MSCs bei einer Kotransplantation mit hämatopoietischen Stammzellen erfolgreich ins Knochenmark einwandern können und hier die kotransplantierten hämatopoietischen Stammzellen bei ihrer Blutbildung unterstützen, ohne selbst hämatopoietische Eigenschaften zu haben (Devine et al. 2001).

In Anbetracht aller dieser Erforschungen gilt zu beachten, dass es sich beim Begriff MSC um einen heterogene Gruppe verschiedener Zellen aus verschiedensten anatomischen Regionen handelt. Daher ist trotz der Einführung der ISCT-Kriterien nicht davon auszugehen, dass es sich bei den verschiedenen Zellpopulationen strikt um dieselben Zellen handelt - vielmehr 
zeigen verschiedene Forschungsarbeiten Unterschiede im Immunphänotyp, Sekretom und Proteom (Murray et al. 2014).

\subsubsection{Mesenchymale Progenitorzellen im Meniskus}

In dieser Arbeitsgruppe wurde eine bisher noch nicht publizierte Population von mesenchymalen Progenitorzellen im Meniskusgewebe von stark osteoarthritisch geschädigten Knien entdeckt, die wie unter Material und Methoden beschrieben durch Kultivierung von menschlichen Menisken, die degenerativ vorgeschädigt waren, isoliert werden konnte. Dabei wurden Zellen jeweils aus der oberflächlichen Zone, dem äußeren Drittel und dem inneren Teil des Meniskus getrennt untersucht. Es zeigte sich, dass sich die Progenitorzellen insbesondere im inneren Teil des Meniskus befanden. Hierzu sei erwähnt, dass es sich bei den untersuchten menschlichen Menisken um Explantate im Rahmen einer Knieendoprothesenoperation handelte und somit von stark osteoarthritisch vorgeschädigtem Gewebe ausgegangen werden muss, so dass die oben beschriebenen Zellen aus der oberflächlichen Zone histologisch nicht mehr nachweisbar waren. Dies erklärt die abweichenden Ergebnisse zu den oben beschriebenen Vermutungen bzw. Beobachtungen anderer Autoren, wonach sich besonders in der superfiziellen Zone Stammzellen befinden sollen.

Andere Mitglieder der Arbeitsgruppe konnten bereits zeigen, dass die Zellen die bereits erwähnten ISTC-Kriterien erfüllen: So konnte in einer FACS-Analyse das Vorhandensein von CD105, CD73, CD90 sowie das Fehlen von CD34 und CD45 nachgewiesen werden, ebenso gelang eine Differenzierung in Osteoblasten, Adipozyten und Chondroblasten.

Da es sich in der Kultur aus dieser Arbeitsgruppe um aus dem Meniskus ausgewanderte Tochterzellen der ursprünglich vorhandenen Stammzelle mit unbekannter Lokalisation handelt und nicht nachgewiesen ist, inwiefern sich diese Tochterzellen hinsichtlich ihres Differenzierungspotentials, ihrer Langlebigkeit und ihrer sekretorischen Aktivität von der ursprünglichen Stammzelle unterscheiden, wird diese Zelle gemäß der oben beschriebenen Definition der Stamm- und Progenitorzelle von dieser Arbeitsgruppe zu den Progenitorzellen gezählt und meniscal progenitor cell (MPC) genannt.

Für MSCs wurde eine deutliche gewebebeinflussende und immunregulatorische Wirkung nachgewiesen, so dass MSCs ein wichtiger Bestandteil in der Bekämpfung von Arthrose werden könnten. Da, wie oben beschrieben, nicht nur der Knorpel, sondern auch der Meniskus eine zentrale Rolle in der Arthrose des Kniegelenkes spielt, sind auch Progenitorzellen aus dem Meniskus ein interessantes Forschungsobjekt im Rahmen von degenerativen Kniegelenkserkrankungen. 
Auch andere Verletzungen des Meniskus sind nicht immer zufriedenstellend behandelbar. Zwar hat sich das Ergebnis von Operationen bei Meniskusläsionen durch das Verlassen von einer totalen Meniskektomie hin zu Meniskusnähten und Meniskusteilresektionen deutlich verbessert, dennoch besteht häufig ein erhöhtes Risiko für die Ausbildung einer Gonarthrose. In letzter Zeit wird daher viel in Richtung eines künstlichen Ersatzes des Meniskus geforscht - sowohl durch synthetisches als auch durch biologisches Material („tissue engineering"). Für Letzteres wurde auch schon heute in verschiedenen Studien ein positiver Effekt von MSCs aus dem Knochenmark oder Synovium beschrieben (Haddad et al. 2013), insofern dürften für weitere Untersuchungen zum tissue engineering von Meniskusgewebe besonders MPCs interessant werden. Murphy et al. konnten 2003 in einem Arthrose-Modell bei Ziegen zeigen, dass es bei Kniegelenken nach kompletter medialer Meniskektomie nach Injektion von zuvor kultivierten MSCs zu einer Regeneration des Meniskus kam, während bei der Kontrollgruppe lediglich deutliche arthrotische Knorpelschäden nachweisbar waren.

\subsubsection{Migration von MSCs}

Nahezu allen Zellen ist die Eigenschaft gemeinsam, dass sie sich bewegen können. Unter konstanten Umweltbedingungen ist diese Migration jedoch nicht zielgerichtet, sondern rein zufällig (Vorotnikov 2011). Durch das Vorhandensein bestimmter löslicher Stoffe in der Zellumgebung kann die Migration angeregt werden. Führt das Vorhandensein eines Stoffes zu einer ungerichteten Migrationsvermehrung der Zelle, wird dies als Chemokinesis bezeichnet (Wilkinson 1990). Findet sich in der Umgebung der Zelle jedoch eine Änderung der Konzentration eines bestimmten löslichen Stoffes, das heißt existiert ein sogenannter Chemogradient eines Stoffes, kann dies das Migrationsverhalten der Zelle bewusst beeinflussen und eine zielgerichtete Bewegung der Zelle zu dem Stoff hin bzw. von diesem weg auslösen. Dieses Verhalten wird Chemotaxis genannt (Vorotnikov 2011). Eine weitere Form der Migration wird als Haptotaxis beschrieben: In diesem Fall wird die Migration nicht durch lösliche Stoffe, sondern durch unlösliche Bestandteile der Extrazellulärmatrix vermittelt (Carter 1967).

In der Literatur und auch in dieser Arbeit werden verschiedene Wachstumsfaktoren beschrieben, welche einen Einfluss auf die Migration haben können. PDGF (platelet-derived growth factor) gilt dabei als Modellsubstanz für ebenjene (Deuel et al. 1991, Kundra et al. 1994, Rönnstrand und Heldin 2001) und ist in dieser Rolle mit Abstand am besten untersucht. Im Folgenden beziehen sich einige Mechanismen explizit auf PDGF bzw. PDGF-vermittelte Reaktionen. Eine Analogie für andere Wachstumsfaktoren ist denkbar, jedoch nicht in jedem Fall erforscht oder bewiesen.

Die Zellen bewältigen die Migration mithilfe von sogenannten Pseudopodien. Diese Zellausstülpungen werden in Lamellipodien und Filopodien unterteilt und besitzen ein Aktin- 
Skelett (Mattila und Lappalainen 2008). Lamellipodien sind dabei breite, flache Zellausstülpungen, die als Basis für die dünnen, langen Filopodien dienen, die antennenmäßig in verschiedene Richtungen ausstrahlen (Svitkina et al. 2003). Obwohl bis heute der genaue Mechanismus der Migration nur wenig verstanden wurde, gibt es doch ein weithin akzeptiertes Grundmodell der Migration: An den Enden der Filopodien sitzen verschiedene Rezeptoren. Bei Substratbindung wird eine intrazelluläre Signalkaskade ausgelöst, die einen extrazellulären Konzentrationsgradienten in einen intrazellulären Gradienten von Signalmolekülen umwandeln kann. Durch diesen intrazellulären Gradienten wird eine Polarisierung der Zelle erreicht, welche die Bewegungsrichtung determiniert (Vorotnikov 2011). Dies geschieht unter anderem durch einen Einfluss auf die Ausbildung von Pseudopodien, die ohne Polarisierung an zufälligen Stellen der Zelle ausgebildet werden. Durch die Polarisierung wird die Neubildung am Vorderende der Polarisierung verstärkt (Insall 2010).

Der detailliertere Ablauf der durch Substratbindung ausgelösten Signalkaskade unterscheidet sich nicht nur erheblich zwischen Pro- und Eukaryoten, sondern auch zwischen verschiedenen menschlichen Zellen. Während beispielsweise Leukozyten eine sogenannte amöboide Migration über G-Protein-gekoppelte Rezeptoren vollziehen, ähnelt die Migration von mesenchymalen Stammzellen einem Migrationsmuster, welches zuerst an Fibroblasten beschrieben wurde und deshalb als fibroblastenähnlich beschrieben wird (Vorotnikov 2011, Swaney et al. 2010). Bei dieser Form der Migration erfolgt der Stimulus über Rezeptor-Tyrosinkinasen, welche wiederum eine intrazelluläre Signalkaskade auslösen, die hauptsächlich über Phosphatidylinositol-3,4,5-Trisphosphat $\left(\mathrm{PIP}_{3}\right)$ vermittelt wird (Hawkins et al. 1995). Im Vergleich mit den Leukozyten zeigt sich, dass sowohl die Signalkaskade als auch die daraus resultierende Bewegung wesentlich langsamer abläuft: Während die Stimulierung eines Rezeptors bei Leukozyten innerhalb von Sekunden zur Ausbildung eines intrazellulären Gradienten führt, dauert dieser Vorgang bei Fibroblasten 5-10 min (Schneider und Haugh 2006). Daher und ebenfalls aufgrund des komplexeren Zytoskeletts bewegen sich Fibroblasten mit einer Geschwindigkeit von lediglich 0,25-1 $\mu \mathrm{m} / \mathrm{min}$, während Leukozyten mit 10-20 $\mu \mathrm{m} / \mathrm{min}$ um ein Vielfaches schneller sind.

Weitere Analysen zeigen, wie Fibroblasten auch über einen langen Zeitraum und über lange Strecken entlang eines Chemogradienten migrieren können. Es wird vermutet, dass Fibroblasten durch Rezeptor-vermittelte Endozytose und Degradation der Signalmoleküle Konzentrationsgradienten selbst aufrechterhalten können. Entsprechende mathematische Analysen stützen dieses Modell (Haugh 2006).

Die eigentliche Bewegung der Zelle wird von vielen Autoren in 4 Schritte unterteilt (Vorotnikov 2001, Mattila und Lappalainen 2008). Abbildung 3 zeigt eine grobe Skizze dieser 4 Schritte. Als erstes erfolgt die Protrusion, das heißt die Zellausstülpung in Form von 
Lamellipodien und Filopodien. Obwohl die genauen Mechanismen bis dato unbekannt sind, wird hauptsächlich die ATP-vermittelte Polymerisation von Aktin verantwortlich gemacht (Pollard und Borisy 2003, Rafelski und Theriot 2004). Durch die Substratbindung von PDGFRezeptoren und die nachfolgende Endozytose wird über die bereits erwähnte $\mathrm{PIP}_{3}$-Signalkaskade die Rho-GTPase Rac1 aktiviert (Hawkins et al. 1995, Kawada et al. 2009). Rac1 wiederum vermittelt zusammen mit anderen GTPasen, u.a. CDC242, die Aktin-Polymerisation (Ridley et al. 1992, Nobes und Hall 1995). Als zweiter Schritt erfolgt die Adhäsion. Um nachfolgend Zugkräfte entwickeln zu können, muss nämlich eine Bindung der Zellausstülpungen an die Umgebung erfolgen. Die Bindung der Zelle an die umgebende Extrazellulärmatrix wird dabei durch Integrine und Cadherine vermittelt (Partridge und Marcantonio 2006, Vasioukhin et al. 2000), welche wiederum fest an das Zytoskelett der Zellprotrusionen gekoppelt sind (Gardel et al. 2010).

Als dritter Schritt folgt die Traktion. Grundlage für die Traktion ist das Aktin-Zytoskelett. Dabei organisieren sich ca. 10-300 Aktin-Filamente zu Fibrillenbündeln, den sogenannten stress fibers (Cramer et al. 1997, Pellegrin und Mellor 2007). Mithilfe dieser stress fibers, welche durch die Adhäsion an die Extrazellulärmatrix verankert sind, kann nun eine Zugkraft entwickelt werden, um die Zelle in Richtung der Bindungsstelle zu bewegen. Der dieser Zugkraft zugrundeliegende Mechanismus ist zu großen Teilen nicht verstanden. Es wird angenommen, dass durch Myosin-II-Aktin-Interaktion eine Bewegung vermittelt wird, welche analog zu der Filamentgleittheorie in Muskelgewebe funktioniert (Huxley und Niedergerke 1954, Huxley 2000, Sweeney und Houdusse 2010). Nach diesem Modell gleiten Aktin- und Myosinfilamente ohne eigene Längenänderung ineinander. Diese Gleitbewegung wird durch kleine Fortsätze des Myosinfilaments bewirkt, den sogenannten Köpfchen. Diese Köpfchen werden ATP-vermittelt abgeklappt und dadurch vorgespannt. Nun können diese Aktin binden, wonach die Köpfchen zurückklappen und somit einen Vorschub von ca. $7 \mathrm{~nm}$ bewirken. Durch Loslösung vom Aktin und erneute ATP-Bindung kann dieser Mechanismus immer wieder wiederholt werden. 
Bewegungsrichtung

a

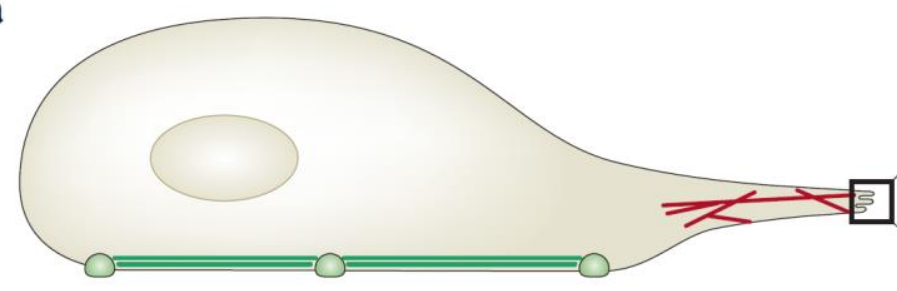

Führendes Ende

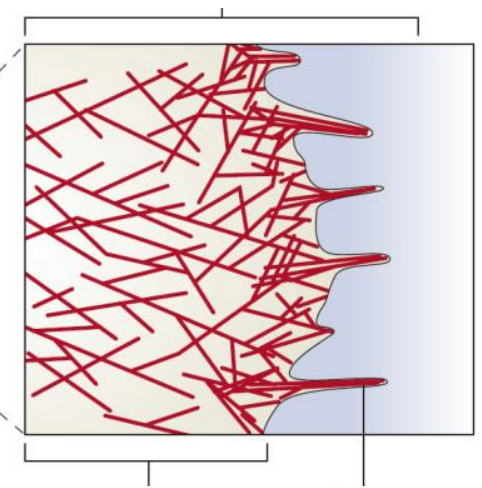

Lamellipodien Filopodien

b
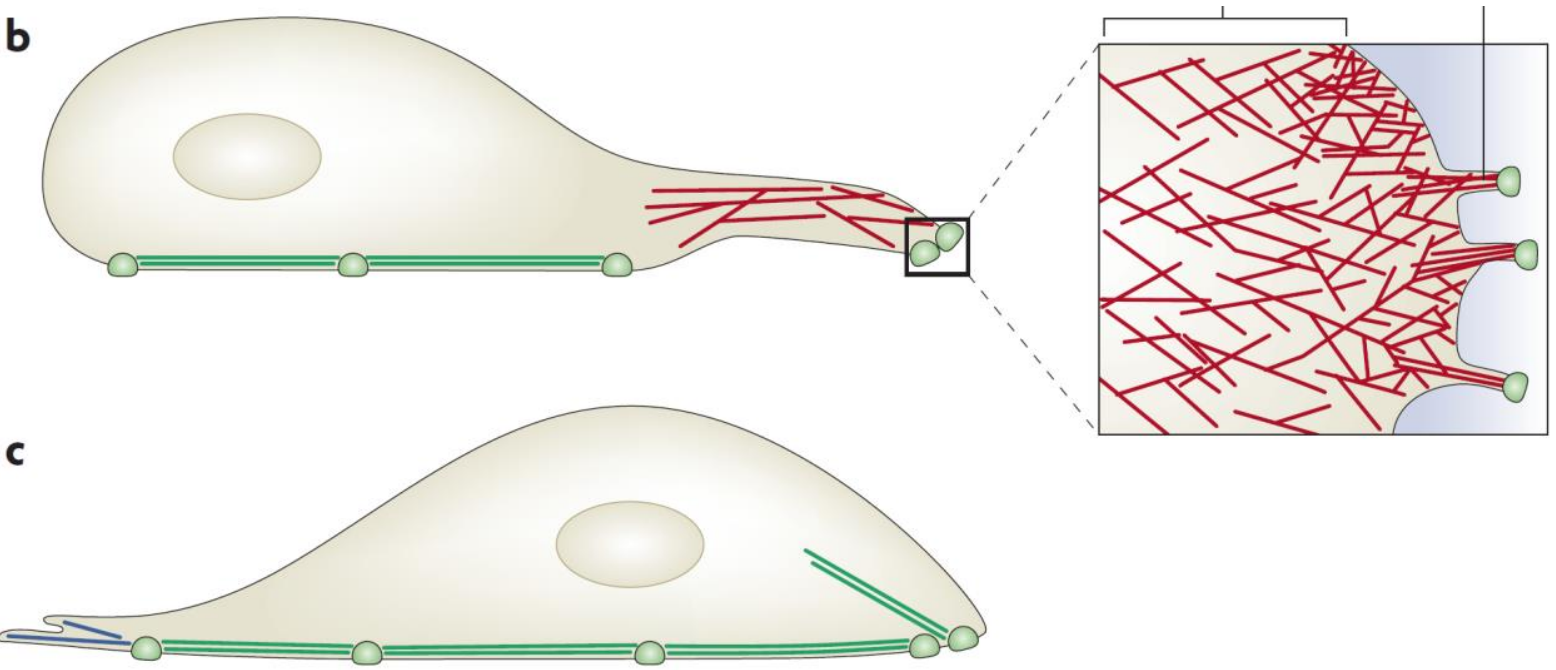

C

d

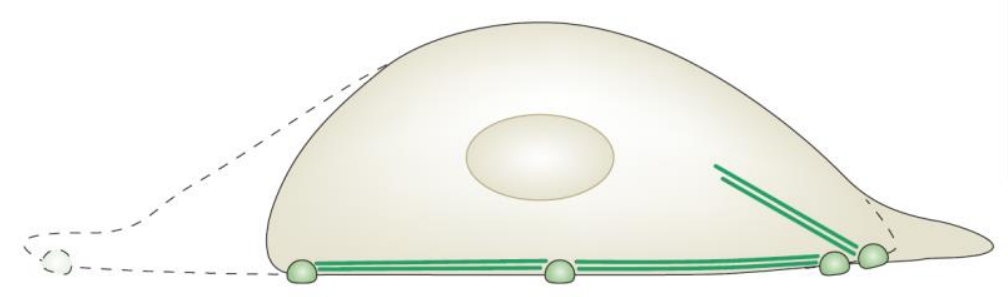

Aktin

- Adhäsion

Stress fibers

Retraction fibers

Abbildung 3: Skizze der Zellmigration. Modifiziert nach Mattila und Lappalainen 2008, S. 447. Diese Abbildung zeigt die vier grundlegenden Schritte der Migration von MSCs: a. Protrusion: In diesem Schritt werden rezeptorvermittelt die Zellausstülpungen in Form von Lamellipodien und Filopodien gebildet. b. Adhäsion: Um nachfolgend Zugkräfte entwickeln zu können, binden die Zellausstülpungen mittels Integrinen und Cadherinen die umgebende Extrazellulärmatrix. c. Traktion: In diesem Schritt wird mittels der stress fibers eine Zugkraft in Richtung des führenden Endes bewirkt. d. Ablösung und Retraktion: Im letzten Schritt erfolgt die Ablösung von Bindungen zwischen der Zelle und der Extrazellulärmatrix am hinteren Ende sowie das Einziehen des hinteren Endes mittels retraction fibers. 
Andererseits beruht diese Analogie größtenteils auf Mutmaßungen, die genauen Abläufe und vor allen Dingen die Organisation der kontraktilen Elemente sind ungeklärt (Vorotnikov 2011). Die Myosin-Aktin-Interaktion scheint von Myosin-Leichtketten-Kinasen kontrolliert zu werden, jedoch ist unklar, ob der Zug am Vorderende der Zelle analog zur Einziehung am Hinterende funktioniert (Totsukawa et al. 2004, Chew et al. 2002).

Die Ablösung und Retraktion ist der vierte Schritt der Zellbewegung. Die Ablösung der Zelle am hinteren Ende wird durch Phosphorylierung und nachfolgenden Abbau der dortigen fokalen Adhäsionen erreicht (Gardel et al. 2010). Dieser Prozess scheint über die NichtRezeptor-Proteintyrokinase FAK (focal adhesion kinase) vermittelt zu werden (llić et al. 1995, Schober et al. 2007). Die Retraktion, also das Einziehen des nun nicht mehr gebundenen freien hinteren Endes, erfolgt über sogenannte retraction fibers. Zwar bestehen diese ebenfalls aus Aktin und Myosin und sind ähnlich den oben erwähnten stress fibers aufgebaut, jedoch unterscheiden sich beide sowohl in der Feinstruktur der Aktinfibrillen als auch den interagierenden Myosin-Isoformen (Vorotnikov 2011, Pellegrin und Mellor 2007, VincenteManzanares et al. 2007).

Für die in-vivo-Migration in einer 3D-Umgebung sind verschiedene limitierende Faktoren bekannt (Wolf et al. 2013). Laut den Autoren der Studie wird die Migrationsgeschwindigkeit der Zelle insbesondere durch den Aufbau der Extrazellulärmatrix (EZM) zum einen und die Fähigkeit der Zelle, die EZM zu degradieren, zum anderen bestimmt. Letztere Fähigkeit wird durch verschiedene proteolytische Enzyme vermittelt, von denen die Matrixmetalloproteasen (MMPs) die wichtigste Rolle zu spielen scheinen (Wolf et al. 2013, Sabeh et al. 2004). Den Einfluss der EZM untersuchten Wolf et al. 2013 anhand von Zellen aus einem Fibrosarkom sowohl unter Einfluss von MMPs als auch unter Inhibition der MMPs. Dabei erwies sich insbesondere die Größe der Poren, welche sich zwischen verschiedenen Kollagenfibrillen bilden, als entscheidender Faktor: Je kleiner die Porengröße ausfiel, desto langsamer erfolgte die Migration, ein Effekt, welcher durch Inhibition der MMPs noch deutlich verstärkt wurde und bei Erreichen einer gewissen Untergrenze bei Inhibition der MMPs zu einem kompletten Einstellen der Migration führte. Außerdem konnten die Autoren nachweisen, dass die Verformbarkeit des Nucleus mit der Migrationsgeschwindigkeit der Zellen korrelierte. 


\subsection{Fragestellung der Arbeit}

Für die von dieser Forschungsgruppe beschriebene ähnliche Population von chondrogenen Progenitorzellen (CPCs) im arthrotisch geschädigten Knorpel konnte bereits die Fähigkeit zur Migration nachgewiesen werden (Koelling et al. 2009). Ziel dieser Arbeit ist es nun, die Migration der ebenfalls von dieser Arbeitsgruppe beschriebenen MPC-Population im menschlichen Kniemeniskus zu untersuchen. Dazu soll nicht nur nachgewiesen werden, dass die Zellen prinzipiell zur Migration fähig sind, sondern auch ein Vergleich zwischen verschiedenen Wachstumsfaktoren durchgeführt werden. Als Wachstumsfaktoren wurden dabei neben PDGF als etabliertestem Migrationsfaktor (siehe oben) nach sorgfältiger Literaturrecherche (u.a. Mishima und Lotz 2008, Ponte et al. 2007) zum Migrationsverhalten anderer MSCs die Wachstumsfaktoren IGF-1 (insulin-like growth factor 1) und EGF (endothelial growth factor) ausgewählt.

Zur Untersuchung dieser Fragestellung wurde zunächst das Vorliegen der entsprechenden Rezeptoren untersucht, und zwar sowohl in vivo in den Fibrochondrozyten des Kniemeniskus mithilfe der Immunhistochemie als auch in vitro mithilfe von PCR-Analysen der MPCs. Im zweiten Schritt wurde danach mithilfe eines Boyden-Chamber-Assays direkt der Einfluss dieser Wachstumsfaktoren auf das Migrationsverhalten untersucht und ausgewertet. Für diese Untersuchung wurden verschiedene Konzentrationen der Wachstumsfaktoren sowie verschiedene Inkubationsdauern untersucht und miteinander verglichen. Als letzter Schritt wurden die Ergebnisse dieser Versuche mit in der Literatur beschriebenen Migrationsversuchen von MSCs sowie anderen ähnlichen Zellpopulationen verglichen und bewertet. 


\section{Material und Methoden}

\subsection{Materialen}

\subsubsection{Chemikalien}

\begin{tabular}{|c|c|c|}
\hline Produkt & Hersteller & Sitz des Herstellers \\
\hline Alzianblau & AppliChem & Darmstadt, DE \\
\hline Ameisensäure & Roth & Karlsruhe, DE \\
\hline BSA & Sigma-Aldrich & St. Louis, MO, USA \\
\hline EDTA & Roth & Karlsruhe, DE \\
\hline Eosin & Roth & Karlsruhe, DE \\
\hline Essigsäure & AppliChem & Darmstadt, DE \\
\hline Ethanol abs. & AppliChem & Darmstadt, DE \\
\hline Eukitt & Sigma-Aldrich & St. Louis, MO, USA \\
\hline Formaldehyd & Roth & Karlsruhe, DE \\
\hline Gentamycin & Roth & Karlsruhe, DE \\
\hline Hämalaun & Merck & Darmstadt, DE \\
\hline Isopropylalkohol & Roth & Karlsruhe, DE \\
\hline Kernechtrot & AppliChem & Darmstadt, DE \\
\hline Paraplast Plus & Roth & Karlsruhe, DE \\
\hline PBS-Tabletten & Sigma-Aldrich & St. Louis, MO, USA \\
\hline Xylol & Roth & Karlsruhe, DE \\
\hline$\beta$-Mercaptoethanol & Sigma-Aldrich & St. Louis, MO, USA \\
\hline
\end{tabular}

Tabelle 1: Liste der verwendeten Chemikalien 


\subsubsection{Puffer und Lösungen}

PBS $10 \%$

Aus PBS-Tabletten angemischt

Entkalkungslösung 1

Ameisensäure $10 \%$

Formaldehyd $2 \%$

Entkalkungslösung 2

EDTA $20 \%$

\subsubsection{Reagenziensätze}

Dako REAL Detection System AP/Red

Artikel-Nr. K500511-2

Dako Denmark A/S

Glostrup, DK

\section{HotStarTaq Plus DNA Polymerase Kit}

Katalog-Nr. 203603

Qiagen $\mathrm{GmbH}$

Hilden, DE

\section{RNeasy Mini Kit}

Katalog-Nr. 74104

Qiagen $\mathrm{GmbH}$

Hilden, DE

\section{QuantiTect Reverse Transcription Kit}

Katalog-Nr. 205310

Qiagen $\mathrm{GmbH}$

Hilden, DE

\subsubsection{Zellkultur}

\section{DMEM Medium}

DMEM (1x) + GlutaMax-I

Artikel-Nr. 21885-025

Gibco by life technologies Corporation, Paisley, UK

\section{Standard-Medium}

DMEM-Medium

$+10 \%$ FCS

$+1 \%$ Gentamycin

\section{Migrationskammer}

Greiner ThinCert Zellkultureinsatz für 24-Well-Platten, Porengröße $8 \mu \mathrm{m}$ Artikel-Nr. 662638

Greiner Bio-One International, Kremsmünster, Austria 


\section{Zellkulturflaschen}

Sarstedt Gewebekulturflaschen mit Belüftungsverschluss

Artikel-Nr. 83.1813.002

Sarstedt, Nümbrecht, DE

\section{4-Well-Platten}

Artikel-Nr. 83.1836

Sarstedt, Nümbrecht, DE

\section{Zentrifugenröhrchen}

50ml: Artikel-Nr. 62.559.001

15ml: Artikel-Nr. 62.554.502

Sarstedt, Nümbrecht, DE

\section{FCS}

Fetal Bovine Serum

Artikel-Nr. 10270-106

Invitrogen by life technologies Corporation, Paisley, UK

\section{Trypsin-Buffer}

Artikel-Nr. P10-024100

Pan-Biotech, Aidenbach, DE

\subsubsection{Antikörper}

Alle verwendeten Antikörper sind primäre monoklonale Antikörper.

\begin{tabular}{|c|c|c|c|c|}
\hline Faktor & Produktname & Ursprung & Firma & Produktnummer \\
\hline PDGFR $\beta$ & $\begin{array}{l}\text { PDGFR beta [PDGFR-B2] } \\
\text { Antibody } \\
\text { Reagiert auf: Mensch, } \\
\text { Schwein }\end{array}$ & Maus & $\begin{array}{l}\text { GeneTex Inc., } \\
\text { Irvine, CA, } \\
\text { USA }\end{array}$ & $\begin{array}{l}\text { Catalog-\# : } \\
\text { GTX108477 }\end{array}$ \\
\hline EGFR & $\begin{array}{l}\text { EGFR (Ab 1070) Antibody } \\
\text { Reagiert auf: Mensch, Maus, } \\
\text { Ratte }\end{array}$ & Kaninchen & $\begin{array}{l}\text { Enogene, New } \\
\text { York, NY, USA }\end{array}$ & $\begin{array}{l}\text { Catalog-\#: } \\
\text { E021073-1 }\end{array}$ \\
\hline IGF-1R & $\begin{array}{l}\text { IGF1-R (Phospho-Tyr1161) } \\
\text { Antibody } \\
\text { Reagiert auf: Mensch, Maus, } \\
\text { Ratte }\end{array}$ & Kaninchen & $\begin{array}{l}\text { Enogene, New } \\
\text { York, NY, USA }\end{array}$ & $\begin{array}{l}\text { Catalog-\#: } \\
\text { E011087-1 }\end{array}$ \\
\hline IGF-1R $\beta$ & $\begin{array}{l}\text { IGF-1Rß (C20): sc-713 } \\
\text { Reagiert auf: Mensch, Maus, } \\
\text { Ratte }\end{array}$ & Kaninchen & $\begin{array}{l}\text { Santa Cruz } \\
\text { Biotechnology } \\
\text { Inc., Dallas, } \\
\text { TX, USA }\end{array}$ & Catalog-\#: sc-713 \\
\hline
\end{tabular}

Tabelle 2: Liste der verwendeten Antikörper 


\subsubsection{Wachstumsfaktoren}

\begin{tabular}{|lllll|}
\hline Faktor & Produktname & Ursprung & Firma & Produktnummer \\
\hline PDGF-BB & $\begin{array}{l}\text { Recombinant Human } \\
\text { Platelet Derived Growth } \\
\text { Factor-BB }\end{array}$ & E. coli & $\begin{array}{l}\text { PromoKine, } \\
\text { Heidelberg, } \\
\text { DE }\end{array}$ & Catalog-\# : C-63022 \\
\hline EGF & Recombinant Human EGF & E. coli & $\begin{array}{l}\text { PeproTech, } \\
\text { Rocky Hill, NJ, } \\
\text { USA }\end{array}$ & $\begin{array}{l}\text { Catalog-\#: AF-100- } \\
\text { Lot-\#: 0212AFC05 }\end{array}$ \\
\hline IGF-1 & Recombinant Human IGF-1 & E. coli & $\begin{array}{l}\text { PeproTech, } \\
\text { Rocky Hill, NJ, } \\
\text { USA }\end{array}$ & $\begin{array}{l}\text { Catalog-\#: 100-11 } \\
\text { Lot-\#: 031001 }\end{array}$ \\
\hline
\end{tabular}

Tabelle 3: Liste der verwendeten Wachstumsfaktoren

\subsubsection{Primer}

Nachfolgend findet sich eine Liste der verwendeten Primer. Für jeden Primer sind eine Forward- und eine Reverse-Sequenz angegeben, die jeweils in 5'-3' notiert sind. Weiterhin ist die optimale Annealing-Temperatur vermerkt sowie die Nummer, die das National Center for Biotechnology Information (NCBI) der Referenzsequenz des Zielgens zugewiesen hat.

Alle Primer wurden von Eurofins MWG Operon, Ebersberg, Deutschland produziert.

\begin{tabular}{|c|c|}
\hline a2macro & $\begin{array}{l}\alpha_{2}-\text { Makrogloulin (Housekeeping-Gen) } \\
\text { NM_000014.4 } \\
\text { Forward: TGGTCTCTGGCTTCATTCC } \\
\text { Reverse: GCAAACTCATCCGTCTCGTA } \\
\text { Annealing-Temperatur: } 60^{\circ} \mathrm{C}\end{array}$ \\
\hline beta2M & $\begin{array}{l}\beta_{2} \text {-Mikroglobulin (Housekeeping-Gen) } \\
\text { NM_004048 } \\
\text { Forward: TGCTGTCTCCATGTTTGATGTATCT } \\
\text { Reverse: TCTCTGCTCCCCACCTCTAA } \\
\text { Annealing-Temperatur: } 61^{\circ} \mathrm{C}\end{array}$ \\
\hline EGFR & $\begin{array}{l}\text { Epidermal growth factor receptor } \\
\text { NM_005228.3 } \\
\text { Forward: CGACAGCTATGAGATGGAGGA } \\
\text { Reverse: GATCCAGAGGAGGAGTATGTGTG } \\
\text { Annealing-Temperatur: } 60^{\circ} \mathrm{C}\end{array}$ \\
\hline HPRT-1 & $\begin{array}{l}\text { Hypoxanthin-Phosphoribosyl-Transferase } 1 \text { (Housekeeping-Gen) } \\
\text { NM_000194 } \\
\text { Forward: TGACACTGGCAAAACAATGCA } \\
\text { Reverse: GGTCCTTTTCACCAGCAAGCT } \\
\text { Annealing-Temperatur: } 61^{\circ} \mathrm{C}\end{array}$ \\
\hline
\end{tabular}


IGF1R Insulin-like growth factor 1 receptor NM_000875.3

Forward: AATTGCATGGTAGCCGAAGA Reverse: GAAGGACTTGCTCGTTGGAC Annealing-Temperatur: $60^{\circ} \mathrm{C}$

LaA Lamin A/C (Housekeeping-Gen)

NM_170707

Forward: GGTCACTGGAAAGGGGAGA

Reverse: TTGCTTTGGGGAGGAGAGA

Annealing-Temperatur: $60^{\circ} \mathrm{C}$

PDGFR $\beta \quad$ Platelet-derived growth factor receptor

NM_002609.3

Forward: ACTGTTGGGCGAAGGT

Reverse: CAGGCAGGGGGATGATATAGTC

Annealing-Temperatur: $60^{\circ} \mathrm{C}$

PPIA Peptidylprolyl-Isomerase A (Housekeeping-Gen)

NM_021130

Forward: ATGGCAAGACCAGCAAGAAG

Reverse: GGGAACAAGGAAAACATGGA

Annealing-Temperatur: $60^{\circ} \mathrm{C}$

RPL13A 60S ribosomales Protein L13a (Housekeeping-Gen)

BC105605

Forward: TCTGGACCGTCTCAAGGTGT

Reverse: GCTGTCACTGCCTGGTACTTC

Annealing-Temperatur: $60^{\circ} \mathrm{C}$

SDHA Succinatdehydrogenase, Untereinheit A (Housekeeping-Gen)

NM_004168.2

Forward: TGGGAACAAGAGGGCATCTG

Reverse: CCACCACTGCATCAAATTCATG

Annealing-Temperatur: $60^{\circ} \mathrm{C}$

\subsubsection{Geräte}

Im Rahmen dieser Arbeit wurden folgende Geräte verwendet:

\section{Autoklaviermaschine}

FNR 4353E

\section{Zentrifugen}

eppendorf Centrifuge 5810

eppendorf Centrifuge 5415R

eppendorf Minispin
Tecnomara

Fernwald, DE
Eppendorf

Eppendorf

Eppendorf
Hamburg, DE

Hamburg, DE

Hamburg, DE 


\section{Sterilbank}

Heraeus HeraSafe

Heraeus

Hanau, DE

\section{Zellzählung}

Nexcelcom Cellometer Auto T4

Nexcelcom

Lawrence, MA, USA

Nexcelcom Cellometer SD100

Nexcelcom

Lawrence, MA, USA

\section{Einbettmaschine}

Shandon-Elliot Automatic Duplex

Shandon-Southern- Pittsburgh, PA, USA Tissue Processor Instruments Inc.

\section{Färbemaschine}

DiaPath Stainix

DiaPath

Martinengo, IT

\section{Lichtmikroskop}

Olympus CX40

Olympus

Tokio, JP

\section{Kamera}

Nikon D90

Nikon

Tokio, JP

\section{Mikrotom}

Jung Biocut 2035

Leica

Wetzlar, DE

\section{Fluoreszenzplattenleser}

PerkinElmer Victor X4

2030 MultiLabel Reader

PerkinElmer

Waltham, MA, USA

Heizblock

eppendorf Thermocycler comfort

eppendorf

Hamburg, DE

PCR

Mastercycler Gradient S

eppendorf

Hamburg, DE

\section{Photometer}

Nanodrop 1000

Peqlab

Erlangen, DE 


\subsection{Methoden}

\subsubsection{Gewinnung von Menisken}

Die menschlichen Menisken stammen aus Operationspräparaten von Patienten mit fortgeschrittener Arthrose, die eine totale Knie-Endoprothese erhielten. Die Patienten wurden im Krankenhaus Neu-Mariahilf in Göttingen in der dortigen orthopädischen Abteilung operiert. Dazu wurden die Patienten im Vorfeld ausführlich über die Verwendung des Materials für die medizinische Forschung aufgeklärt. Das Studiendesign wurde zudem zuvor von der Ethikkommission der medizinischen Fakultät der Universität Göttingen begutachtet und unter der Nummer 25/12/10 bewilligt.

Für den Transport des Explantationsmaterials wurden Plastikbehälter mit jeweils $50 \mathrm{ml}$ DMEM-Medium und $50 \mathrm{ml}$ PBS verwendet. Diese wurden in dem hiesigen Labor autoklaviert, unter der Sterilbank befüllt und anschließend ins Krankenhaus Neu-Mariahilf transportiert, wo sie bis zu ihrer Verwendung kühl gelagert wurden. Im Verlauf der Kniegelenksoperationen wurde das Material in die vorbereiteten Plastikbehälter gefüllt und diese wurden fest verschlossen. Auf den Behältern wurden keine Daten zum operierten Patienten hinterlegt, mit Ausnahme des Geschlechts, Alters und Gewichtes. Danach wurden diese durch einen Transportdienst in die Universitätsmedizin Göttingen gebracht.

Dort wurden die Behältnisse bis zur erstmaligen Öffnung unter der Sterilbank weiterhin gekühlt. In der Sterilbank wurde das Operationsmaterial begutachtet und auf das Vorhandensein von Kniemenisken untersucht.

\subsubsection{Gewinnung von mesenchymalen Progenitorzellen (MPCs)}

Die Operationspräparate wurden unter sterilen Bedingungen auf Vorhandensein von Menisken überprüft. Vorhandene Menisken wurden mit dem Skalpell zunächst in ca. 5-10 mm dicke Scheiben sagittal unterteilt. Diese wurden danach zonenweise unterteilt (siehe Kapitel 1.1.2). Zunächst wurde eine ca. $1 \mathrm{~mm}$ dicke Schicht apikal und basal abgetrennt und als superfizielle Zone klassifiziert (siehe Abbildung 4). Danach wurde etwa das äußere Drittel als äußere Zone abgetrennt, der verbleibende Teil wurde als innere Zone bezeichnet. 


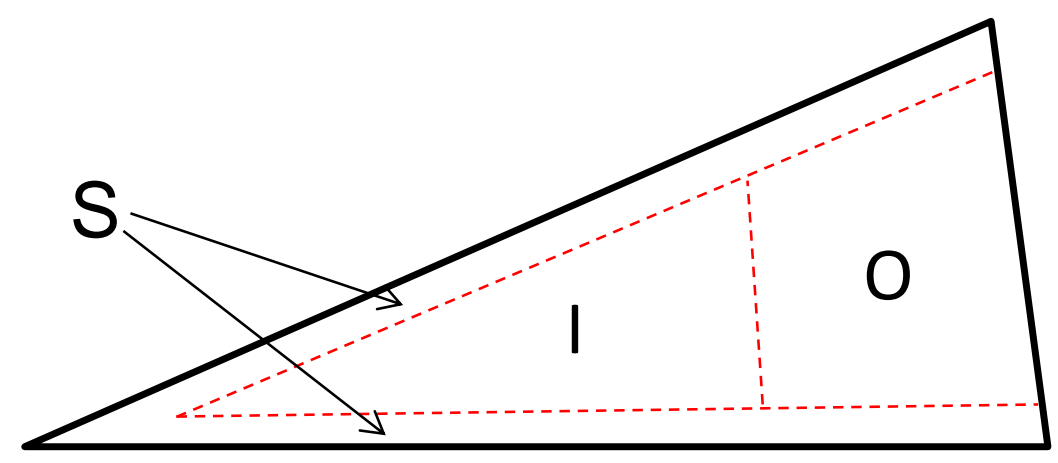

Abbildung 4: Skizze der Einteilung des Meniskus in Zonen. Meniskus im Querschnitt. S: superfizielle (oberflächliche) Zone. I: innere Zone. O: äußere (outer) Zone. Skizze wurde selbst erstellt.

Die einzelnen Zonen wurden danach in ca. $8 \mathrm{~mm}^{3}$ große Stücke zerteilt und für 10 Tage ohne Mediumwechsel in Standardmedium bei Standardbedingungen $\left(37^{\circ} \mathrm{C}, 5 \% \mathrm{CO}_{2}\right)$ kultiviert. In dieser Phase wuchsen die MPCs aus den Meniskusstücken aus und hafteten am Plastik fest. Nach den 10 Tagen wurden die Meniskusstücke ausgewaschen und die am Plastik heftenden Zellen danach wie unten beschrieben weiter kultiviert.

Im Rahmen dieser Arbeit wurden MPCs von 10 unterschiedlichen Patienten gewonnen.

\subsubsection{Zellkultivierung}

Die Zellen wurden in Flaschen unter Standardbedingungen $\left(37^{\circ} \mathrm{C}, 5 \% \mathrm{CO}_{2}\right)$ im Standardmedium kultiviert. Ein Mediumwechsel erfolgte zweimal wöchentlich, eine Aufteilung auf mehrere Flaschen nach Konfluenz der Zellen und Bedarf. Für die Aufteilung wurden die Zellen mit $3 \mathrm{ml}$ Trypsin-Buffer sieben Minuten inkubiert, wodurch sich die Zellen vom Flaschenboden lösten. Danach wurden $5 \mathrm{ml}$ Medium hinzugefügt und die Zellen für 10 Minuten bei $280 \mathrm{G}$ abzentrifugiert. Danach wurde die Flüssigkeit abgesaugt und die Zellen wurden in Medium resuspendiert und auf mehrere Flaschen aufgeteilt. Bei Bedarf wurden dazu die Zellen vorher gezählt.

\subsubsection{Zellzählung}

Für die Zellzählung wurden die Zellen wie oben beschrieben gelöst und abzentrifugiert. Der Überstand wurde danach je nach Bedarf in $1 \mathrm{ml}$ PBS bzw. Medium resuspendiert. Danach wurden $20 \mu \mathrm{l}$ in eine Zählkammer pipettiert und automatisch durch das Programm Cellometer Auto Counter in Verbindung mit einem Nexcelcom Cellometer Auto T4 gezählt. 


\subsubsection{Migrationsassays}

Die Migrationsassays wurden mithilfe eines modifizierten Boyden-Chamber-Assays durchgeführt. Boyden beschrieb 1962 in einer Arbeit über die Chemotaxis von Leukozyten einen inzwischen sehr gut etablierten Test zur Untersuchung der Migration von Zellen. Der Testaufbau des sogenannten „Boyden Chamber Assays“ ist dabei relativ simpel: Zwei verschiedene Medien werden durch eine Membran mit Mikroporen getrennt. In die obere Kammer werden dabei Zellen eingefügt, in die untere Kammer chemotaktische Agentien. Die Poren erlauben nun den Zellen einen Durchtritt - ein Vergleich des Ausmaßes der stattfindenden Migration zwischen einer Probe und einer negativen Kontrolle, in der in der unteren Kammer kein chemotaktisches Agens vorhanden ist und somit nur zufällige Zellmigration stattfindet, erlaubt dabei Rückschlüsse auf die Migration aufgrund von Chemotaxis.

Dazu wurden die Zellen über Nacht in serumfreien DMEM-Medium mit $0.2 \%$ BSA und $1 \%$ Gentamycin inkubiert. Am nächsten Tag wurden die Zellen geerntet und zweifach mit PBS gewaschen. Danach wurde in eine 24-Well-Platte pro Well jeweils $600 \mu \mathrm{l}$ serumfreies Medium mit oder ohne Chemoattraktant (in einer Konzentration von 10 oder $40 \mathrm{ng} / \mathrm{ml}$ ) pipettiert. Danach wurden Zellkultureinsätze (Greiner Bio-One ThinCert) mit einer Porengröße von $8 \mu \mathrm{m}$ in jedes Well eingesetzt. In jeden Einsatz wurden je $200 \mu$ l serumfreies Medium mit 50.000 Zellen suspendiert. Für die drei gemessenen Wachstumsfaktoren sowie für die Negativkontrolle wurden jeweils sechs Wells parallel gefüllt.

Danach wurde die 24-Well-Platte für eine variable Zeit (3, 9 oder 24 Stunden) unter Standardbedingungen inkubiert. Darauf wurde das Medium aus den Wells entfernt und durch je $450 \mu \mathrm{l}$ serumfreies Medium mit $8 \mu \mathrm{mol} / \mathrm{L}$ Calcein-AM ersetzt und die Platte wurde wiederum für 45 Minuten unter Standardbedingungen inkubiert.

In der Zwischenzeit wurde eine neue 24-Well-Platte mit $1000 \mu$ l vorgewärmten Trypsin-EDTA pro Well vorbereitet. Die Zellkultureinsätze wurden danach leergesaugt und in die neue Platte transferiert. Die Platte wurde danach für 10 Minuten unter Standardbedingungen inkubiert und dabei ab und zu geschüttelt, um die Zellen zu lösen. Daraufhin wurden von jedem Ansatz je viermal $200 \mu \mathrm{l}$ in eine schwarze 96-Well-Platte pipettiert, zusätzlich wurde noch mindestens viermal reine Trypsin-EDTA-Lösung als Leerwert pipettiert.

Die Platte wurde daraufhin in einem Fluoreszenzplattenleser bei einer Exzitationswellenlänge von $485 \mathrm{~nm}$ und einer Emissionswellenlänge von $535 \mathrm{~nm}$ ausgelesen. Die Messwerte wurden danach gemittelt und der Leerwert wurde abgezogen.

Calcein-AM (Calcein-Acetoxymethylester) ist zellwandpermeabel und diffundiert als nichtfluoreszierende Substanz in das Zytoplasma der Zellen. Dort wird durch Esterasen die 
Acetoxymethyl-Gruppe abgespalten, was eine Fluoreszenz des Calceins bewirkt. Die Calcein-AM-Aufnahme der Zellen und somit ihre resultierende Fluoreszenz korrelieren demnach mit der Zellzahl.

Zur Signifikanzbestimmung wurde ein t-Test in Microsoft Excel 2010 benutzt. Dabei galt ein Signifikanzniveau von $p<0,05$. Dargestellt werden die Daten jeweils ein 2 Formen: Zum einen als Boxplot, wobei die Fehlerindikatoren die gesamte Streubreite der Einzelmesswerte angeben, zum anderen als Säulendiagramm, wobei die Fehlerindikatoren die Standardabweichung angeben.

Die Migrationsassays wurden über verschiedene Zeiträume durchgeführt, um die Beziehung zwischen Inkubationsdauer und Migrationsverhalten zu untersuchen. In dieser Arbeit werden alle untersuchten Zeiträume im Ergebnisteil besprochen. Insgesamt wurden vier verschiedene primäre Zelllinien aus unterschiedlichen Spendern untersucht.

\subsubsection{Quantitativer mRNA-Nachweis mithilfe von real-time RT-PCR}

Durch RNA-Extraktion aus Zellen mithilfe des Quiagen RNeasy-Kits wurde das Transkriptom gewonnen, welches durch das Quiagen QuantiTect Reverse-Transcription-Kit in komplementäre DNA (cDNA) umgeschrieben wurde.

Die quantitative Real-Time PCR (qRT-PCR) ermöglicht die Amplifizierung bestimmter GenAbschnitte von vorhandener mRNA. Dadurch kann das Vorhandensein der entsprechenden mRNA im Transkriptom bewiesen werden - dies lässt indirekt Rückschlüsse auf die Expression des entsprechenden Gens durch die Zelle zu. Die Amplifizierung wird dabei durch eine Taq-Polymerase unter Zugabe eines Basen-Mixes, eines passenden Primers (siehe unten) und einer cDNA ermöglicht.

Dabei wird folgender Zyklus in der Regel 40fach wiederholt:

- 15 s Denaturierung: Bei $95^{\circ} \mathrm{C}$ wird die DNA in Einzelstränge aufgeteilt.

- $10 \mathrm{~s}$ Annealing: Bei der für den jeweiligen Primer spezifischen Temperatur (i.d.R. ungefähr $60^{\circ} \mathrm{C}$ ) lagert sich der Primer an der passenden Bindungsstelle an und dient damit als Ausgangspunkt für die Amplifikation.

- $15 \mathrm{~s}$ Elongation: Bei $72{ }^{\circ} \mathrm{C}$ synthetisiert die Taq-Polymerase ausgehend von den angelagerten Primern einen komplementären DNA-Strang.

Durch SYBRGreen, einem interkalierenden Farbstoff, der an doppelsträngige DNA bindet, kann dabei bei jedem Zyklus photometrisch die Menge an doppelsträngiger DNA und damit die Menge des PCR-Produktes quantifiziert werden. Der Zyklus, bei dem ein bestimmter Fluoreszenz-Schwellenwert, auf den die PCR-Maschine geeicht ist, überschritten wird, gibt 
den ct-Wert an, anhand dessen die Menge der gesuchten mRNA festgehalten werden kann. Als Schlussfolgerung daraus ergibt sich, dass je eher dieser Schwellenwert erreicht wird, d.h. je niedriger der ct-Wert ist, desto höher der mRNA-Gehalt des Zielgens ist.

\subsubsection{Durchführung der RNA-Isolation aus Zellen}

Die RNA-Isolation des Transkriptoms der Zellen erfolgte mithilfe des Quiagen RNeasy-Kits. Für die RNA-Isolation wurden ca. 1 Million Zellen mit Trypsin geerntet und sorgfältig abzentrifugiert. Danach wurden diese mit $350 \mu \mathrm{l}$ von dem im Kit enthaltenen RLT-Puffer zuzüglich 3,5 $\mu \mathrm{l} \beta$-Mercaptoethanol resuspendiert, um eine Lyse der Zellen zu erreichen. Das Hinzufügen des $\beta$-Mercaptoethanols diente dabei der Inaktivierung von unspezifischen RNAsen. Diese Zellsuspension wurde mithilfe eines Vortexers gemischt und danach für 2 Minuten bei Raumtemperatur stehen gelassen. Danach wurde die Suspension in eine QuiagenShredder-Säule gegeben und für 2 Minuten bei voller Geschwindigkeit (13.200 upm in der eppendorf Centrifuge 5415R) zentrifugiert. Der Durchfluss wurde mit $70 \%$ Ethanol resuspendiert und auf eine RNA-easy-mini-Säule gegeben, welche für 15-30 Sekunden bei 10.000 upm in derselben Zentrifuge zentrifugiert wurde. Der Durchfluss wurde verworfen und $700 \mu \mathrm{l}$ vom RW1-Buffer auf die Säule gegeben, woraufhin wiederum für 15-30 Sekunden bei 10.000 upm zentrifugiert wurde. Erneut wurde der Durchfluss verworfen und danach wurden $500 \mu \mathrm{l}$ vom RPE-Buffer auf die Säule gegeben, welche danach wiederum wie gehabt zentrifugiert wurde. Dieser Schritt wurde nochmals wiederholt. Danach wurde die Säule in ein neues Sammelröhrchen gegeben und für 1 Minute bei voller Geschwindigkeit zentrifugiert. Die Säule wurde nun in ein neues Röhrchen gegeben. Dann wurden 30-50 $\mu$ l RNAse-freies $\mathrm{H}_{2} \mathrm{O}$ direkt auf die Membran pipettiert und das Röhrchen für 5 Minuten bei Raumtemperatur inkubiert. Jetzt wurde erneut 1 Minute bei voller Geschwindigkeit zentrifugiert, wonach die RNA im Durchfluss enthalten war.

Mithilfe eines Photometers wurden danach die Menge und die Qualität der RNA bestimmt. Die RNA-Extraktion inklusive nachfolgender Untersuchungen wurde an 6 verschiedenen Menisken durchgeführt.

\subsubsection{Umschreiben der RNA in cDNA}

Die Umschreibung von RNA in DNA wurde mithilfe des QuantiTect Reverse Transcription Kit durchgeführt. Dazu wurde die RNA zunächst mit dem gDNA Wipe Out Puffer für 2 Minuten bei $42{ }^{\circ} \mathrm{C}$ inkubiert, um restliche genomische DNA zu entfernen. Danach wurden $4 \mu \mathrm{RT}$ Transkriptionspuffer, $1 \mu \mathrm{l}$ RT-Transkriptase und $1 \mu \mathrm{l}$ RT-Primer-Mix hinzugefügt und für 15 Minuten bei $42^{\circ} \mathrm{C}$ sowie nachfolgend für 3 Minuten bei $95^{\circ} \mathrm{C}$ inkubiert. Danach wurde unter der hypothetischen Annahme, dass die mRNA im Verhältnis von 1:1 in cDNA umgeschrieben 
wurde, mithilfe der zuvor im Photometer gemessenen RNA-Konzentration die cDNA auf $1 \mathrm{ng} / \mu \mathrm{l}$ mit RNAse-freiem Wasser verdünnt.

Die gewonnene cDNA wurde danach bei $-20^{\circ} \mathrm{C}$ aufbewahrt.

\subsubsection{Durchführung der PCR}

In eine 96-Well-Platte wurde jeweils pipettiert:

- $2 \mu \mathrm{l}$ RNAse-freies $\mathrm{H}_{2} \mathrm{O}$

- $5 \mu$ I SYBR Green plus Nukleotid-Mix

- $2 \mu \mathrm{l}$ PCR-Primer-Mix (Forward- und Reverse-Primer jeweils $10 \mathrm{pmol} / \mu \mathrm{l}$ )

- $1 \mu \mathrm{l}$ cDNA (in einer Konzentration von $1 \mathrm{ng} / \mu \mathrm{l}$ )

Für ausreichende statistische Signifikanz wurden stets jeweils drei Wells gleich gefült und der gesamte Versuch wurde dreifach wiederholt, so dass insgesamt neun Messungen pro Messwert vorlagen.

Die 96-Well-Platten wurden danach nach dem oben beschriebenen Protokoll in der PCRMaschine amplifiziert und gemessen.

\subsubsection{Standardisierung der Messwerte}

Um den mRNA-Gehalt einer Zelle zu bestimmen, wurde in dieser Arbeit die relative mRNAQuantifizierung nach der $2^{-\Delta \Delta C T}$-Methode vorgenommen, welche 2001 von Pfaffl beschrieben worden ist. Hierzu wurde der mRNA-Gehalt eines Zielgens in Relation zu einem Housekeeping-Gen gesetzt ( $\triangle \mathrm{CT}$-Wert) und somit normalisiert. Als Housekeeping-Gene werden Gene bezeichnet, welche ubiquitär in allen Zellen in einer homogenen Menge exprimiert werden. Im Falle dieser Arbeit wurde nach vorangegangenen Voruntersuchungen PPIA (Peptidylprolyl-Isomerase A) als Housekeeping-Gen ausgewählt. Daraufhin wurde der $\triangle \mathrm{CT}$ Wert einer Probe mit dem $\Delta C T$-Wert einer Kontrolle verglichen ( $\Delta \Delta \mathrm{CT}$-Wert). Mithilfe der arithmetischen Formel $2^{-\Delta \Delta C T}$ konnte schließlich der relative Expressionsunterschied berechnet werden. Außerdem wurden die $\Delta \Delta C T$-Werte mithilfe eines t-Tests auf Signifikanz untersucht, Signifikanzniveau war hierbei ebenfalls $p<0,05$

Die PCR-Untersuchungen wurden an der cDNA von 6 verschiedenen Präparaten durchgeführt und die Ergebnisse wurden nach der Auswertung nach Pfaffl wurden gemittelt.

\subsubsection{Primer-Design}

Für das Primer-Design wurde zunächst die mRNA des Zielgens in der NCBI-NukleotidDatenbank gesucht. Mithilfe der Software Primer3 (http://frodo.wi.mit.edu/) wurde danach 
nach passenden Primern gesucht (Koressaar und Remm 2007, Untergasser et al. 2012). Dabei wurde, abweichend von den Standard-Einstellungen, auf folgende Punkte geachtet:

- Der Anteil an Guanin- und Cytosin-Basen sollte möglichst zwischen 40 und 60 Prozent liegen

- Der Temperaturunterschied der Annealing-Temperatur sollte nicht größer als $1^{\circ} \mathrm{C}$ betragen

- Die maximale Selbstkomplementarität sollte nicht mehr als 4,0, die maximale 3'Selbstkomplementarität nicht mehr als 1,0 betragen

Nachfolgend wurden die Vorschläge mithilfe von NCBI Nucleotide Blast (http://blast.ncbi.nlm.nih.gov/) auf ihre Spezifizität untersucht. Es wurden lediglich PrimerPaare akzeptiert, die jeweils keine weiteren möglichen mRNA-Alignments im menschlichen Transkriptom aufwiesen.

Die Primer wurden bei Eurofins Operon bestellt und durch eine Gradienten-PCR überprüft. Dabei wurden die Primer bei unterschiedlichen Annealing-Temperaturen zwischen 48 und $68^{\circ} \mathrm{C}$ zusammen mit einer Test-cDNA amplifiziert. Anhand einer Schmelzkurve wurde die optimale Annealing-Temperatur bestimmt. Das bei dieser Temperatur gewonnene PCRProdukt wurde durch die Firma SeqLab Göttingen sequenziert, um zu verifizieren, dass tatsächlich das gewünschte Zielgen amplifiziert wurde. Das Sequenzierungsergebnis wurde dazu erneut mit dem NCBI Nucleotide Blast ausgewertet.

Eine Liste der verwendeten Primer findet sich weiter oben.

\subsubsection{Histologie}

\subsubsection{Herstellen von Paraffin-Präparaten}

Für das Herstellen von Paraffin-Präparaten wurden OP-Präparate zunächst in ein Gefäß mit Fixierlösung aus Formaldehydlösung und Sörensen-Puffer gegeben, um Autolyseprozesse zu unterbrechen. Dieses Gefäß wurde aufgrund der Photosensibilität des Formaldehyds vor Lichteinfall geschützt und für $72 \mathrm{~h}$ in einem Kühlschrank bei $4^{\circ} \mathrm{C}$ aufbewahrt.

Als nächstes wurden die Präparate entkalkt, damit diese sich später ohne Probleme am Mikrotom schneiden ließen. Dazu wurden diese zunächst für $48 \mathrm{~h}$ erneut lichtsensibel bei $4{ }^{\circ} \mathrm{C}$ in einer Lösung aus $10 \%$ Ameisensäure und 2,5\% Formaldehyd inkubiert. Danach erfolgte die Inkubation für 72 Stunden bei Raumtemperatur in einer EDTA-Lösung (Ethylendiamintetraessigsäure). Dabei wurde die Probe auf einer Wippe gelagert und die EDTALösung täglich gewechselt. 
Als nächster Schritt erfolgte die Dehydrierung der Probe in einem Einbett-Automaten. Dazu wurde folgendes Protokoll benutzt:

- 3 h Alkohol $70 \%$

- 1 h Alkohol $80 \%$

- $1 \mathrm{~h}$ Alkohol $90 \%$

- $1 \mathrm{~h}$ Alkohol $96 \%$

- 2 h Alkohol $100 \%$

- 2 h Alkohol $100 \%$

- $2 \mathrm{~h}$ Isopropylalkohol

- $1,5 \mathrm{~h}$ Isopropylalkohol

- 30 min Xylol

- 45 min Xylol

- 45 min Xylol

- 6 h Paraplast Plus bei $52^{\circ} \mathrm{C}$

- $7 \mathrm{~h}$ Paraplast Plus bei $56^{\circ} \mathrm{C}$

Danach wurde die Probe in flüssigem Paraffin eingebettet, wobei die Probe innerhalb des Probenkörbchens analog zur späteren Schnittrichtung ausgerichtet wurde. Die Proben wurden danach sorgfältig beschriftet und über Nacht zum Aushärten in den Kühlschrank gelegt.

\subsubsection{Herstellung der Schnitte im Mikrotom}

Zum Herstellen der Schnitte wurden die in Paraffin eingebetteten Proben in ein Mikrotom gespannt. Dieses wurde je nach Beschaffenheit des Präparats und gewünschtem Schnitt auf eine Schnittdicke von $7 \mu \mathrm{m}$ eingestellt. Danach wurde der Block so lange unter Verwurf der Schnitte angeschnitten, bis sich das Mikrotom auf einer Schnittebene befand, welche einen repräsentativen Querschnitt des Präparats erfasste.

Jetzt wurden die Schnitte vorsichtig einzeln angefertigt und mithilfe eines feinen Pinsels in ein auf $37^{\circ} \mathrm{C}$ erhitztes Wasserbad transportiert, wo diese sich entfalten konnten. Danach wurde ein Objektträger vorsichtig in das Wasserbett eingetaucht und die auf dem Wasser schwimmende Probe vorsichtig von unten kommend auf diesen aufgetragen. Schließlich wurde der Objektträger beschriftet und auf eine auf $43^{\circ} \mathrm{C}$ erhitzte Wärmeplatte gelegt.

Nachdem genügend viele Schnitte angefertigt wurden, wurden die Objektträger noch einmal begutachtet und makroskopisch ungenügende Präparate wurden bereits im Vorfeld aussortiert. Die anderen Präparate wurden über Nacht im Brutschrank bei $37^{\circ} \mathrm{C}$ zum Trocknen inkubiert und konnten ab dem nächsten Tag für weitere Färbungen verwendet werden. 


\subsubsection{HE-Färbung}

Als Übersichtsfärbung für Präparate wurde eine Hämatoxylin-Eosin-Färbung durchgeführt. Für diese wurde ein Färbeautomat der Firma DiaPath verwendet. Es wurde folgendes Protokoll angewendet:

- 5 min Xylol

- 2 min Alkohol $100 \%$

- 2 min Alkohol $80 \%$

- 2 min Aqua dest.

- 4 min Hämalaun nach Mayer, 1:4 verdünnt

- 1 min Aqua dest.

- 15 min fließendes Wasser

- 7 min Eosin

- 1 min Aqua dest.

- 1 min Alkohol $60 \%$

- 1 min Alkohol $80 \%$

- 1 min Alkohol $100 \%$

- 3 min Xylol

- 3 min Xylol

Danach wurden die Präparate mit Eukitt eingedeckelt. 


\subsubsection{Alzianblau-Kernechtrot-Färbung}

Ebenfalls als Übersichtsfärbung wurde die Alzianblau-Kernechtrot-Färbung benutzt. Wiederum im DiaPath-Färbeautomaten wurde folgendes Protokoll verwendet:

- 5 min Xylol

- 2 min Alkohol $100 \%$

- 2 min Alkohol $80 \%$

- 2 min Alkohol $60 \%$

- 1 min PBS

- 2 min Essig $3 \%$

- 5 min Alzianblau

- 4 min fließendes Wasser

- 5 min Kernechtrot

- 4 min fließendes Wasser

- 2 min Alkohol $80 \%$

- 2 min Alkohol $100 \%$

- 3 min Xylol

- 3 min Xylol

Danach wurden die Präparate mit Eukitt eingedeckelt.

\subsubsection{Immunhistochemie}

Die Immunhistochemie wurde mithilfe des DAKO-Real-Kits durchgeführt. Zunächst wurden die Präparate zweimal 5 Minuten mit Xylol entparaffiniert und durch eine absteigende Alkoholreihe (jeweils 5 Minuten Alkohol $100 \%, 90 \%, 80 \%, 60 \%, 50 \%$ ) rehydriert. Danach wurden eventuell im Gewebe vorhandene endogene alkalische Phosphatasen mit Levamisole geblockt. Mithilfe von ProTaqs I wurden 20 Minuten bei $60^{\circ} \mathrm{C}$ Antigene demaskiert. Danach erfolgte mithilfe von Protease 24 für 1-5 Minuten eine Vorverdauung des Gewebes und somit eine weitere Demaskierung von Proteinbindungsstellen. Mit einer Lösung $1 \%$ BSA in PBS wurden daraufhin unspezifische Bindungsstellen für 10 Minuten geblockt, danach erfolgte eine Inkubation mit Antikörpern über Zeiträume zwischen einer Stunde bis über Nacht, jeweils bei Raumtemperatur.

Danach wurde zunächst ein sekundär biotinylierter Antikörper für 15 Minuten und nach einem Waschschritt mit PBS danach eine Streptavidin-Alkalische-Phosphatase ebenfalls für 15 Minuten hinzugegeben, welche an den biotinylierten Antikörper bindet. Schließlich wurde nach einem erneuten Waschschritt mit einer Chromogen-Lösung eine rötliche Färbung 
bewirkt. Eine Gegenfärbung wurde mit Hämalaun nach Mayer 1:4 verdünnt bewirkt, danach wurde das Präparat in aufsteigender Alkoholreihe dehydriert und mit Eukitt eingedeckelt.

Für das Entparaffinieren und Dehydrieren wurde ein automatischer Färbeautomat von DiaPath benutzt.

Es wurden die Schnitte von 6 verschiedenen Patienten untersucht. Für die hier gezeigten Präparate wurden jeweils Antikörperverdünnungen zwischen 1:50 und 1:250 ausprobiert und Inkubationen zwischen einer Stunde und über Nacht. Dabei zeigten sich die besten, hier abgebildeten Ergebnisse bei folgenden Protokollen:

PDGFR: 1:50, Inkubation über Nacht

EGFR: 1:50, Inkubation über Nacht

IGF-1R: Es konnte bei keinem Protokoll der IGF-1R nachgewiesen werden. Die hier gezeigten Bilder entstanden ebenfalls bei einer Verdünnung von 1:50 und Inkubation über Nacht. 


\section{Ergebnisse}

\subsection{Lichtmikroskopie}

Ziel der Lichtmikroskopie war es, zunächst Übersichtsaufnahmen des untersuchten Meniskusgewebes anzufertigen. Danach wurde immunhistochemisch nach dem Vorhandensein von Rezeptoren für die untersuchten Wachstumsfaktoren in den Fibrochondrozyten des Meniskus gesucht.

\subsection{1 Übersichtsaufnahmen}

Zunächst wurden Übersichtsaufnahmen der Menisken angefertigt. Dazu wurden die Präparate mit Hämalaun-Eosin bzw. mit Alzianblau-Kernechtrot gefärbt. Alzianblau färbt die im Gewebe enthaltenen sauren Mukosubstanzen wie Glykosaminoglykane und Aggrekan, Kernechtrot erzeugt dabei eine rote Gegenfärbung der Zellkerne.

In den Übersichtsfärbungen fiel dabei auf, dass bei sämtlichen untersuchten Menisken deutliche Zeichen der Arthrose erkennbar waren. Dies äußerte sich vor allen Dingen im Fehlen der superfiziellen Zone des Meniskus: Die in der Literatur für den gesunden Meniskus beschriebenen spindelförmigen Zellen der superfiziellen Zone (siehe Kapitel 1.1.2) ließen sich nicht nachweisen, stattdessen zeigte sich die Oberfläche des Meniskus als aufgeraut und ausgefranst (siehe Abbildung 5). Die Zellen an der Oberfläche stellten sich stattdessen als rundlich und mit deutlicher perizellulärer Matrix dar, wie es für die Fibrochondrozyten der inneren Zone beschrieben ist.

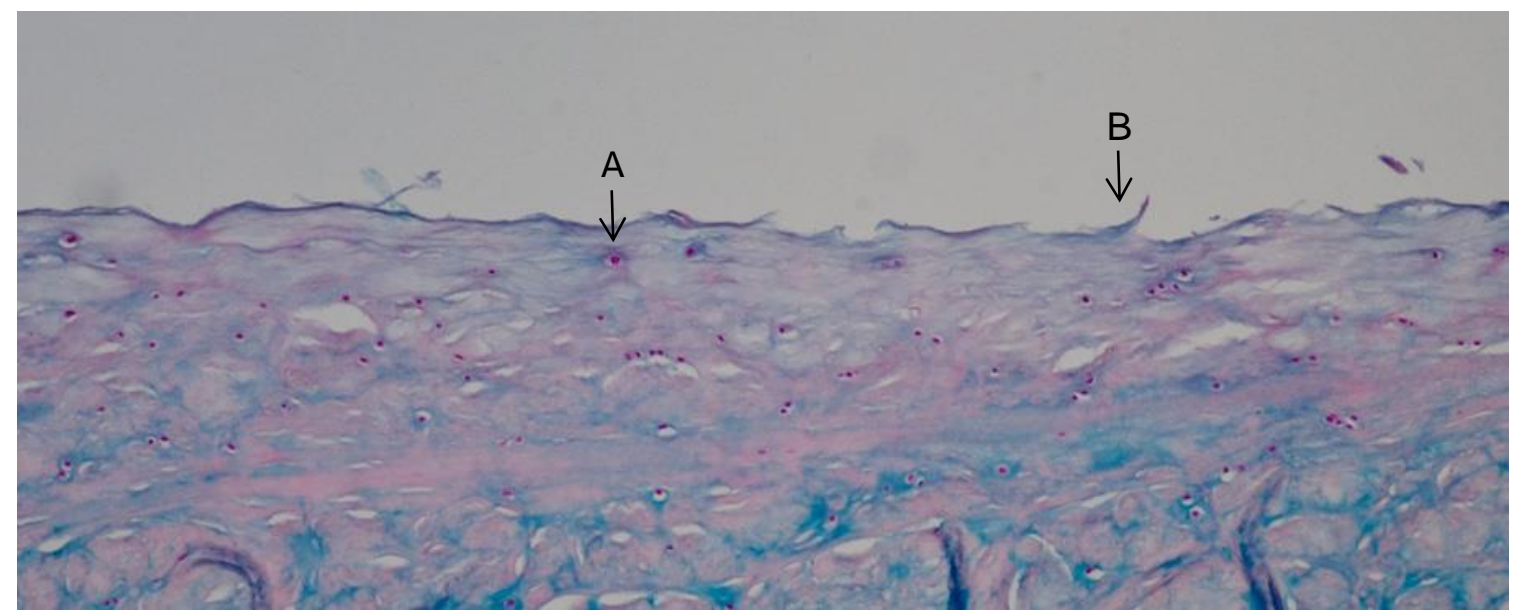

Abbildung 5: Schnitt der Oberfläche eines Meniskus, Alzianblau-Kernechtrot-Färbung. 10x Vergrößerung. A: Die Zellen der oberflächlichen Zone weisen nicht den in der Literatur für gesunde Menisken beschriebenen abgeflachten Zellkern auf, sondern ähneln den Fibrochondrozyten der inneren Zone. B: Wie sich deutlich erkennen lässt, ist die Oberfläche stark aufgeraut und abgeschilfert. 


\subsubsection{Nachweis von PDGFR}

Für PDGF konnte dabei das Vorliegen des Rezeptors in den untersuchten Kniemenisken mithilfe einer Immunhistochemie deutlich gezeigt werden. Dabei konnte das Vorliegen des Rezeptors sowohl im Zellkern und im perinukleären Zytoplasma als auch zirkulär an der Zellmembran nachgewiesen werden.

Beim Anfärbeverhalten zeigten sich deutliche regionale Unterschiede zwischen den verschiedenen Zonen des Meniskus: Die deutlichste Färbung zeigte sich in der zentralen inneren Zone des Meniskus, wo homogen sämtliche Fibrochondrozyten den PDGF-Rezeptor aufwiesen. Auch in der als superfiziell klassifizierten Zone zeigte sich eine homogene Anfärbung aller Zellen, wobei jedoch beachtet werden muss, dass wie in Kapitel 3.1.1 besprochen die hier vorliegenden Zellen zumindest makroskopisch nicht den in der Literatur beschriebenen Zellen der oberflächlichen Zone aus dem gesunden Meniskus entsprachen.

In der äußeren, vaskularisierten Zone des Meniskus hingegen konnte der PDGF-Rezeptor nicht nachgewiesen werden. Lediglich in den perivaskulären Perizyten der kleinen Gefäße konnte der Rezeptor nachgewiesen werden, was jedoch für das hier untersuchte Migrationsverhalten der MPCs irrelevant ist.

Abbildung 6 zeigt ein repräsentatives Bild aus den sechs identisch verlaufenden Immunhistochemie-Versuchen. 

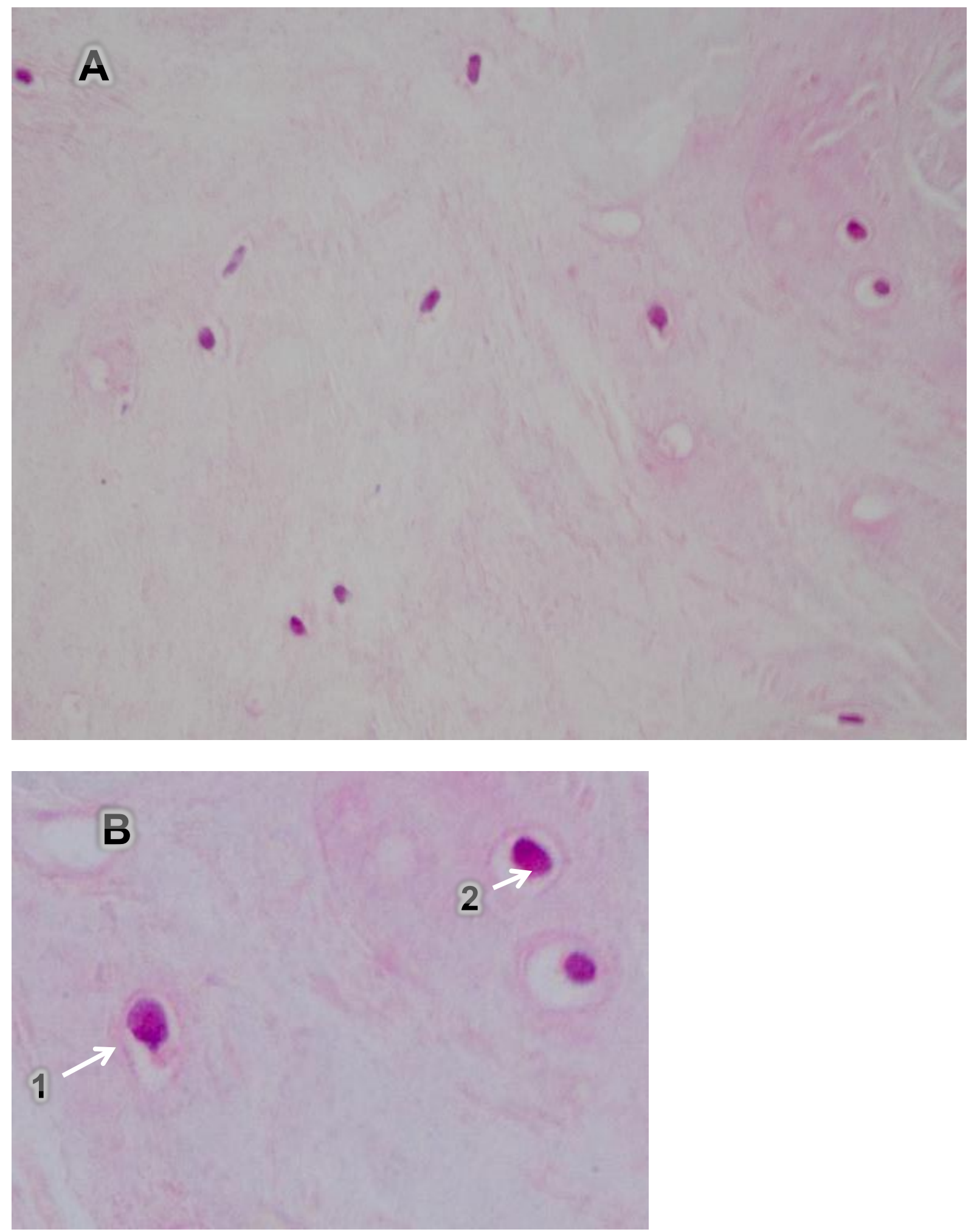

Abbildung 6: Schnitt durch die Innenzone des Meniskus, Immunhistochemie für PDGFR, Verdünnung 1:50 über Nacht. A: Übersichtsaufnahme, 40x Vergrößerung. Deutlich zeigt sich, wie sich die Zellkerne und die Zellmembran angefärbt haben. B: Detailaufnahme, 60x Vergrößerung. Pfeil 1: Färbung der Zellmembran. Pfeil 2: Anfärbung des perinukleären Zytoplasmas. 


\subsubsection{Nachweis von EGFR}

Der EGF-Rezeptor wurde ebenfalls per Immunhistochemie nachgewiesen. Analog zum PDGF-Rezeptor konnte auch für den EGF-Rezeptor das Vorliegen sowohl im Zellkern und perinukleären Zytoplasma als auch in der Zellmembran gezeigt werden.

Ebenfalls zeigte sich für den EGF-Rezeptor die deutlichste Anfärbung in der zentralen inneren Zone des Meniskus mit einer homogenen Anfärbung der Fibrochondrozyten. Im Gegensatz zum PDGF-Rezeptor zeigte sich die Anfärbung in den oberflächlich gelegenen Zellen der als superfiziell klassifizierten Zone deutlich geringer, hier lag keine homogene Anfärbung aller Zellen vor, außerdem waren die Anfärbungen insgesamt weniger deutlich. Abbildung 7 zeigt ein repräsentatives Bild aus den sechs identisch verlaufenden ImmunhistochemieVersuchen.

In der äußeren, vaskularisierten Zone des Meniskus zeigte sich wiederum keine deutliche Anfärbung der Zellen. Jedoch zeigte sich hier im Unterschied zum PDGF-Rezeptor neben der Anfärbung der Perizyten auch eine vereinzelte Anfärbung der Fibroblasten-ähnlichen Zellen, welche sich jedoch im Ausmaß bei Weitem geringer darstellte als die Färbung der inneren Zone.

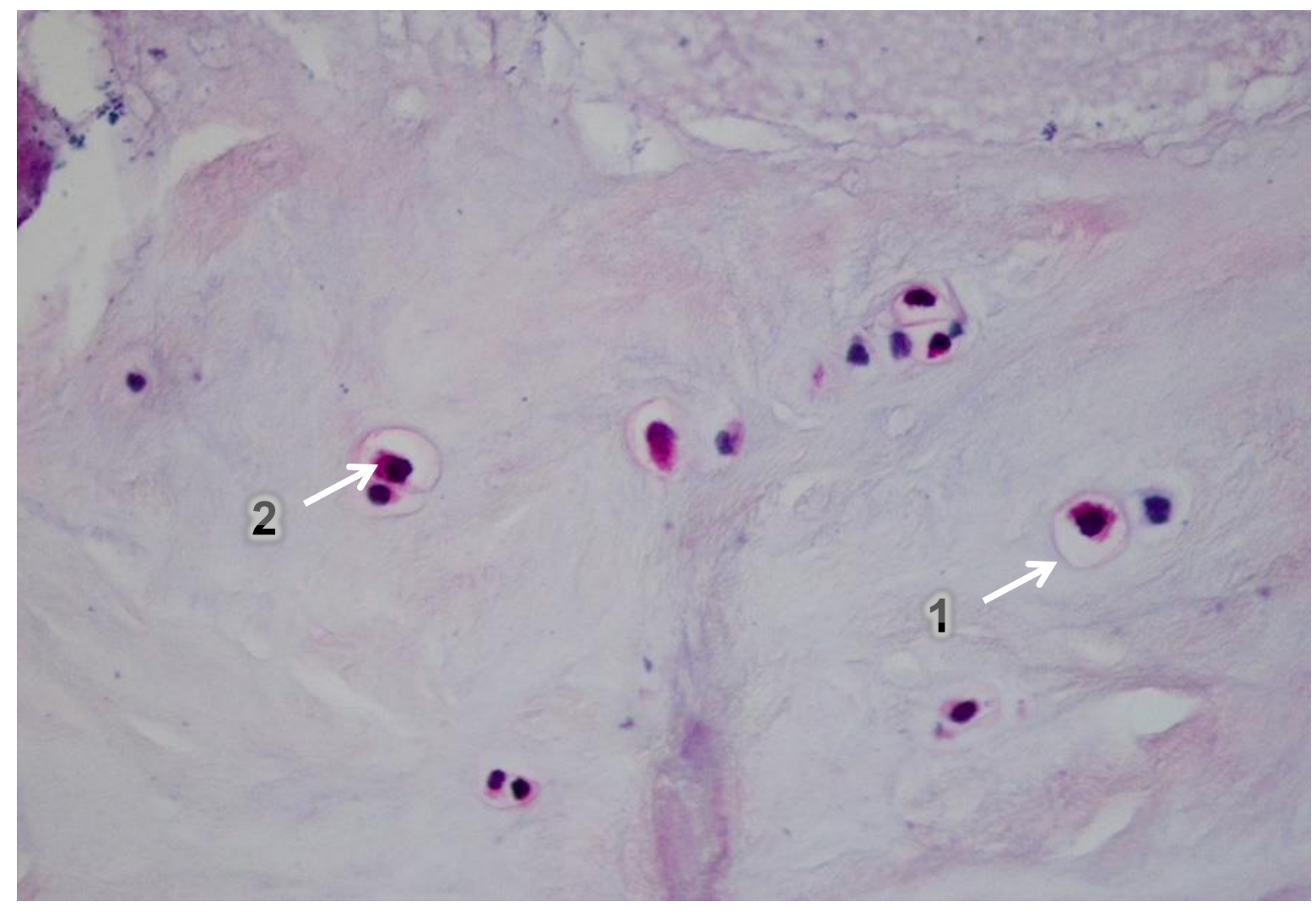

Abbildung 7: Schnitt durch die Innenzone des Meniskus, Immunhistochemie für EGFR, Verdünnung 1:50 über Nacht, 40x Vergrößerung. Deutlich zeigt sich die rosafarbene Anfärbung der Zellkerne und Zellmembran. Pfeil 1: Färbung der Zellmembran. Pfeil 2: Anfärbung des perinukleären Zytoplasmas. 


\subsubsection{Nachweis von IGF-1R}

Schließlich wurde versucht, auch den IGF-1-Rezeptor darzustellen. Trotz Verwendung von zwei unterschiedlichen Antikörpern gelang es jedoch nicht, das Vorhandsein dieses Rezeptors nachzuweisen.
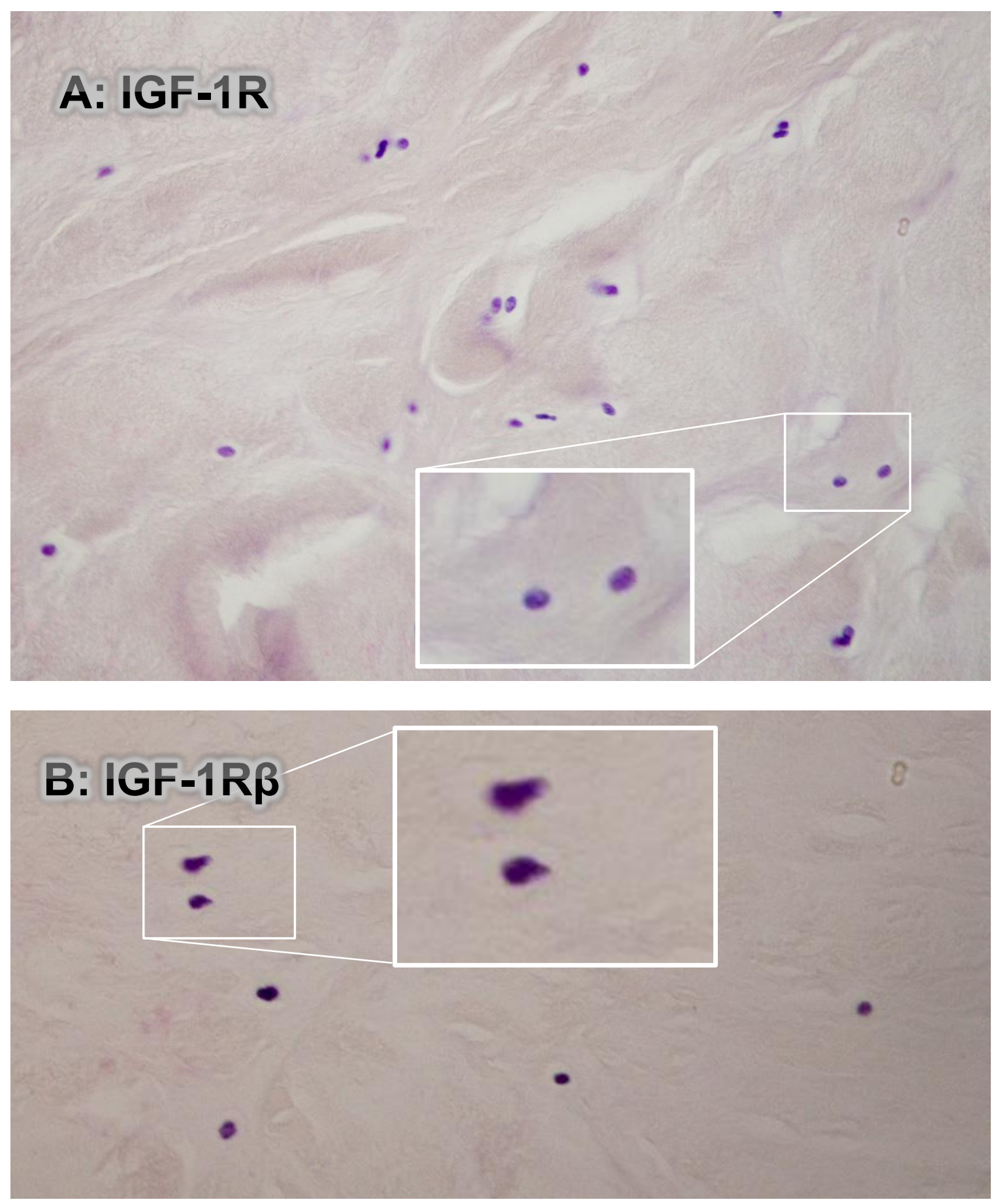

Abbildung 8: Schnitt durch die Innenzone des Meniskus, Immunhistochemie für IGF-1R, Verdünnung 1:50 über Nacht. Vergrößerung jeweils 40x, bei Ausschnitten 60x. A: IGF1-R (Phospho-Tyr1161). Es kann keine Anfärbung des IGF-1R gezeigt werden. B: IGF1-Rß. Auch bei diesem Antikörper kann kein IGF-1R nachgewiesen werden. 


\subsection{PCR-Analyse der mRNA}

Für die Genexpressionsanalyse via mRNA wurden jeweils die drei verschiedenen Zonen des Meniskus getrennt auf das Vorliegen von mRNA der drei untersuchten Rezeptoren untersucht. Dazu wurden die Daten anhand des Vorliegens von PPIA als Housekeeping-Gens standardisiert und jeweils die relative Genexpression im Verhältnis zur inneren Zone festgestellt (siehe Kapitel 2.2.6.4).

Für alle 6 untersuchten Proben konnte gezeigt werden, dass für alle drei Rezeptoren der mRNA-Gehalt in der inneren Zone am höchsten war. In der äußeren Zone war der mRNAGehalt jeweils nicht-signifikant erniedrigt, in der superfiziellen Zone war der mRNA-Gehalt in allen Fällen signifikant erniedrigt.

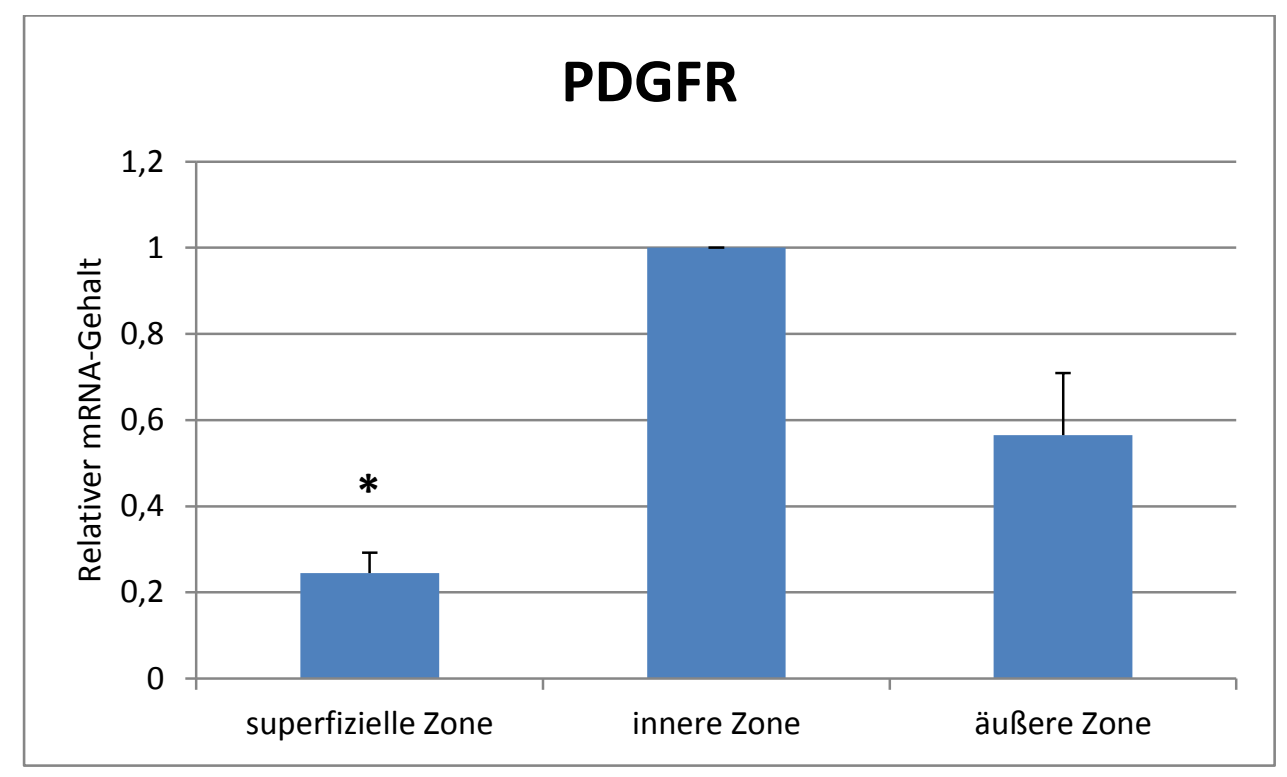

Abbildung 9: Relativer mRNA-Gehalt für PDGFR im Vergleich zwischen superfizieller, innerer und äußerer Zone. Dabei wurden die Daten nach Pfaffl 2001 normalisiert und jeweils als relativer mRNA-Gehalt zur inneren Zone angegeben. ${ }^{*}=$ signifikanter Unterschied zum Referenzwert (innere Zone) mit $p<0,05$. 


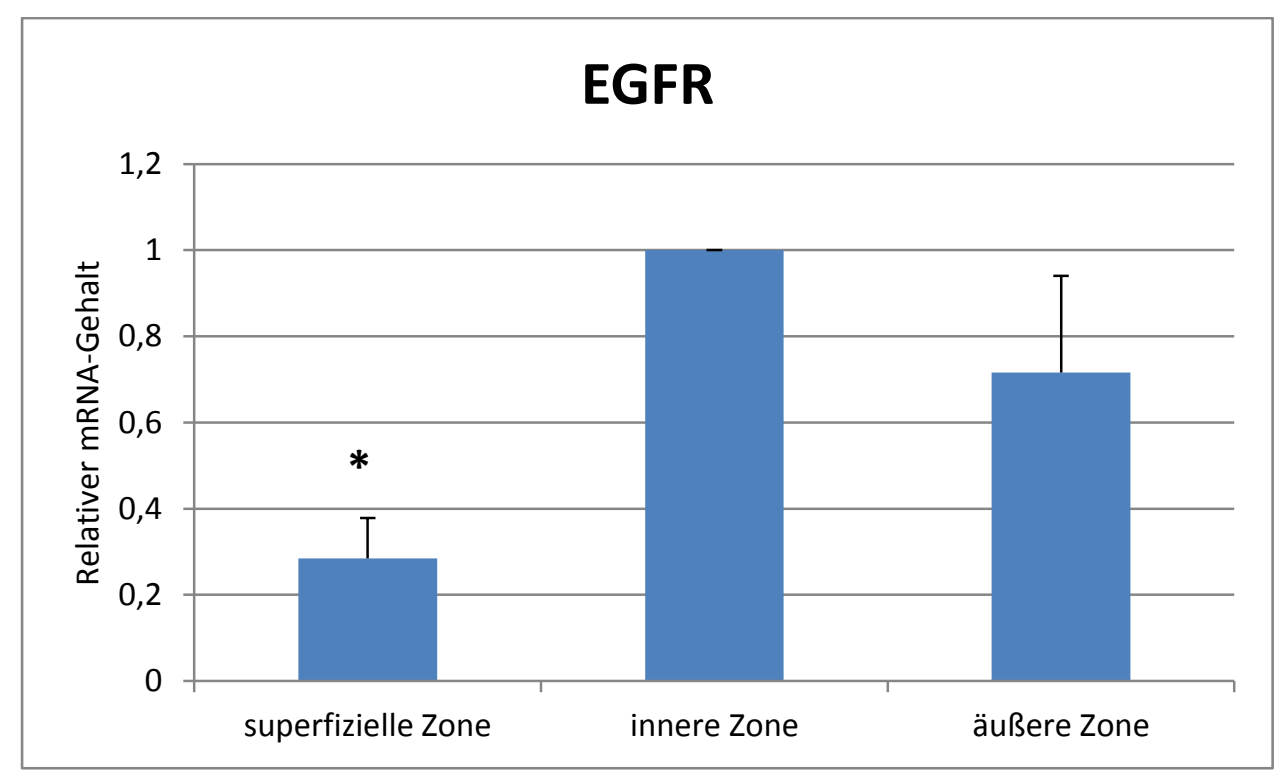

Abbildung 10: Relativer mRNA-Gehalt für EGFR im Vergleich zwischen superfizieller, innerer und äußerer Zone. Dabei wurden die Daten nach Pfaffl 2001 normalisiert und jeweils als relativer mRNA-Gehalt zur inneren Zone angegeben. ${ }^{*}=$ signifikanter Unterschied zum Referenzwert (Innere Zone) mit $p<0,05$.

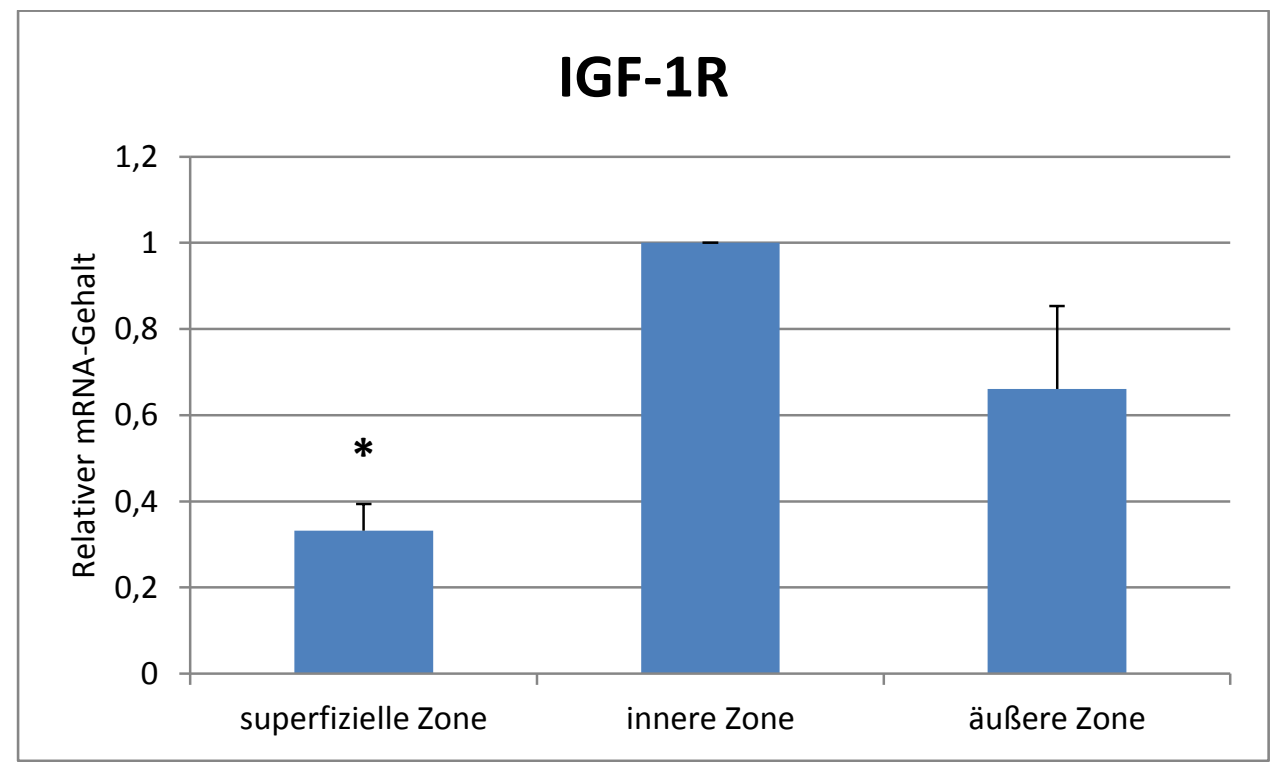

Abbildung 11: Relativer mRNA-Gehalt für IGF-1R im Vergleich zwischen superfizieller, innerer und äußerer Zone. Dabei wurden die Daten nach Pfaffl 2001 normalisiert und jeweils als relativer mRNA-Gehalt zur inneren Zone angegeben. ${ }^{*}=$ signifikanter Unterschied zum Referenzwert (Innere Zone) mit $p<0,05$.

Diese Beobachtung steht damit in Kongruenz zu den Ergebnissen der Immunhistochemie, in denen sich ebenfalls die deutlichsten Hinweise auf das Vorhandensein des Rezeptors in der inneren Zone finden ließen. 


\subsection{Migrationsassays}

Um das Migrationsverhalten von kultivierten MPCs in vitro zu untersuchen, wurde ein Migrationsassay nach Boyden verwendet. Dazu wurden lediglich MPCs der inneren Zone verwendet.

Es wurden drei Migrationsassays durchgeführt, in denen das Migrationsverhalten der MPCs über verschiedene Zeiträume (3, 9 und 24 Stunden) und bei verschiedenen Konzentrationen der Wachstumsfaktoren (10 ng/ml bzw. $40 \mathrm{ng} / \mathrm{ml}$ ) untersucht wurde. Dabei wurde jeweils eine negative Kontrolle durchgeführt, bei der sich auf beiden Seiten der Membran serumfreies Medium befand. Für jeden Messwert wurden je sechs einzelne Migrationskammern inkubiert, jede dieser Migrationskammern wurde danach vierfach mittels Zytofluoreszenz gemessen. Die Ergebnisse der Migrationsversuche werden im Folgenden jeweils als Boxplot und als Säulendiagramm gezeigt.

Zunächst wurde die Migration über einen Zeitraum von neun Stunden untersucht. Dabei wurden die Wachstumsfaktoren jeweils in einer Konzentration von $40 \mathrm{ng} / \mathrm{ml}$ in die untere Kammer pipettiert. Danach wurde die relative Zellanzahl durch eine Fluoreszenz-Messung mit Calcein-AM bestimmt.

In diesem Experiment zeigte sich eine signifikant gesteigerte Migration der Zellen unter Einfluss von PDGF, während sich bei EGF und IGF-1 eine Minderung der Migration nachweisen ließ, welche allerdings nur für IGF-1 signifikant war. 


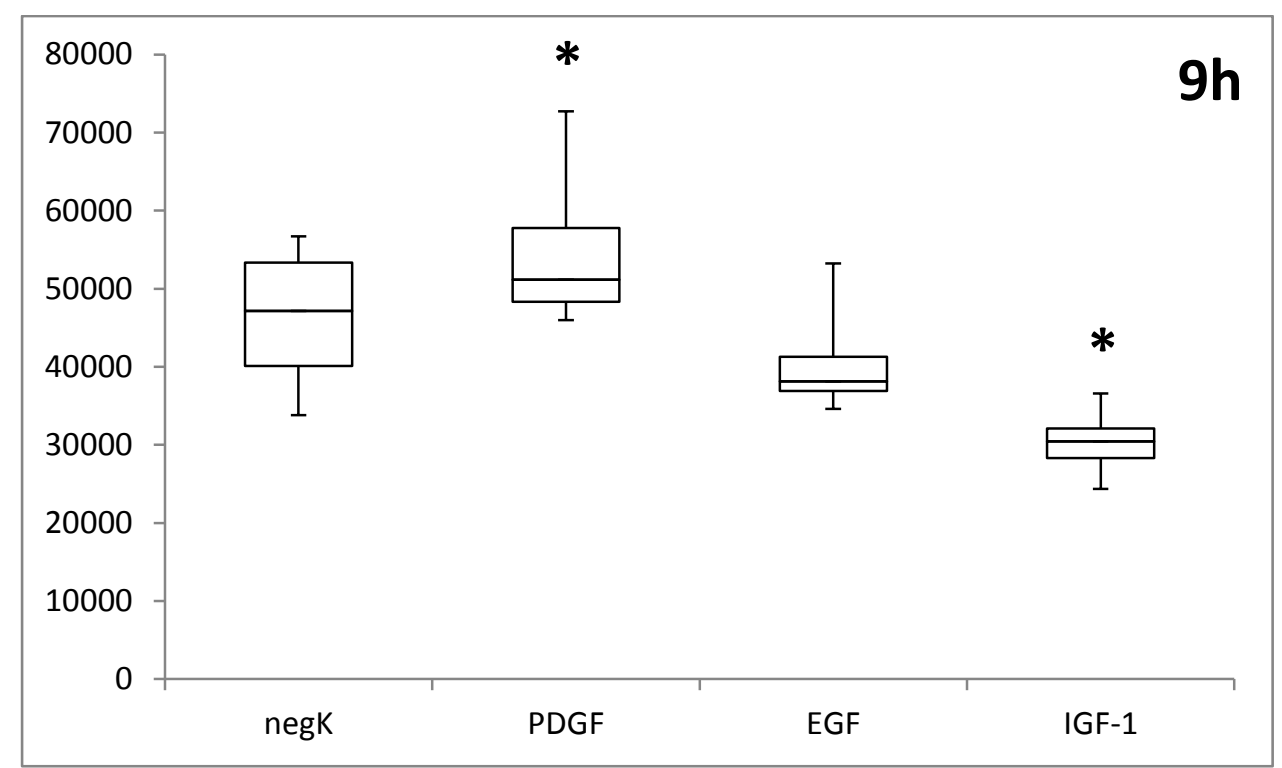

Abbildung 12: Migrationsassay nach 9 h. Darstellung als Boxplot, die Fehlerindikatoren geben die gesamte Streubreite der Einzelmesswerte an. negK = negative Kontrolle. Alle Messwerte bei einer WachstumsfaktorKonzentration von $40 \mathrm{ng} / \mathrm{ml}$. ${ }^{*}=$ signifikante Steigerung bzw. Minderung der Migration. Es zeigt sich eine signifikante Steigerung der Migration bei PDGF sowie eine signifikante Abnahme der Migration für IGF-1.

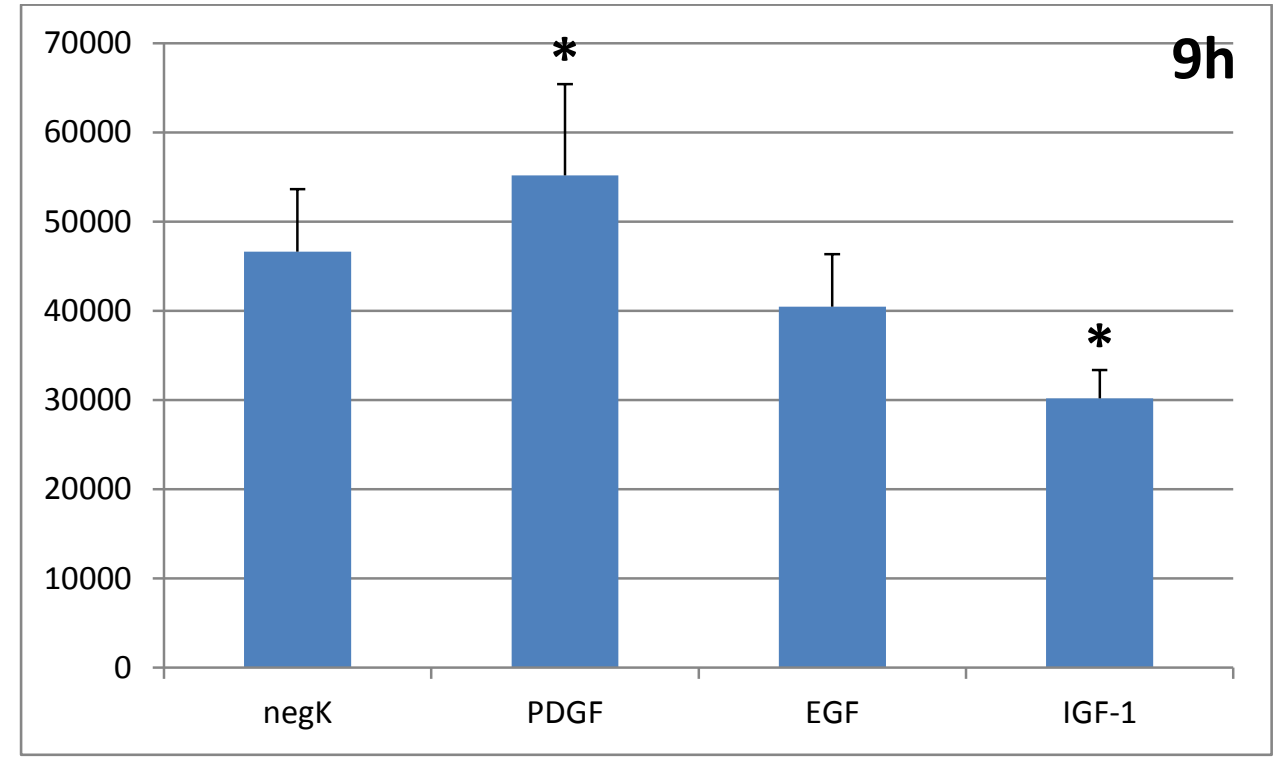

Abbildung 13: Migrationsassay nach 9 h. Darstellung als Säulendiagramm, die Fehlerindikatoren geben die Standardabweichung an. negK = negative Kontrolle. Alle Messwerte bei einer Wachstumsfaktor-Konzentration von $40 \mathrm{ng} / \mathrm{ml}$. * = signifikante Steigerung bzw. Minderung der Migration. Es zeigt sich eine signifikante Steigerung der Migration bei PDGF sowie eine signifikante Abnahme der Migration für IGF-1. 
Daraufhin wurde ein weiterer Migrationsassay über einen kürzeren Zeitraum von drei Stunden durchgeführt. Bei diesem Versuch wurden wiederum für jeden Wachstumsfaktor und für die negative Kontrolle je sechs parallele Versuche angesetzt. Bei diesem Migrationsassay wurde zusätzlich untersucht, inwiefern sich das Migrationsverhalten bei verschiedenen Konzentrationen der Wachstumsfaktoren unterschied. Dazu wurden niedrige Konzentrationen von $10 \mathrm{ng} / \mathrm{ml}$ gegen höhere Konzentrationen von $40 \mathrm{ng} / \mathrm{ml}$, die bereits im letzten Experiment verwendet wurden, untersucht.

Die Messergebnisse zeigten, dass bei dieser kurzen Inkubationsdauer eine sehr hohe Streuungsbreite der Einzelmesswerte vorlag, wie besonders aus dem Boxplot (Abbildung 14) hervorgeht. Obwohl die Ergebnisse für PDGF zwar von der Tendenz her gleichlautend waren wie beim vorherigen Versuch über neun Stunden, erreichten die Ergebnisse knapp nicht das Signifikanzniveau von $p<0,05$. Für EGF zeigte sich bei einer Konzentration von $10 \mathrm{ng} / \mathrm{ml}$ eine signifikant erniedrigte Migration, die Ergebnisse für IGF-1 waren nicht signifikant.

Schließlich wurde ein Migrationsassay über einen Zeitraum von 24 Stunden durchgeführt (siehe Abbildung 16 bis 19 auf S. 49-50). Für diesen langen Zeitraum wurden zwei primäre Zelllinien von zwei unterschiedlichen Meniskus-Patienten untersucht, wobei für jede der Zelllinien pro gemessenem Wachstumsfaktor bzw. Negativkontrolle jeweils sechs parallele Migrationsversuche gemessen und nachfolgend gemittelt wurden. Über diesen langen Zeitraum zeigten sich insgesamt die deutlichsten Unterschiede zwischen den verschiedenen Wachstumsfaktoren. So konnte für PDGF bei einer Konzentration von $40 \mathrm{ng} / \mathrm{ml}$ für beide Kulturen eine signifikante Steigerung der Migration nachgewiesen werden. Eine signifikante Minderung der Migration zeigte sich für EGF in einer Konzentration von $40 \mathrm{ng} / \mathrm{ml}$ ebenfalls für beide Kulturen. Bezüglich des Migrationsverhaltens unter Einfluss von IGF-1 unterschieden sich hingegen die Messwerte: Während für die erste Zelllinie IGF-1 sowohl in der hohen Dosis von $40 \mathrm{ng} / \mathrm{ml}$ als auch in der niedrigen Dosis von $10 \mathrm{ng} / \mathrm{ml}$ eine signifikante Minderung der Migration bewirkte, bewirkte es in der zweiten Zelllinie in beiden Fällen keine signifikante Änderung der Migration. 


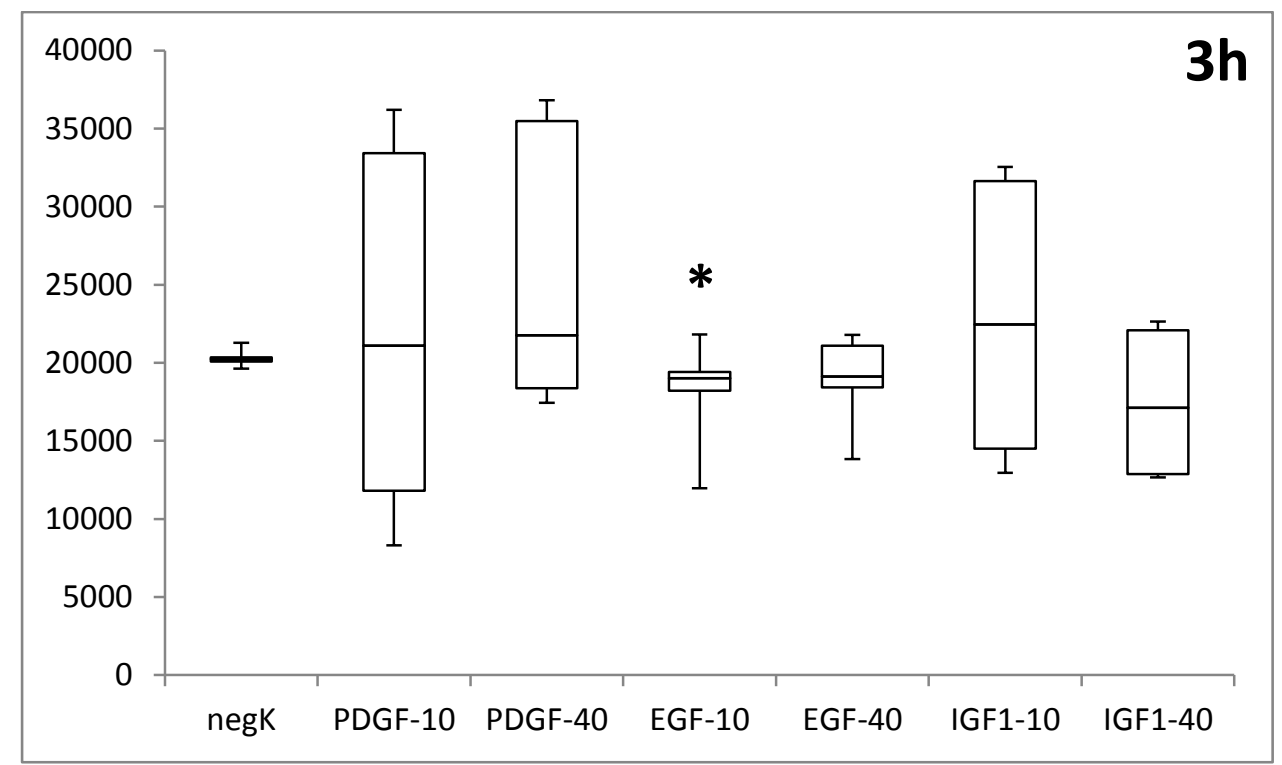

Abbildung 14: Migrationsassay nach $3 \mathrm{~h}$. Darstellung als Boxplot, die Fehlerindikatoren geben die gesamte Streubreite der Einzelmesswerte an. negK = negative Kontrolle. Alle Messwerte bei einer WachstumsfaktorKonzentration von $10 \mathrm{ng} / \mathrm{ml}$ („xxx-10“) bzw. $40 \mathrm{ng} / \mathrm{ml}$ („xxx-40“). * = signifikante Steigerung bzw. Minderung der Migration. Es zeigt sich eine signifikante Abnahme der Migration für EGF bei einer Konzentration von $10 \mathrm{ng} / \mathrm{ml}$.

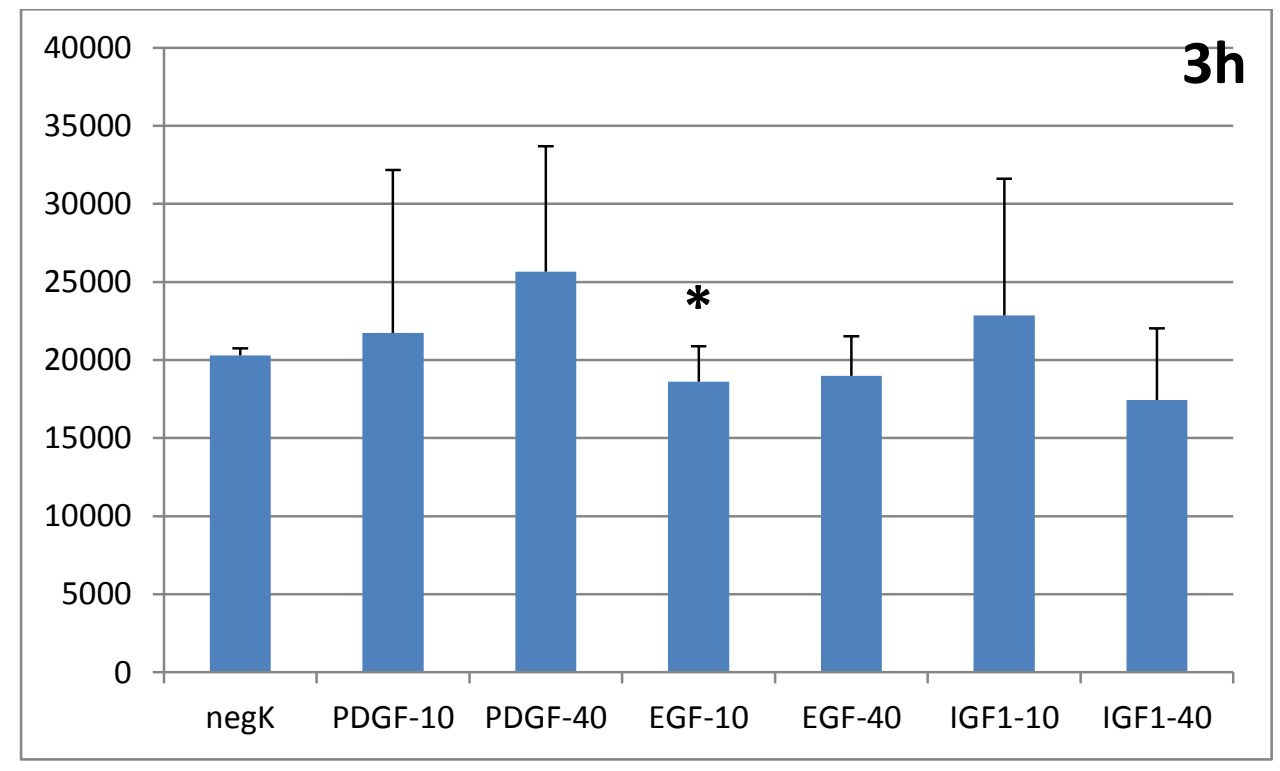

Abbildung 15: Migrationsassay nach $3 \mathrm{~h}$. Darstellung als Säulendiagramm, die Fehlerindikatoren geben die Standardabweichung an. negK = negative Kontrolle. Alle Messwerte bei einer Wachstumsfaktor-Konzentration von $10 \mathrm{ng} / \mathrm{ml}(, x x x-10 “)$ bzw. $40 \mathrm{ng} / \mathrm{ml}(,, x x x-40 “) .{ }^{*}=$ signifikante Steigerung bzw. Minderung der Migration. Es zeigt sich eine signifikante Abnahme der Migration für EGF bei einer Konzentration von $10 \mathrm{ng} / \mathrm{ml}$. 


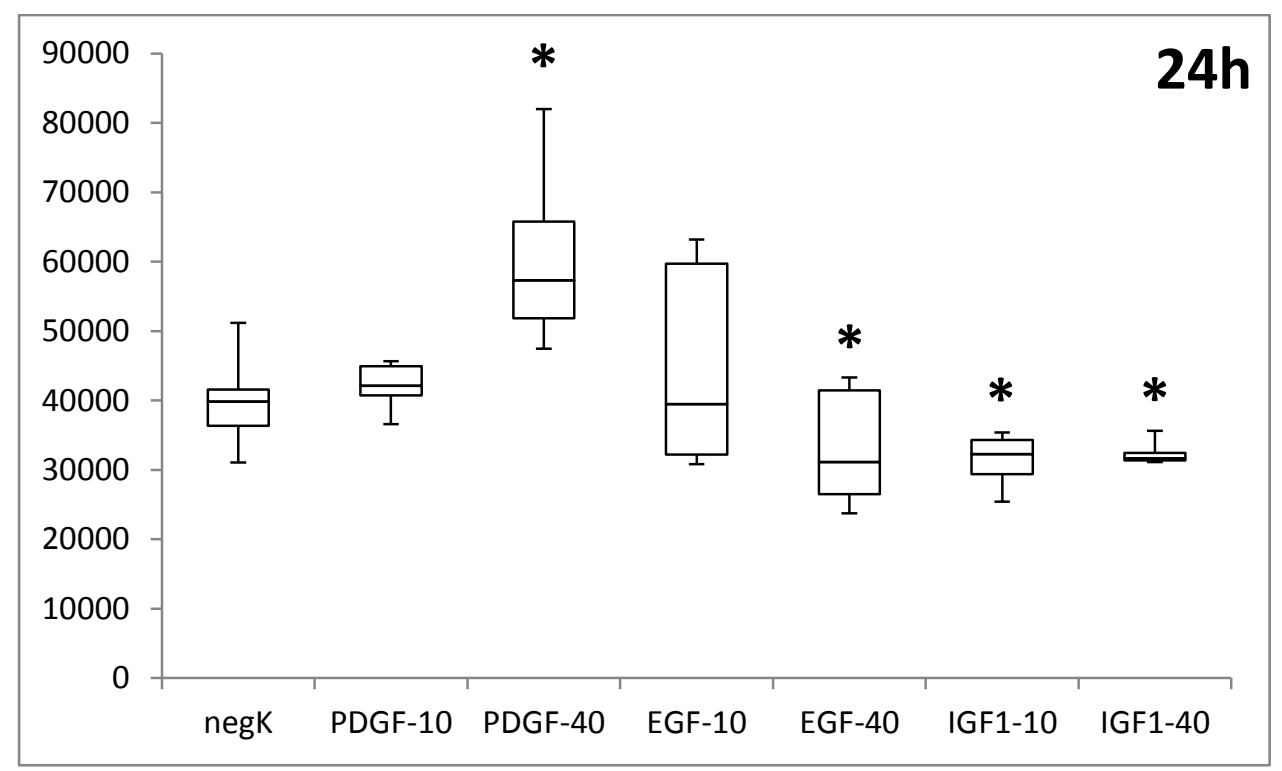

Abbildung 16: Migrationsassay nach 24 h (Zelllinie 1). Darstellung als Boxplot, die Fehlerindikatoren geben die gesamte Streubreite der Einzelmesswerte an. negK = negative Kontrolle. Alle Messwerte bei einer Wachstumsfaktor-Konzentration von $10 \mathrm{ng} / \mathrm{ml}$ (,xxx-10“) bzw. $40 \mathrm{ng} / \mathrm{ml}$ (,xxx-40“). * = signifikante Steigerung bzw. Minderung der Migration. Es zeigt sich eine signifikante Steigerung der Migration für PDGF bei einer Konzentration von $40 \mathrm{ng} / \mathrm{ml}$ sowie eine signifikante Abnahme der Migration für EGF bei einer Konzentration von $40 \mathrm{ng} / \mathrm{ml}$ sowie für IGF-1 bei einer Konzentration von 10 und $40 \mathrm{ng} / \mathrm{ml}$.

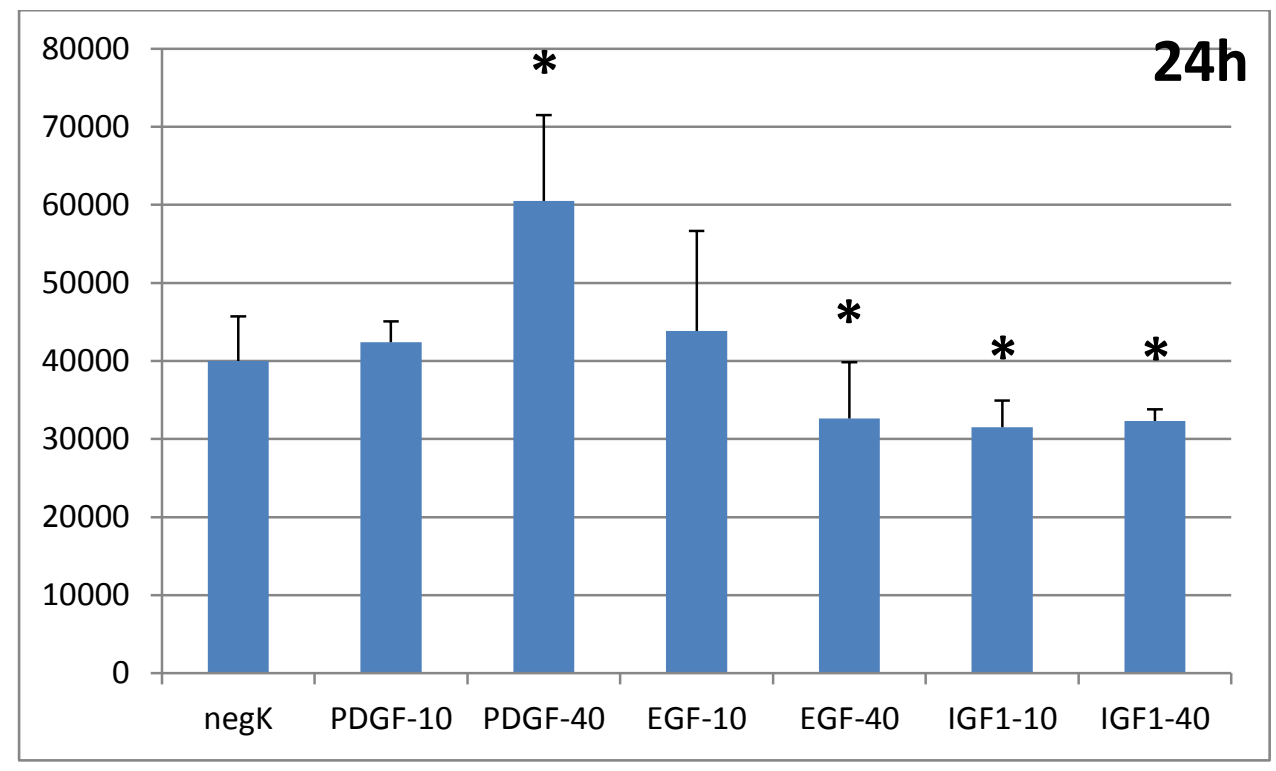

Abbildung 17: Migrationsassay nach 24 h (Zelllinie 1). Darstellung als Säulendiagramm, die Fehlerindikatoren geben die Standardabweichung an. negK = negative Kontrolle. Alle Messwerte bei einer WachstumsfaktorKonzentration von $10 \mathrm{ng} / \mathrm{ml}$ („xxx-10“) bzw. $40 \mathrm{ng} / \mathrm{ml}$ („,xxx-40“). * = signifikante Steigerung bzw. Minderung der Migration. Es zeigt sich eine signifikante Steigerung der Migration für PDGF bei einer Konzentration von $40 \mathrm{ng} / \mathrm{ml}$ sowie eine signifikante Abnahme der Migration für EGF bei einer Konzentration von $40 \mathrm{ng} / \mathrm{ml}$ sowie für IGF-1 bei einer Konzentration von 10 und $40 \mathrm{ng} / \mathrm{ml}$. 


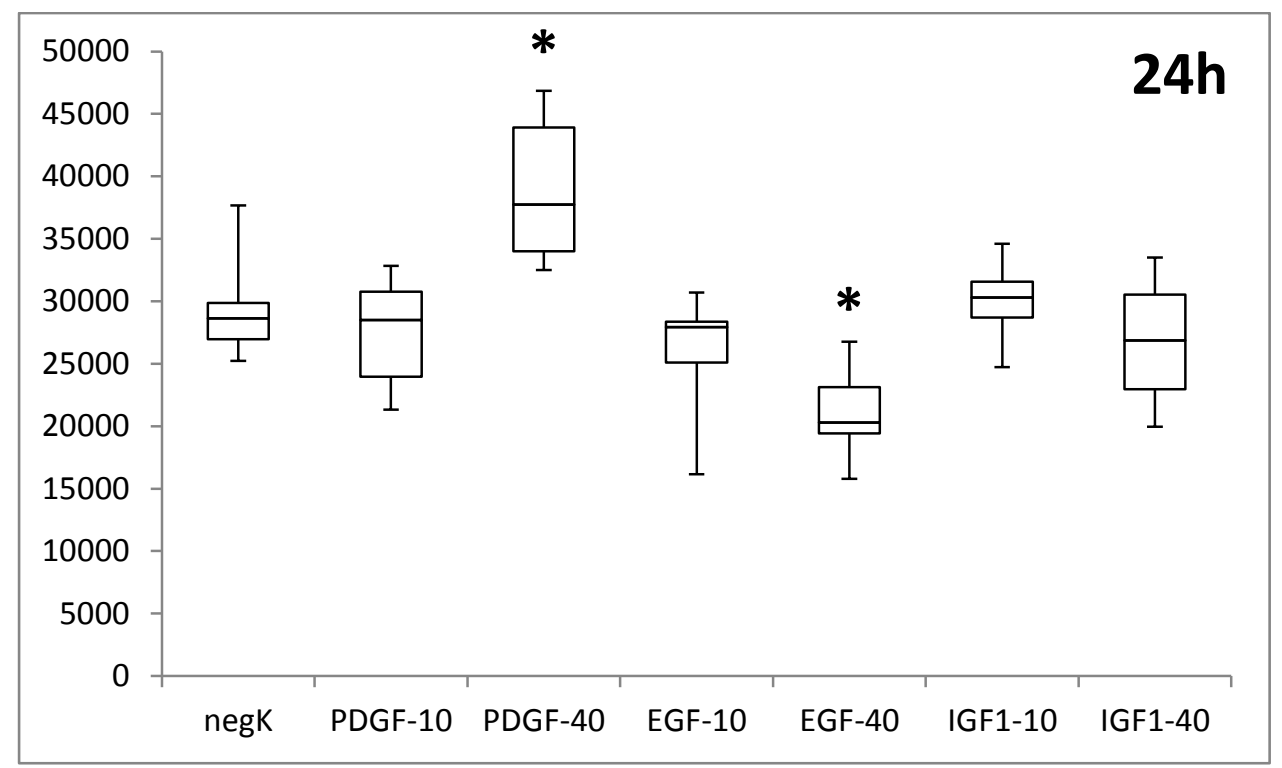

Abbildung 18: Migrationsassay nach 24 h (Zelllinie 2). Darstellung als Boxplot, die Fehlerindikatoren geben die gesamte Streubreite der Einzelmesswerte an. negK = negative Kontrolle. Alle Messwerte bei einer Wachstumsfaktor-Konzentration von $10 \mathrm{ng} / \mathrm{ml}$ (,xxx-10“) bzw. $40 \mathrm{ng} / \mathrm{ml}$ (,xxx-40“). * = signifikante Steigerung bzw. Minderung der Migration. Es zeigt sich eine signifikante Steigerung der Migration für PDGF bei einer Konzentration von $40 \mathrm{ng} / \mathrm{ml}$ sowie eine signifikante Abnahme der Migration für EGF bei einer Konzentration von $40 \mathrm{ng} / \mathrm{ml}$, während für IGF-1 konzentrationsunabhängig kein signifikanter Einfluss auf die Migration gezeigt werden kann.

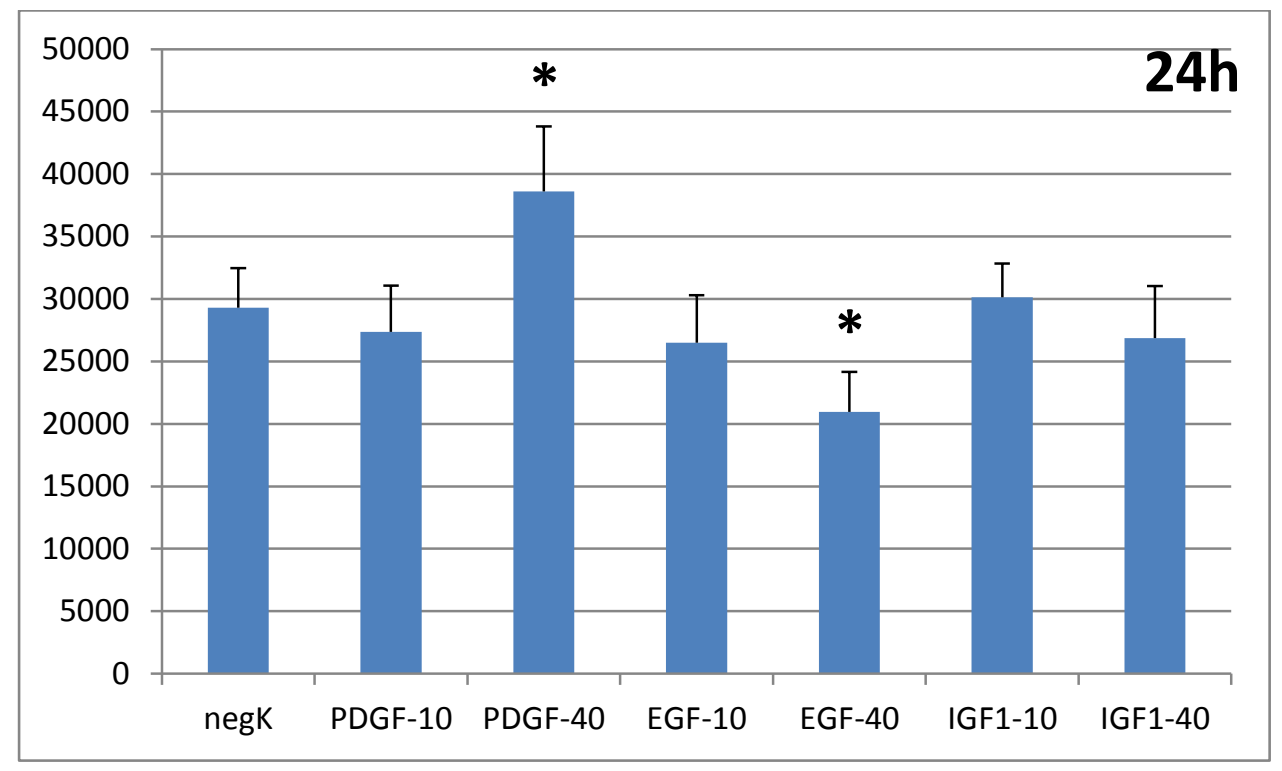

Abbildung 19: Migrationsassay nach 24 h (Zelllinie 2). Darstellung als Säulendiagramm, die Fehlerindikatoren geben die Standardabweichung an. negK = negative Kontrolle. Alle Messwerte bei einer WachstumsfaktorKonzentration von $10 \mathrm{ng} / \mathrm{ml}$ („xxx-10“) bzw. 40 ng/ml (,xxx-40“). * = signifikante Steigerung bzw. Minderung der Migration. Es zeigt sich eine signifikante Steigerung der Migration für PDGF bei einer Konzentration von $40 \mathrm{ng} / \mathrm{ml}$ sowie eine signifikante Abnahme der Migration für EGF bei einer Konzentration von $40 \mathrm{ng} / \mathrm{ml}$, während für IGF-1 konzentrationsunabhängig kein signifikanter Einfluss auf die Migration gezeigt werden kann. 


\section{4 Übersicht der Ergebnisse}

Die folgende Tabelle gibt eine Übersicht über die Ergebnisse der einzelnen Methoden.

Dabei gilt zu beachten, dass für die Immunhistochemie und die PCR-Analyse jeweils die entsprechenden Rezeptoren für die Wachstumsfaktoren nachgewiesen wurden, während für die Migration an sich natürlich der Wachstumsfaktor selbst verwendet wurde.

\begin{tabular}{|lllll|}
\hline & & PDGF & EGF & IGF-1 \\
\hline In vivo & Immunhistochemie & + & + & - \\
\hline In vitro & rtPCR & + & + & + \\
\hline In vitro & Migration & ++ & - & - \\
\hline
\end{tabular}

Tabelle 4: Übersicht der Ergebnisse

Es konnte also gezeigt werden, dass die Zellen einen PDGF-Rezeptor besitzen und durch Stimulation mit PDGF auch zur Migration angeregt werden.

Für EGF wurde zwar ebenso gezeigt, dass der Rezeptor in den Zellen vorhanden zu sein scheint, jedoch bewirkte die Stimulation dieses Rezeptors eine Abnahme der Migration.

Für IGF-1 konnte der Rezeptor nicht nachgewiesen werden, dennoch zeigte sich eine teilweise signifikante Abnahme der Migration. 


\section{Diskussion}

\subsection{Einfluss der Wachstumsfaktoren auf die Migration}

In dieser Arbeit konnte gezeigt werden, dass die kultivierten MPCs prinzipiell zur Migration fähig waren. Dazu wurden lediglich die MPCs aus dem als innere Zone klassifizierten Bereich ausgewählt, weil sich hier zum einen sowohl in der Immunhistochemie als auch in der PCR-Analyse die deutlichsten Hinweise für das Vorliegen der entsprechenden Rezeptoren für die untersuchten Wachstumsfaktoren ergeben hatten und zum anderen andere Mitglieder dieser Arbeitsgruppe die innere Zone des Meniskus als diejenige Zone klassifiziert hatten, in welcher am meisten MPCs vorlagen. Außerdem sind in dem äußeren, vaskularisierten Teil des Meniskus neben den MPCs auch weitere zur Migration fähige Zellen wie Perizyten zu erwarten, die theoretisch zu einem verfälschten Ergebnis hätten führen können.

Auf mRNA-Ebene konnte gezeigt werden, dass die Rezeptoren für alle drei der untersuchten Rezeptoren transkribiert wurden (PDGFR, EGFR und IGF-1R), so dass mRNA zur erfolgreichen Amplifikation vorlag.

In der Immunhistochemie hingegen wurden nicht gezielt MPCs untersucht, sondern das ganze Gewebe. Die dargestellten Zellen dürften daher hauptsächlich den Fibrochondrozyten zuzurechnen sein (siehe Kapitel 1.1.2). Diese Zellen könnten zwar differenzierte Abkömmlinge der MPCs oder zumindest eng mit diesen verwandt sein, weisen jedoch ein anderes Genexpressionsprofil auf. In den Fibrochondrozyten konnte zwar das Vorhandensein von PDGFR und EGFR gezeigt werden, jedoch konnte das Vorhandensein des IGF-1Rs trotz Einsatz von zwei verschiedenen Antikörpern nicht bewiesen werden. Diese im Vergleich zur PCR abweichenden Ergebnisse lassen mehrere Schlussfolgerungen zu (siehe Kapitel 4.1.3).

Die Interpretation der Ergebnisse aus den Migrationsversuchen muss bei kritischer Betrachtung unter Berücksichtigung mehrerer Vorbehalte erfolgen: Der Boyden-ChamberAssay gilt als einer der klassischen Versuchsaufbauten zur Untersuchung von Zellmigration, gleichzeitig sind jedoch Einschränkungen in der Interpretation der Ergebnisse bekannt. So beschreiben Schneider und Haugh 2006, dass der beobachtete Dosis-Wirkungs-Zusammenhang von der Struktur, Adhäsion und Dicke der Membran abhängt sowie von der Inkubationszeit.

Während in dieser Arbeit der Zusammenhang zwischen der Inkubationszeit und dem Migrationsverhalten untersucht wurde, bleiben die anderen Fehlerquellen vorhanden. Die verwendeten unbeschichteten Zellkultureinsätze der Firma Greiner Bio-One mit einer Porengröße von $8 \mu \mathrm{m}$ wurden für diese Arbeit ausgewählt, weil bereits andere Mitarbeiter der Arbeitsgruppe mit diesen Einsätzen bei Progenitorzellen im Knorpelgewebe (CPCs) gute Ergeb- 
nisse beobachten konnten. Gleichzeitig bietet dieselbe Firma Zellkultureinsätze mit verschiedenen Beschichtungen und unterschiedlichen Porengrößen an, ganz abgesehen von den diversen Mitbewerbern, welche ähnliche Produkte anbieten.

Ebenfalls unterschiedlich sind die verwendeten Wachstumsfaktoren, die ebenfalls von einer großen Anzahl von Herstellern angeboten werden. Insgesamt dürfte sich also allein aus den verwendeten Materialien ein großer Unsicherheitsfaktor ergeben, welcher einen nicht unerheblichen Einfluss auf die abweichenden Ergebnisse verschiedener Autoren zu dem Thema haben dürfte (siehe Tabelle 5). Zigmond und Hirsch gaben 1973 weiterhin zu bedenken, dass durch das Messen der migrierten Zellen nicht zwischen Chemokinesis und Chemotaxis unterschieden wird, d.h. dass nicht gemessen wird, ob der Wachstumsfaktor eine gezielte Migration in Richtung des Chemogradienten bewirkt oder ob er vielmehr lediglich eine Steigerung der ungezielten Migration bewirkt.

Des Weiteren sind sämtliche der durchgeführten Experimente in einer 2D-Kultur durchgeführt worden. Während sich die Zellen auf diese Weise gut kultivieren lassen, ist unklar, inwiefern das Wachstumsverhalten, die Genexpression und die Zelldifferenzierung mit den Vorgängen in vivo übereinstimmt. Ebenso ist fraglich, wie groß die Übereinstimmungen zwischen einer Migration in vivo und dem Migrationsassay nach Boyden sind (Wolf et al. 2013). Insofern wäre weitere Forschung im Sinne eines in-vitro-Migrationsassays im Gewebe oder sogar eines in-vivo-Assays notwendig, um die Relevanz dieser Ergebnisse zu begutachten.

\subsubsection{PDGF}

Wie bereits in der Einleitung erwähnt, gilt PDGF als Modell-Zytokin für die Migration (Deuel et al. 1991) und ist im Zusammenhang mit dieser mit Abstand am besten erforscht. Angesichts der verschiedenen Isoformen von PDGF konnten unter anderem Mishima und Lotz 2008 für Chondrozyten zeigen, dass PDGF-AB und PDGF-BB einen wesentlich größeren Effekt auf die Migration haben als PDGF-AA, auch wenn die Autoren auch für letzteres immer noch eine signifikante Steigerung auf die Migration beschreiben (siehe Abbildung 20). Es ist außerdem mehrfach beschrieben, dass vor allen Dingen der PDGF-Rezeptor $\beta$ die Migration vermittelt (Rönnstrand und Heldin 2001). 


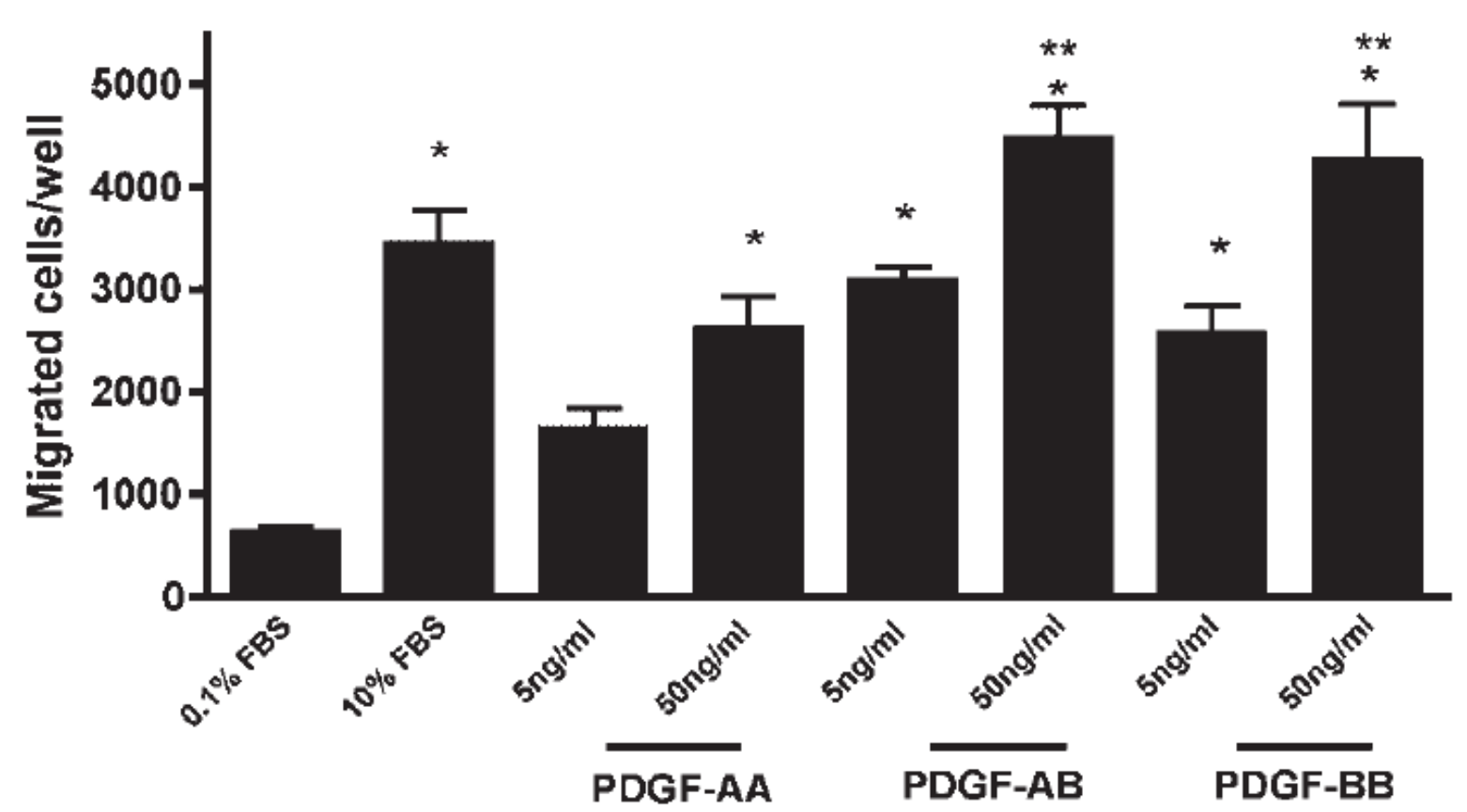

Abbildung 20: Einfluss von PDGF auf die Migration von Chondrozyten. FBS (fetal bovine serum) ist dabei ein Synonym für FCS (fetal calf serum). *: signifikant gesteigerte Migration versus $0.1 \%$ FBS mit $p<0,05,{ }^{* *}$ : signifikant gesteigerte Migration versus $50 \mathrm{ng} / \mathrm{ml}$ PDGF-AA mit $\mathrm{p}<0,05$. Aus Mishima und Lotz 2008, S. 1410

Dementsprechend wurde für die Migrationsversuche dieser Arbeit PDGF-BB als Vertreter der PDGF-Familie ausgewählt und ein Antikörper gegen PDGFRß ausgewählt. Wie erwartet konnte auch für die untersuchten MPCs gezeigt werden, dass PDGF einen deutlichen Einfluss auf die Migration auslösen konnte. Signifikant war dieser Effekt jedoch lediglich bei einer Konzentration von $40 \mathrm{ng} / \mathrm{ml}$, während eine geringere Konzentration von $10 \mathrm{ng} / \mathrm{ml}$ in keinem Fall eine signifikante Steigerung auslösen konnte.

Der positive Effekt von PDGF auf die Migration ist gerade aufgrund der entscheidenden Rolle von PDGF in der Wundheilung interessant. PDGF liegt in hoher Konzentration in Thrombozyten vor, wird bei Verletzungen in die Umgebung abgegeben und steigert so vermutlich die Geweberegeneration und -heilung (Schmidt et al. 2006, Allen et al. 2014, Steel 2006, Kaltalioglu et al. 2013). Dabei wirkt PDGF zusammen mit VEGF auch proangiogenetisch (Gaengel et al. 2009, Banfi et al. 2012). Interessanterweise kann PDGF MSCs rekrutieren (Mishima und Lotz 2008, Ponte et al. 2007), ohne eine weitere Differenzierung der MSCs zu bewirken (Kratchmarova et al. 2005). Auch für viele weitere Zellen, die in der Wundheilung eine Rolle spielen, konnte eine Steigerung der Migration durch PDGF gezeigt werden, unter anderem für Neutrophile und Monozyten (Deuel et al. 1982).

Spindler et al. konnten 1995 zeigen, dass die Fibrochondrozyten im Meniskus von Schafen auf Stimulation durch PDGF mit einer gesteigerten Mitose reagieren. Gleichzeitig zeigten sich in dieser Studie jedoch deutliche regionale Unterschiede: Während in der äußeren Zone des Meniskus die beschriebene deutliche Steigerung dosisabhängig induziert werden 
konnte, ließ sich in der zentralen Zone unabhängig von der Dosis keine Stimulation der Zellteilung erreichen. Bhargava et al. fanden 1999 in einer ähnlichen Studie an den Menisken von Rindern abweichend hiervon eine deutlich gesteigerte Zellteilung der Fibrochondrozyten sowohl in der äußeren als auch in der mittleren (rot-weißen) und inneren Zone des Meniskus. Gleichzeitig konnten die Autoren für alle drei Zonen eine deutliche Steigerung der Migration der Fibrochondrozyten in einem Boyden-Chamber-Assay als Antwort auf PDGF zeigen.

Auch für die Migration in einer 3D-Umgebung spielt PDGF insofern eine wichtige Rolle, als dass Sun et al. 2013 nachweisen konnten, dass PDGF-BB in MSCs die Bildung von MMPs induziert, welche essentieller Bestandteil der Migration in 3D-Umgebungen sind (siehe Kapitel 1.4.2).

Im Rahmen der Arthrose scheint PDGF eher eine untergeordnete Rolle zu spielen. So ist dem Autor dieser Arbeit keine Arbeit bekannt, in der ein deutlicher Zusammenhang zwischen PDGF und der Arthrose beschrieben wird. Im Gegenteil haben Untersuchungen über die Konzentration von Zytokinen in der Synovialflüssigkeit von Arthrosepatienten keine signifikant höheren PDGF-Konzentrationen gegenüber gesunden Patienten aufzeigen können (Mabey et al. 2014).

\subsubsection{EGF}

Wie in der Einleitung bereits erwähnt, übt EGF einen positiven Effekt auf die Zellproliferation aus und verhindert die Apoptose (Herbst 2004). Salehinejad et al. konnten 2013 diesen Effekt auch für menschliche MSCs aus der Nabelschnur beweisen. Dabei scheint der Effekt maßgeblich über eine Aktivierung der TERT (telomerase reverse transcriptase) vermittelt zu werden. Dieses Enzym spielt eine wichtige Rolle bei der Zellproliferation, gleichzeitig findet die Enzyminduktion jedoch nur bei Zellen statt, welche eine basale Grundaktivität von TERT aufweisen (Maida et al. 2002). Kratchmarova et al. beschrieben 2005, dass eine Inkubation von humanen MSCs mit EGF zu einer gesteigerten Differenzierung der Zelle in Osteoblasten resultiert.

In der Literatur ist zudem ein positiver Effekt auf die Zellmigration beschrieben. Ponte et al. zeigten 2007 eine signifikante Erhöhung der Zellmigration von MSCs bei Applikation von 10 ng/ml EGF. Bhargava et al. zeigten 1999 für Fibrochondrozyten aus den Menisken von Rindern einen positiven Effekt auf die Migration bei Konzentrationen von $1 \mathrm{ng} / \mathrm{ml}$ und $10 \mathrm{ng} / \mathrm{ml}$, wobei die Migration interessanterweise lediglich für Zellen der weißen und roten Zone, nicht aber der rot-weißen Zone gezeigt werden konnte. Gleichzeitig zeigten die Autoren, dass eine hohe Konzentration von 100 ng/ml EGF keine signifikante Steigerung der Mig- 
ration bewirken konnte. Auch für viele andere Zellreihen ist ein positiver Einfluss von EGF auf die Migration beschrieben, besonders für Karzinome (Segall et al. 1996, Hou et al. 2012).

In den Migrationsassays, die im Rahmen dieser Arbeit durchgeführt wurden, konnte abweichend von den Untersuchungen von Bhargava et al. 1999 und Ponte et al. 2007 keine Steigerung der Migration erreicht werden. Zwar konnte das Vorhandensein des EGF-Rezeptors in vitro und in vivo nachgewiesen werden, jedoch bewirkte die Applikation von EGF in den Dosen $10 \mathrm{ng} / \mathrm{ml}$ und $40 \mathrm{ng} / \mathrm{ml}$ keine Steigerung der Migration. Interessanterweise zeigte sich sogar eine Tendenz zu einer Abnahme der Migration bei Applikation von EGF im Vergleich zur negativen Kontrolle. Signifikant waren diese Ergebnisse bei einer Inkubationsdauer von 24 Stunden bei einer Konzentration von $40 \mathrm{ng} / \mathrm{ml}$. Die Bedeutung und das Zustandekommen dieser Beobachtung sind ungeklärt, jedoch zeigt sich, dass die MPCs sich hier deutlich von beschriebenen MSC- und Fibrochondrozyten-Kulturen unterscheiden.

Hinsichtlich der Fähigkeit von EGF, die Bildung von VEGF zu induzieren (Goldman et al. 1993, siehe Einleitung), ist die Relevanz für den Meniskus unklar. Theoretische Überlegungen angesichts der Tatsachen, dass zum einen der Meniskus in der avaskulären Zone eine deutlich verminderte Heilungstendenz gegenüber der vaskulären Zone aufweist, und dass zum anderen VEGF ein mächtiger proangiogenetischer Faktor ist, hatten die Hoffnung geweckt, durch lokale Applikation von VEGF die Heilung der avaskulären Zone zu verbessern (Kopf et al. 2010). Von diesen Autoren durchgeführte in-vivo-Experimente an den Menisken von Schafen konnten jedoch keinen positiven Einfluss auf die Heilung beobachten. Hinsichtlich des Einflusses von VEGF auf die Migration variieren die Aussagen: Während Ponte et al. 2007 keine signifikante Änderung des Migrationsverhalten von MSCs beschrieben, konnten Mishima und Lotz 2008 in Ihrer Arbeit eine signifikante Steigerung finden.

\subsubsection{IGF-1}

Der Zusammenhang von Arthrose und IGF-1 wurde bereits in der Einleitung erläutert. So ist IGF-1 wichtig für die Aufrechterhaltung der Gewebshomöostase und insbesondere für die Produktion von Proteoglykanen im Knorpel. Gleichzeitig wurde ebenfalls bereits dargestellt, dass in Arthrosegewebe erhöhte IGF-1-Konzentrationen bei gleichzeitig verminderter Reagibilität der Zellen vorliegen (Martel-Pelletier et al. 1998). Insgesamt zeigt sich also, dass IGF1 eine wichtige Rolle in der Arthrose zu spielen scheint, und insofern wäre gerade dieser Wachstumsfaktor auch im Zusammenspiel mit den MPCs interessant.

Hinsichtlich des Einflusses auf die Migration finden sich in der Literatur widersprüchliche Angaben. Ponte et al. beschrieben 2007 eine signifikante Zunahme der Migration für MSCs bei einer Konzentration von 30mg/nl. Bhargava et al. konnten 1996 in ihrer Arbeit mit Fibrochondrozyten von Rindermenisken ebenfalls einen deutlichen Einfluss auf die Migration fest- 
stellen, und zwar sowohl bei $1 \mathrm{ng} / \mathrm{ml}$ als auch bei 10 und $100 \mathrm{ng} / \mathrm{ml}$. Einschränkend muss hierbei erwähnt werden, dass diese Steigerung lediglich in der roten und rot-weißen Zone auftrat, während in der weißen Zone wie in dieser Arbeit keine signifikante Steigerung beobachtet werden konnte. Mishima und Lotz konnten 2010 hingegen keinen Einfluss auf die Migration von MSCs nachweisen.

In dieser Arbeit wurden hinsichtlich IGF-1 Resultate gefunden, die eine genauere Betrachtung notwendig machen. So ließ sich zwar die mRNA für den IGF-1-Rezeptor nachweisen, nicht jedoch das Vorhandensein in der Lichtmikroskopie. Dafür gibt es verschiedene potentielle Erklärungen: Theoretisch könnten beide verwendete Antikörper mit der angewandten Methode der Immunhistochemie (DAKO Real) inkompatibel sein. Insgesamt erscheint diese Möglichkeit aufgrund der für die anderen getesteten Rezeptoren zuverlässigen Methode sowie des Einsatzes von zwei verschiedenen Antikörpern eher unwahrscheinlich. Wahrscheinlicher ist, dass die in der Immunhistochemie dargestellten Fibrochondrozyten tatsächlich kein IGF-1R exprimieren bzw. IGF-1R nur in einer sehr geringen Anzahl unterhalb der Nachweisgrenze vorliegt. Die Diskrepanz zu den Ergebnissen der PCR könnte sich daraus erklären, dass es sich bei den Fibrochondrozyten letztlich um andere Zellen handelt als um die MPCs. Gleichzeitig gilt auch zu beachten, dass die PCR lediglich die Transkription der Gen-DNA in mRNA anzeigt. Dies beweist jedoch keinesfalls, dass die gebildete mRNA auch tatsächlich translatiert wird bzw. dass das translatierte Protein korrekt gefaltet und in die Membran eingebaut wird bzw. vor einem direkten Abbau durch Proteasen geschützt wird.

Hinsichtlich des Migrationsverhaltens wichen die Ergebnisse deutlich von den oben diskutierten Ergebnissen in der Literatur ab. So konnte bei einer Migrationsdauer von drei Stunden kein Einfluss beschrieben werden, bei einer Versuchsdauer von 9 Stunden zeigte sich hingegen eine signifikante Abnahme der Migration, sowohl bei 10 als auch bei $40 \mathrm{ng} / \mathrm{ml}$. Bei einer Versuchsdauer von 24 Stunden wichen die Ergebnisse zwischen den untersuchten Patienten ab: Während bei den MPCs aus dem einen Präparat für beide Konzentrationen eine signifikante Minderung vorlag, konnte für die MPCs aus der anderen Probe keine signifikante Auswirkung auf die Migration nachgewiesen werden.

Der teilweise negative Einfluss von IGF-1 auf die Migration ist insofern bemerkenswert, als dass selbst Mishima und Lotz, die IGF-1 keinen signifikanten Einfluss auf die Migration zuschrieben, zeigten, dass IGF-1 tendenziell eher eine Zunahme der Migration bewirkte, welche lediglich unterhalb des Signifikanzniveaus von $p<0,05$ blieb. Für IGF-1 zeigt sich also nach EGF wiederum ein deutlicher Unterschied im Migrationsverhalten von MPCs gegenüber dem von MSCs und Fibrochondrozyten. 
Es bleibt unklar, inwiefern der Einfluss bei gleichzeitig nicht nachweisbarem Rezeptor vermittelt werden kann. Hierbei ist zu erwähnen, dass IGF-1 mit geringer Affinität auch am Insulinrezeptor bindet (Stewart und Rotwein 1996). Denkbar wäre es, dass durch diese andere Rezeptorbindung ein gegenteiliger Effekt auf die Migration vorliegt. Insgesamt können die Beobachtungen jedoch nicht ohne weitere Forschung interpretiert werden.

\subsubsection{Zusammenhang zwischen der Inkubationszeit und dem Migrationsverhalten}

In den Versuchen konnte gezeigt werden, dass das Ausmaß der Migration mit zunehmender Inkubationszeit zunimmt. So zeigte sich nach einer Inkubationszeit von drei Stunden eine tendenzielle Zunahme der Migration unter PDGF, die jedoch knapp unter dem Signifikanzniveau von $p<0,05$ blieb. Hier fiel jedoch vor allen Dingen eine relativ hohe Streubreite der Einzelmesswerte auf.

Bei einer Inkubationszeit von neun Stunden hingegen wurden die Messwerte bereits deutlicher in der Tendenz und Signifikanz, die deutlichsten Ergebnisse fanden sich bei einer Inkubationszeit von 24 Stunden.

Auch bezüglich der Inkubationszeit gibt es verschiedene Beobachtungen in der Literatur, wobei dem Autor dieser Arbeit jedoch keine Arbeit bekannt ist, in welcher ein Vergleich zwischen verschiedenen Inkubationszeiten vorgenommen wird. Während Mishima und Lotz 2008 für ihre Arbeit lediglich eine Inkubationszeit von zwei Stunden angeben, wurden die Versuche von Ponte et al. 2007 bei einer Inkubation über Nacht durchgeführt. Bhargava et al. geben 1999 für ihre Beobachtungen an Fibrochondrozyten eine Inkubationszeit von vier Stunden an.

\subsection{Klinische Relevanz und weitere Forschung}

Die hier untersuchten Wachstumsfaktoren stellen selbstverständlich nur einen kleinen Anteil der Wachstumsfaktoren und Zytokine dar, die in vivo auf MPCs einwirken. Dazu kommen noch etliche weitere, die im Rahmen dieser Arbeit nicht weiter untersucht werden konnten, sowie eine vermutlich große Anzahl bisher unbekannter Zytokine.

Tabelle 5 gibt einen Überblick über verschiedene Arbeiten, welche sich mit dem Migrationsverhalten von MSCs oder Fibrochondrozyten beschäftigen, von denen mehrere auch im Zusammenhang mit MPCs und Arthrose interessant wären. So gilt IL-1 als Faktor, der an katabolen Prozessen in der Arthrose beteiligt ist. TGF- $\beta$ sowie die BMPs wiederum gelten als anabole Faktoren in der Arthrose, ähnlich dem IGF-1 (Goldring und Goldring 2004). Auch VEGF wird in von Arthrose betroffenem Gewebe vermehrt exprimiert (Jansen et al. 2012). Eine Untersuchung des Migrationsverhaltens von MPCs im Zusammenhang mit diesen Faktoren wäre also ein interessantes Gebiet für weitere Forschung. 


\begin{tabular}{|c|c|c|c|c|c|c|c|c|c|c|c|c|c|}
\hline & & $\begin{array}{l}\text { D̊ } \\
\text { ภ }\end{array}$ & 瞄 & 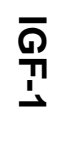 & $\begin{array}{l}\text { エ } \\
\mathbb{T}\end{array}$ & 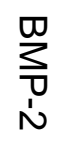 & 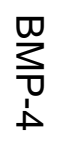 & 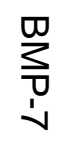 & $\overline{\bar{I}}$ & $\begin{array}{l}\bar{\Gamma} \\
\bar{\infty}\end{array}$ & 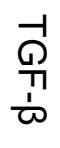 & $\stackrel{T}{\top}$ & 盈 \\
\hline $\begin{array}{l}\text { Bhargava et } \\
\text { al. } 1999\end{array}$ & $\begin{array}{l}\text { bovine } \\
\text { Fibrochondrozyten }\end{array}$ & + & + & + & + & + & & & + & & & & \\
\hline $\begin{array}{l}\text { Mishima und } \\
\text { Lotz } 2008\end{array}$ & MSCs & + & & \pm & & \pm & + & + & & + & \pm & \pm & + \\
\hline $\begin{array}{l}\text { Ponte et al. } \\
2007\end{array}$ & BM-MSCs & + & + & + & + & & & & & & & \pm & \pm \\
\hline diese Arbeit & MPCs & + & - & - & & & & & & & & & \\
\hline
\end{tabular}

Tabelle 5: Übersicht über den Einfluss von verschiedenen Wachstumsfaktoren auf die Zellmigration, wie er von verschiedenen Autoren beschrieben wurde. Ausgewählt wurden Paper, welche das Migrationsverhalten von MSCs oder anderer in diesem Zusammenhang relevanter Zellen untersucht haben. Legende: + (grün): signifikante Steigerung der Migration. \pm (gelb): kein signifikanter Einfluss. - (rot): signifikante Abnahme der Migration. Leere Zelle (weiß): Dieser Wachstumsfaktor wurde in dem Paper nicht untersucht. Die in dieser Arbeit untersuchten Wachstumsfaktoren wurden jeweils fett markiert.

Auch wenn die Forschungsergebnisse dieser Arbeit als Grundlagenforschung anzusehen sind, ist langfristig eine hohe klinische Relevanz denkbar: So könnten MPCs eine Rolle in zukünftigen therapeutischen Versuchen spielen, sowohl für degenerative als auch traumatische Verletzungen des Meniskus. Mithilfe der Ergebnisse dieser Arbeit könnten dabei MPCs durch den Einsatz von PDGF gezielt an der gewünschten Stelle rekrutiert werden. Auch im tissue engineering von künstlichem Meniskusgewebe wäre es denkbar, MPCs durch künstliche Herstellung eines Chemogradienten an einer bestimmten Stelle zu rekrutieren. 


\section{Zusammenfassung}

In dieser Arbeit wurde das Migrationsverhalten von mesenchymalen Stammzellen im menschlichen Kniemeniskus von Arthrosepatienten untersucht. Dabei zeigte sich, dass diese MPCs zur Migration fähig waren und auf Stimulation durch unterschiedliche Wachstumsfaktoren ihr Migrationsverhalten anpassen konnten.

Untersucht wurden dabei drei verschiedene Wachstumsfaktoren, PDGF, EGF und IGF-1, für die jeweils sowohl ein Einfluss auf die Migration von mesenchymalen Stammzellen als auch eine Relevanz im Zusammenhang mit der Arthrose in der Literatur beschrieben ist. Zunächst wurde das Vorliegen der jeweiligen Rezeptoren untersucht, wobei lediglich die Rezeptoren für PDGF und EGF nachgewiesen werden konnten, während der IGF-1-Rezeptor nicht sicher nachgewiesen werden konnte.

In der nachfolgenden Untersuchung des Migrationsverhaltens der MPCs unter dem Einfluss der Wachstumsfaktoren zeigte sich zum einen, dass sich die deutlichsten Ergebnisse bei einer Inkubationsdauer von 9 bzw. 24 Stunden zeigten, während zum anderen die Untersuchungen bei einer Inkubationsdauer von 3 Stunden Ergebnisse mit hohen Streubreiten und wenig signifikanten Aussagen produzierten.

In der Auswertung der verschiedenen Wachstumsfaktoren konnte nachgewiesen werden, dass PDGF eine signifikante Steigerung der Migration bewirken konnte, während EGF und IGF-1 eine signifikante Minderung der Migration bewirkten. Damit unterschied sich das Migrationsverhalten der MPCs deutlich von zuvor beschriebenen Zellkulturen aus mesenchymalen Stammzellen und Fibrochondrozyten. 


\section{Literaturverzeichnis}

Allen, RJ, Soares MA, Haberman ID, Szpalski C, Schachar J, Lin CD, Nguyen PD, Saadeh PB, Warren SM (2014): Combination therapy accelerates diabetic wound closure. PLoS ONE $\underline{9}$, e92667

Alshami AM (2014): Knee osteoarthritis related pain: a narrative review of diagnosis and treatment. Int J Health Sci (Qassim) $\underline{8}, 85-104$

Anderson JJ, Felson DT (1988): Factors associated with osteoarthritis of the knee in the first national Health and Nutrition Examination Survey (HANES I). Evidence for an association with overweight, race, and physical demands of work. Am J Epidemiol $\underline{128}$, 179-189

Arnoczky SP, Warren RF (1982): Microvasculature of the human meniscus. Am J Sports Med 10, 90-95

Assanah MC, Bruce JN, Suzuki SO, Chen A, Goldman JE, Canoll P (2009): PDGF stimulates the massive expansion of glial progenitors in the neonatal forebrain. Glia $\underline{57}$, $1835-1847$

Baker J, Liu JP, Robertson EJ, Efstratiadis A (1993): Role of insulin-like growth factors in embryonic and postnatal growth. Cell $\underline{75}, 73-82$

Banfi A, Degenfeld G von, Gianni-Barrera R, Reginato S, Merchant MJ, McDonald DM, Blau HM (2012): Therapeutic angiogenesis due to balanced single-vector delivery of VEGF and PDGF-BB. FASEB J $\underline{26}, 2486-2497$

Beaufils P, Verdonk R: The meniscus. Springer Verlag, Heidelberg/New York 2010

Bergsten E, Uutela M, Li X, Pietras K, Ostman A, Heldin CH, Alitalo K, Eriksson U (2001): PDGF-D is a specific, protease-activated ligand for the PDGF beta-receptor. Nat Cell Biol $\underline{3}, 512-516$

Bhargava MM, Attia ET, Murrell GA, Dolan MM, Warren RF, Hannafin JA (1999): The effect of cytokines on the proliferation and migration of bovine meniscal cells. Am J Sports Med $\underline{27}, 636-643$

Bianco P, Robey PG, Simmons PJ (2008): Mesenchymal stem cells: revisiting history, concepts, and assays. Cell Stem Cell 2, $313-319$ 
Bouacida A, Rosset P, Trichet V, Guilloton F, Espagnolle N, Cordonier T, Heymann D, Layrolle P, Sensébé L, Deschaseaux F (2012): Pericyte-like progenitors show high immaturity and engraftment potential as compared with mesenchymal stem cells. PLoS ONE $\underline{7}$, e48648

Boyden S (1962): The chemotactic effect of mixtures of antibody and antigen on polymorphonuclear leucocytes. J Exp Med $\underline{115}, 453-466$

Buckwalter JA, Mankin HJ (1997): Articular Cartilage, Part II: Degeneration and Osteoarthritis, Repair, Regeneration, and Transplantation. J Bone Joint Surg $\underline{79-A}, 612$ 632

Bullough PG, Munuera L, Murphy J, Weinstein AM (1970): The strength of the menisci of the knee as it relates to their fine structure. J Bone Joint Surg $\mathrm{Br} \underline{52}, 564-567$

Caplan Al (1991): Mesenchymal stem cells. J Orthop Res $\underline{9}, 641-650$

Caplan Al, Dennis JE (2006): Mesenchymal stem cells as trophic mediators. J Cell Biochem $\underline{98}, 1076-1084$

Carpenter G, Cohen S (1990): Epidermal growth factor. J Biol Chem $\underline{265}$, 7709-7712

Carter SB (1967): Haptotaxis and the mechanism of cell motility. Nature $\underline{213}, 256-260$

Cheung HS (1987): Distribution of type I, II, III and V in the pepsin solubilized collagens in bovine menisci. Connect Tissue Res $\underline{16}$, 343-356

Chew T, Wolf WA, Gallagher PJ, Matsumura F, Chisholm RL (2002): A fluorescent resonant energy transfer-based biosensor reveals transient and regional myosin light chain kinase activation in lamella and cleavage furrows. J Cell Biol 156, 543-553

Christoforakis J, Pradhan R, Sanchez-Ballester J, Hunt N, Strachan RK (2005): Is there an association between articular cartilage changes and degenerative meniscus tears? Arthroscopy 21, 1366-1369

Covas DT, Panepucci RA, Fontes AM, Silva WA, Orellana MD, Freitas MC, Neder L, Santos AR, Peres LC, Jamur MC et al. (2008): Multipotent mesenchymal stromal cells obtained from diverse human tissues share functional properties and gene-expression profile with CD146+ perivascular cells and fibroblasts. Exp Hematol 36, 642-654

Cramer LP, Siebert M, Mitchison TJ (1997): Identification of novel graded polarity actin filament bundles in locomoting heart fibroblasts: implications for the generation of motile force. J Cell Biol 136, 1287-1305 
Crisan M, Yap S, Casteilla L, Chen C, Corselli M, Park TS, Andriolo G, Sun B, Zheng B, Zhang L et al. (2008): A Perivascular Origin for Mesenchymal Stem Cells in Multiple Human Organs. Cell Stem Cell $\underline{3}, 301-313$

Daughaday WH, Rotwein P (1989): Insulin-like growth factors I and II. Peptide, messenger ribonucleic acid and gene structures, serum, and tissue concentrations. Endocr Rev $\underline{10}$, $68-91$

Deuel TF, Senior RM, Huang JS, Griffin GL (1982): Chemotaxis of monocytes and neutrophils to platelet-derived growth factor. J Clin Invest $\underline{69}, 1046-1049$

Deuel TF, Kawahara RS, Mustoe TA, Pierce AF (1991): Growth factors and wound healing: platelet-derived growth factor as a model cytokine. Annu Rev Med $\underline{42}, 567-584$

Devine SM, Bartholomew AM, Mahmud N, Nelson M, Patil S, Hardy W, Sturgeon C, Hewett T, Chung T, Stock W et al. (2001): Mesenchymal stem cells are capable of homing to the bone marrow of non-human primates following systemic infusion. Exp Hematol $\underline{29}$, 244-255

Dominici M, Le Blanc K, Mueller I, Slaper-Cortenbach I, Marini F, Krause D, Deans R, Keating A, Prockop D, Horwitz E (2006): Minimal criteria for defining multipotent mesenchymal stromal cells. The International Society for Cellular Therapy position statement. Cytotherapy $\underline{8}, 315-317$

Donatis A de, Comito G, Buricchi F, Vinci MC, Parenti A, Caselli A, Camici G, Manao G, Ramponi G, Cirri $P$ (2008): Proliferation versus migration in platelet-derived growth factor signaling: the key role of endocytosis. J Biol Chem $\underline{283}, 19948-19956$

Engebraaten O, Bjerkvig R, Pedersen PH, Laerum OD (1993): Effects of EGF, bFGF, NGF and PDGF $(\mathrm{bb})$ on cell proliferative, migratory and invasive capacities of human braintumour biopsies in vitro. Int J Cancer $\underline{53}, 209-214$

Englund M, Guermazi A, Lohmander SL (2009): The role of the meniscus in knee osteoarthritis: a cause or consequence? Radiol Clin North Am (Radiologic clinics of North America) $\underline{47}, 703-712$

Fairbank TJ (1948): Knee joint changes after meniscectomy. J Bone Joint Surg Br $\underline{30 B}, 664-$ 670

Felson DT (1988): Epidemiology of hip and knee osteoarthritis. Epidemiol Rev 10, 1-28 
Felson DT, Lawrence RC, Dieppe PA, Hirsch R, Helmick CG, Jordan JM, Kington RS, Lane NE, Nevitt MC, Zhang $Y$ et al. (2000): Osteoarthritis: new insights. Part 1: the disease and its risk factors. Ann Intern Med 133, 635-646

Fredriksson L, Li H, Eriksson U (2004): The PDGF family: four gene products form five dimeric isoforms. Cytokine Growth Factor Rev 15, 197-204

Friedenstein AJ, Chailakhjan RK, Lalykina KS (1970): The development of fibroblast colonies in monolayer cultures of guinea-pig bone marrow and spleen cells. Cell Tissue Kinet $\underline{3}$, 393-403

Fuerst M, Bertrand J, Lammers L, Dreier R, Echtermeyer F, Nitschke Y, Rutsch F, Schäfer, FK, Niggemeyer O, Steinhagen J et al. (2009): Calcification of articular cartilage in human osteoarthritis. Arthritis Rheum $\underline{60}, 2694-2703$

Fukubayashi T, Kurosawa $H$ (1980): The contact area and pressure distribution pattern of the knee. A study of normal and osteoarthrotic knee joints. Acta Orthop Scand $\underline{51}, 871-879$

Gaengel K, Genove G, Armulik A, Betsholtz C (2009): Endothelial-mural cell signaling in vascular development and angiogenesis. Arterioscler Thromb Vasc Biol 29, 630-638

Gardel ML, Schneider IC, Aratyn-Schaus Y, Waterman CM (2010): Mechanical integration of actin and adhesion dynamics in cell migration. Annu Rev Cell Dev Biol (Annual review of cell and developmental biology) $\underline{26}, 315-333$

Ghadially FN, Lalonde JM, Wedge JH (1983): Ultrastructure of normal and torn menisci of the human knee joint. J Anat $\underline{136}, 773-791$

Gnecchi M, He H, Liang OD, Melo LG, Morello F, Mu H, Noiseux N, Zhang L, Pratt RE, Ingwall JS et al. (2005): Paracrine action accounts for marked protection of ischemic heart by Akt-modified mesenchymal stem cells. Nat Med 11, 367-368

Goldman CK, Kim J, Wong WL, King V, Brock T, Gillespie GY (1993): Epidermal growth factor stimulates vascular endothelial growth factor production by human malignant glioma cells: a model of glioblastoma multiforme pathophysiology. Mol Biol Cell $\underline{4}, 121-$ 133

Goldring SR, Goldring MB (2004): The role of cytokines in cartilage matrix degeneration in osteoarthritis. Clin Orthop Relat Res $\underline{427}$, S27-36

Grotle M, Hagen KB, Natvig B, Dahl FA, Kvien TK (2008): Obesity and osteoarthritis in knee, hip and/or hand: an epidemiological study in the general population with 10 years followup. BMC Musculoskelet Disord $\underline{9}, 132$ 
Haddad B, Pakravan AH, Konan S, Adesida A, Khan W (2013): A systematic review of tissue engineered meniscus: cell-based preclinical models. Curr Stem Cell Res Ther $\underline{8}, 222$ 231

Hannan MT, Felson DT, Pincus T (2000): Analysis of the discordance between radiographic changes and knee pain in osteoarthritis of the knee. J Rheumatol 27, 1513-1517

Haugh JM (2006): Deterministic model of dermal wound invasion incorporating receptormediated signal transduction and spatial gradient sensing. Biophys $\mathrm{J}$ (Biophysical journal) $\underline{90}, 2297-2308$

Häuselmann HJ, Fernandes RJ, Mok SS, Schmid TM, Block JA, Aydelotte MB, Kuettner KE, Thonar EJ (1994): Phenotypic stability of bovine articular chondrocytes after long-term culture in alginate beads. J Cell Sci 107 (Pt 1), 17-27

Hawkins PT, Eguinoa A, Qiu RG, Stokoe D, Cooke FT, Walters R, Wennstrom S, ClaessonWelsh L, Evans T, Symons M (1995): PDGF stimulates an increase in GTP-Rac via activation of phosphoinositide 3-kinase. Curr Biol $\underline{5}$, 393-403

Hede MS, Salimova E, Piszczek A, Perlas E, Winn N, Nastasi T, Rosenthal N (2012): Epeptides control bioavailability of IGF-1. PLoS ONE $\underline{7}$, e51152

Heemskerk VH, Daemen MA, Buurman WA (1999): Insulin-like growth factor-1 (IGF-1) and growth hormone $(\mathrm{GH})$ in immunity and inflammation. Cytokine Growth Factor Rev $\underline{10}, 5$ 14

Hellio Le Graverand, MP, Ou Y, Schield-Yee T, Barclay L, Hart D, Natsume T, Rattner JB (2001): The cells of the rabbit meniscus: their arrangement, interrelationship, morphological variations and cytoarchitecture. J Anat $\underline{198}, 525-535$

Herbst RS (2004): Review of epidermal growth factor receptor biology. Int J Radiat Oncol Biol Phys $\underline{59}, 21-26$

Herwig J, Egner E, Buddecke E (1984): Chemical changes of human knee joint menisci in various stages of degeneration. Ann Rheum Dis $\underline{43}, 635-640$

Hoberg M, Uzunmehmetoglu G, Sabic L, Reese S, Aicher WK, Rudert M (2006): Characterisation of human meniscus cells. Z Orthop Ihre Grenzgeb $\underline{144}, 172-178$

Hou Y, Hedberg S, Schneider IC (2012): Differences in adhesion and protrusion properties correlate with differences in migration speed under EGF stimulation. BMC Biophys $\underline{5}, 8$ 
Hough, AJ, Webber RJ (1990): Pathology of the meniscus. Clin Orthop Relat Res 252, 3240

Huxley AF (2000): Mechanics and models of the myosin motor. Philos Trans R Soc Lond, B, Biol Sci (Philosophical transactions of the Royal Society of London. Series B, Biological sciences) $\underline{355}, 433-440$

Huxley AF, Niedergerke R (1954): Structural Changes in Muscle During Contraction: Interference Microscopy of Living Muscle Fibres. Nature 173, 971-973

Ilić D, Furuta Y, Kanazawa S, Takeda N, Sobue K, Nakatsuji N, Nomura S, Fujimoto J, Okada M, Yamamoto T (1995): Reduced cell motility and enhanced focal adhesion contact formation in cells from FAK-deficient mice. Nature $\underline{377}, 539-544$

Ingman AM, Ghosh P, Taylor TK (1974): Variation of collagenous and non-collagenous proteins of human knee joint menisci with age and degeneration. Gerontologia 20, 212223

Insall RH (2010): Understanding eukaryotic chemotaxis: a pseudopod-centred view. Nat Rev Mol Cell Biol 11, 453-458

Jansen $H$, Meffert RH, Birkenfeld F, Petersen W, Pufe T (2012): Detection of vascular endothelial growth factor (VEGF) in moderate osteoarthritis in a rabbit model. Ann Anat (Annals of anatomy $=$ Anatomischer Anzeiger official organ of the Anatomische Gesellschaft) 194 , 452-456

Jensen LK, Mikkelsen S, Loft IP, Eenberg W, Bergmann I, Logager V (2000): Radiographic knee osteoarthritis in floorlayers and carpenters. Scand J Work Environ Health 26, 257262

Johns DE, Athanasiou KA (2008): Growth factor effects on costal chondrocytes for tissue engineering fibrocartilage. Cell Tissue Res $\underline{333}, 439-447$

Jørgensen U, Sonne-Holm S, Lauridsen F, Rosenklint A (1987): Long-term follow-up of meniscectomy in athletes. A prospective longitudinal study. J Bone Joint Surg $\operatorname{Br} \underline{69}, 80$ 83

Jui H, Lin C, Hsu W, Liu Y, Hsu R, Chiang B, Tseng WI, Chen M, Wu KK, Lee C (2012): Autologous mesenchymal stem cells prevent transplant arteriosclerosis by enhancing local expression of interleukin-10, interferon- $\gamma$, and indoleamine 2,3-dioxygenase. Cell Transplant 21, 971-984 
Kaltalioglu K, Coskun-Cevher S, Tugcu-Demiroz F, Celebi N (2013): PDGF supplementation alters oxidative events in wound healing process: a time course study. Archives of dermatological research $\underline{305}, 415-422$

Kawada K, Upadhyay G, Ferandon S, Janarthanan S, Hall M, Vilardaga J, Yajnik V (2009): Cell migration is regulated by platelet-derived growth factor receptor endocytosis. Mol Cell Biol (Molecular and cellular biology) 29, 4508-4518

Kinnaird T, Stabile E, Burnett MS, Shou M, Lee CW, Barr S, Fuchs S, Epstein SE (2004): Local delivery of marrow-derived stromal cells augments collateral perfusion through paracrine mechanisms. Circulation $\underline{109}, 1543-1549$

Koelling S, Kruegel J, Irmer M, Path JR, Sadowski B, Miro X, Miosge N (2009): Migratory chondrogenic progenitor cells from repair tissue during the later stages of human osteoarthritis. Cell Stem Cell $\underline{4}$, 324-335

Kolf CM, Cho E, Tuan RS (2007): Mesenchymal stromal cells. Biology of adult mesenchymal stem cells: regulation of niche, self-renewal and differentiation. Arthritis Res Ther $\underline{9}, 204$

Kopf S, Birkenfeld F, Becker R, Petersen W, Starke C, Wruck CJ, Tohidnezhad M, Varoga D, Pufe $T$ (2010): Local treatment of meniscal lesions with vascular endothelial growth factor. J Bone Joint Surg Am 92, 2682-2691

Koressaar T, Remm M (2007): Enhancements and modifications of primer design program Primer3. Bioinformatics $\underline{23}, 1289-1291$

Kratchmarova I, Blagoev B, Haack-Sorensen M, Kassem M, Mann M (2005): Mechanism of divergent growth factor effects in mesenchymal stem cell differentiation. Science $\underline{308}$, 1472-1477

Kuettner KE (1992): Biochemistry of articular cartilage in health and disease. Clin Biochem $\underline{25}, 155-163$

Kundra V, Escobedo JA, Kazlauskas A, Kim HK, Rhee SG, Williams LT, Zetter BR (1994): Regulation of chemotaxis by the platelet-derived growth factor receptor-beta. Nature $\underline{367}, 474-476$

Kuo Y, Chen C, Shih H, Goto S, Huang C, Wang C, Chen C, Wei F (2011): Prolongation of composite tissue allotransplant survival by treatment with bone marrow mesenchymal stem cells is correlated with T-cell regulation in a swine hind-limb model. Plast Reconstr Surg $\underline{127}, 569-579$ 
Kusayama T, Harner CD, Carlin GJ, Xerogeanes JW, Smith BA (1994): Anatomical and biomechanical characteristics of human meniscofemoral ligaments. Knee Surg Sports Traumatol Arthrosc 2, $234-237$

Leung DW, Cachianes G, Kuang WJ, Goeddel DV, Ferrara N (1989): Vascular endothelial growth factor is a secreted angiogenic mitogen. Science $\underline{246}, 1306-1309$

Li X, Ponten A, Aase K, Karlsson L, Abramsson A, Uutela M, Backstrom G, Hellstrom M, Bostrom H, Li H et al. (2000): PDGF-C is a new protease-activated ligand for the PDGF alpha-receptor. Nat Cell Biol 2, 302-309

Liu C, Toma IC, Mastrogiacomo M, Krettek C, Lewinski G von, Jagodzinski M (2013): Meniscus reconstruction: today's achievements and premises for the future. Arch Orthop Trauma Surg $\underline{133}, 95-109$

Mabey T, Honsawek S, Saetan N, Poovorawan Y, Tanavalee A, Yuktanandana P (2014): Angiogenic cytokine expression profiles in plasma and synovial fluid of primary knee osteoarthritis. Int Orthop $\underline{38}, 1885-1892$

Maida Y, Kyo S, Kanaya T, Wang Z, Yatabe N, Tanaka M, Nakamura M, Ohmichi M, Gotoh N, Murakami S et al. (2002): Direct activation of telomerase by EGF through Etsmediated transactivation of TERT via MAP kinase signaling pathway. Oncogene 21 , 4071-4079

Makris EA, Hadidi P, Athanasiou KA (2011): The knee meniscus: structure-function, pathophysiology, current repair techniques, and prospects for regeneration. Biomaterials $\underline{32}, 7411-7431$

Martel-Pelletier J, Di Battista, J A, Lajeunesse D, Pelletier JP (1998): IGF/IGFBP axis in cartilage and bone in osteoarthritis pathogenesis. Inflamm Res $\underline{47}, 90-100$

Mattila PK, Lappalainen P (2008): Filopodia: molecular architecture and cellular functions. Nat Rev Mol Cell Biol $\underline{9}$, 446-454

McDermott ID, Sharifi F, Bull, A M J, Gupte CM, Thomas RW, Amis AA (2004): An anatomical study of meniscal allograft sizing. Knee Surg Sports Traumatol Arthrosc $\underline{12}$, $130-135$

McDevitt CA, Webber RJ (1990): The ultrastructure and biochemistry of meniscal cartilage. Clin Orthop Relat Res 252, 8-18

Michael JW, Schlüter-Brust KU, Eysel P (2010): The epidemiology, etiology, diagnosis, and treatment of osteoarthritis of the knee. Dtsch Arztebl Int 107, 152-162 
Mishima Y, Lotz M (2008): Chemotaxis of human articular chondrocytes and mesenchymal stem cells. J Orthop Res $\underline{26}, 1407-1412$

Mitchell NS, Cruess RL (1977): Classification of degenerative arthritis. Can Med Assoc J 117, 763-765

Murphy JM, Fink DJ, Hunziker EB, Barry FP (2003): Stem cell therapy in a caprine model of osteoarthritis. Arthritis Rheum $\underline{48}, 3464-3474$

Murray IR, West CC, Hardy WR, James AW, Park TS, Nguyen A, Tawonsawatruk T, Lazzari L, Soo C, Péault B (2014): Natural history of mesenchymal stem cells, from vessel walls to culture vessels. Cell Mol Life Sci (Cellular and molecular life sciences CMLS) $\underline{71}$, 1353-1374

Nelson EW, LaPrade RF (2000): The anterior intermeniscal ligament of the knee. An anatomic study. Am J Sports Med $\underline{28}, 74-76$

Nero P, Nogueira I, Vilar R, Pimentao JB, Branco JC (2006): Synovial fluid crystal identification by electron microscopy. Acta Reumatol Port $\underline{31}, 75-81$

Nobes CD, Hall A (1995): Rho, rac, and cdc42 GTPases regulate the assembly of multimolecular focal complexes associated with actin stress fibers, lamellipodia, and filopodia. Cell $\underline{81}, 53-62$

Noble J, Hamblen DL (1975): The pathology of the degenerate meniscus lesion. J Bone Joint Surg $\operatorname{Br} \underline{57}, 180-186$

Ohlstein B, Kai T, Decotto E, Spradling A (2004): The stem cell niche: theme and variations. Curr Opin Cell Biol 16, 693-699

Olson LE, Soriano P (2011): PDGFR $\beta$ signaling regulates mural cell plasticity and inhibits fat development. Dev Cell (Developmental cell) 20, 815-826

Olson SA, Horne P, Furman B, Huebner J, Al-Rashid M, Kraus VB, Guilak F (2014): The role of cytokines in posttraumatic arthritis. J Am Acad Orthop Surg 22, 29-37

Partridge MA, Marcantonio EE (2006): Initiation of attachment and generation of mature focal adhesions by integrin-containing filopodia in cell spreading. Mol Biol Cell 17, 4237-4248

Pellegrin S, Mellor H (2007): Actin stress fibres. J Cell Sci 120, 3491-3499

Petersen W, Tillmann B (1995): Age-related blood and lymph supply of the knee menisci. A cadaver study. Acta Orthop Scand $\underline{66}, 308-312$ 
Petersen W, Tillmann B (1999): Struktur und Blutgefässversorgung der Kniegelenkmenisken. Z Orthop Ihre Grenzgeb 137, 31-37

Petersson IF (1996): Occurrence of osteoarthritis of the peripheral joints in European populations. Ann Rheum Dis $\underline{55}$, 659-661

Petersson IF, Jacobsson, LT (2002): Osteoarthritis of the peripheral joints. Best Pract Res Clin Rheumatol $\underline{16}, 741-760$

Pfaffl MW (2001): A new mathematical model for relative quantification in real-time RT-PCR. Nucleic Acids Res $\underline{29}$, e45

Pinto D, Gregorieff A, Begthel H, Clevers H (2003): Canonical Wnt signals are essential for homeostasis of the intestinal epithelium. Genes Dev $\underline{17}, 1709-1713$

Pittenger MF, Mackay AM, Beck SC, Jaiswal RK, Douglas R, Mosca JD, Moorman MA, Simonetti DW, Craig S, Marshak DR (1999): Multilineage Potential of Adult Human Mesenchymal Stem Cells. Science 284, 143-147

Pollard TD, Borisy GG (2003): Cellular motility driven by assembly and disassembly of actin filaments. Cell $\underline{112}, 453-465$

Ponte AL, Marais E, Gallay N, Langonne A, Delorme B, Herault O, Charbord P, Domenech J (2007): The in vitro migration capacity of human bone marrow mesenchymal stem cells: comparison of chemokine and growth factor chemotactic activities. Stem Cells $\underline{25}$, 17371745

Radin EL, Rose RM (1986): Role of subchondral bone in the initiation and progression of cartilage damage. Clin Orthop Relat Res $\underline{213}, 34-40$

Rafelski SM, Theriot JA (2004): Crawling toward a unified model of cell mobility: spatial and temporal regulation of actin dynamics. Annu Rev Biochem $\underline{73}$, 209-239

Ridley AJ, Paterson HF, Johnston CL, Diekmann D, Hall A (1992): The small GTP-binding protein rac regulates growth factor-induced membrane ruffling. Cell $\underline{70}, 401-410$

Rönnstrand L, Heldin CH (2001): Mechanisms of platelet-derived growth factor-induced chemotaxis. Int J Cancer $\underline{91}, 757-762$

Sabeh F, Ota I, Holmbeck K, Birkedal-Hansen H, Soloway P, Balbin M, Lopez-Otin C, Shapiro S, Inada M, Krane S et al. (2004): Tumor cell traffic through the extracellular matrix is controlled by the membrane-anchored collagenase MT1-MMP. J Cell Biol $\underline{167}$, 769-781 
Salehinejad P, Alitheen NB, Mandegary A, Nematollahi-Mahani SN, Janzamin E (2013): Effect of EGF and FGF on the expansion properties of human umbilical cord mesenchymal cells. In Vitro Cell Dev Biol Anim (In vitro cellular \& developmental biology. Animal) $\underline{49}, 515-523$

Sanchez-Adams J, Athanasiou KA (2009): The Knee Meniscus: A Complex Tissue of Diverse Cells. Cel Mol Bioeng (Cellular and Molecular Bioengineering) 2, 332-340

Sanchez-Adams J, Athanasiou KA (2012): Biomechanics of meniscus cells: regional variation and comparison to articular chondrocytes and ligament cells. Biomech Model Mechanobiol 11, 1047-1056

Sarugaser R, Ennis J, Stanford WL, Davies JE (2009): Isolation, propagation, and characterization of human umbilical cord perivascular cells (HUCPVCs). Methods Mol Biol (Methods in molecular biology (Clifton, N.J.)) 482, 269-279

Savage, C R Jr, Inagami T, Cohen S (1972): The primary structure of epidermal growth factor. J Biol Chem 247, 7612-7621

Schmidt MB, Chen EH, Lynch SE (2006): A review of the effects of insulin-like growth factor and platelet derived growth factor on in vivo cartilage healing and repair. Osteoarthr Cartil (Osteoarthritis and cartilage / OARS, Osteoarthritis Research Society) 14, 403412

Schneider IC, Haugh JM (2006): Mechanisms of gradient sensing and chemotaxis: conserved pathways, diverse regulation. Cell Cycle $\underline{5}, 1130-1134$

Schneider S, Schmitt G, Mau H, Schmitt H, Sabo D, Richter W (2005): Prävalenz und Korrelate der Osteoarthrose in der BRD. Orthopäde $\underline{34}, 782-790$

Schober M, Raghavan S, Nikolova M, Polak L, Pasolli HA, Beggs HE, Reichardt LF, Fuchs E (2007): Focal adhesion kinase modulates tension signaling to control actin and focal adhesion dynamics. J Cell Biol 176, 667-680

Schofield R (1978): The relationship between the spleen colony-forming cell and the haemopoietic stem cell. Blood Cells $\underline{4}, 7-25$

Schünke M, Schulte E, Schumacher U: Prometheus: LernAtlas der Anatomie: Allgemeine Anatomie und Bewegungssystem, 2. Auflage; Thieme, Stuttgart 2007

Segall JE, Tyerech S, Boselli L, Masseling S, Helft J, Chan A, Jones J, Condeelis J (1996): EGF stimulates lamellipod extension in metastatic mammary adenocarcinoma cells by an actin-dependent mechanism. Clin Exp Metastasis 14, 61-72 
Simmons PJ, Torok-Storb B (1991): Identification of stromal cell precursors in human bone marrow by a novel monoclonal antibody, STRO-1. Blood $\underline{78}, 55-62$

Snoeker, BA, Bakker, EW, Kegel, CA, Lucas C (2013): Risk factors for meniscal tears: a systematic review including meta-analysis. J Orthop Sports Phys Ther $\underline{43}, 352-367$

Solomon L (1976): Patterns of osteoarthritis of the hip. J Bone Joint Surg Br $\underline{58}, 176-183$

Song X, Xie T (2002): DE-cadherin-mediated cell adhesion is essential for maintaining somatic stem cells in the Drosophila ovary. Proc Natl Acad Sci U S A 99, 14813-14818

Spector TD, Cicuttini F, Baker J, Loughlin J, Hart D (1996): Genetic influences on osteoarthritis in women: a twin study. BMJ $\underline{312}, 940-943$

Spindler KP, Mayes CE, Miller RR, Imro AK, Davidson JM (1995): Regional mitogenic response of the meniscus to platelet-derived growth factor (PDGF-AB). J Orthop Res $\underline{13}$, 201-207

Steed DL (2006): Clinical evaluation of recombinant human platelet-derived growth factor for the treatment of lower extremity ulcers. Plast Reconstr Surg 117, 143S-149S; discussion 150S-151S

Stewart CE, Rotwein P (1996): Growth, differentiation, and survival: multiple physiological functions for insulin-like growth factors. Physiol Rev $\underline{76}$, 1005-1026

Sun X, Gao X, Zhou L, Sun L, Lu C (2013): PDGF-BB-induced MT1-MMP expression regulates proliferation and invasion of mesenchymal stem cells in 3-dimensional collagen via MEK/ERK1/2 and PI3K/AKT signaling. Cell Signal 25, 1279-1287

Sun Y, Mauerhan DR (2012): Meniscal calcification, pathogenesis and implications. Curr Opin Rheumatol 24, 152-157

Sun Y, Mauerhan DR, Kneisl JS, James Norton H, Zinchenko N, Ingram J, Hanley EN, Gruber HE (2012): Histological examination of collagen and proteoglycan changes in osteoarthritic menisci. Open Rheumatol J $\underline{6}, 24-32$

Svitkina TM, Bulanova EA, Chaga OY, Vignjevic DM, Kojima S, Vasiliev JM, Borisy GG (2003): Mechanism of filopodia initiation by reorganization of a dendritic network. J Cell Biol 160, 409-421

Swaney KF, Huang C, Devreotes PN (2010): Eukaryotic chemotaxis: a network of signaling pathways controls motility, directional sensing, and polarity. Annu Rev Biophys $\underline{39}$, 265289 
Sweeney HL, Houdusse A (2010): Structural and functional insights into the Myosin motor mechanism. Annu Rev Biophys $\underline{39}, 539-557$

Totsukawa G, Wu Y, Sasaki Y, Hartshorne DJ, Yamakita Y, Yamashiro S, Matsumura F (2004): Distinct roles of MLCK and ROCK in the regulation of membrane protrusions and focal adhesion dynamics during cell migration of fibroblasts. J Cell Biol $\underline{164}, 427-439$

Untergasser A, Cutcutache I, Koressaar T, Ye J, Faircloth BC, Remm M, Rozen SG (2012): Primer3--new capabilities and interfaces. Nucleic Acids Res $\underline{40}$, e115

Vasioukhin V, Bauer C, Yin M, Fuchs E (2000): Directed actin polymerization is the driving force for epithelial cell-cell adhesion. Cell 100, 209-219

Vicente-Manzanares M, Zareno J, Whitmore L, Choi CK, Horwitz AF (2007): Regulation of protrusion, adhesion dynamics, and polarity by myosins IIA and IIB in migrating cells. $\mathrm{J}$ Cell Biol $\underline{176}, 573-580$

Vorotnikov AV (2011): Chemotaxis: movement, direction, control. Biochemistry (Mosc) $\underline{76}$, $1528-1555$

Vrancken AC, Buma P, van Tienen TG (2013): Synthetic meniscus replacement: a review. Int Orthop 37, 291-299

Walker PS, Erkman MJ (1975): The role of the menisci in force transmission across the knee. Clin Orthop Relat Res $\underline{109}, 184-192$

Wan AC, Felle P (1995): The menisco-femoral ligaments. Clin Anat $\underline{8}, 323-326$

Watt FM, Hogan BL (2000): Out of Eden: stem cells and their niches. Science 287, 14271430

Wilkinson PC (1990): How do leucocytes perceive chemical gradients? FEMS Microbiology Letters $\underline{64}, 303-311$

Williams LT (1989): Signal transduction by the platelet-derived growth factor receptor. Science $\underline{243}, 1564-1570$

Wilson A, Trumpp A (2006): Bone-marrow haematopoietic-stem-cell niches. Nat Rev Immunol $\underline{6}$, 93-106

Wolf K, Te Lindert M, Krause M, Alexander S, Te Riet J, Willis AL, Hoffman RM, Figdor CG, Weiss SJ, Friedl P (2013): Physical limits of cell migration: control by ECM space and nuclear deformation and tuning by proteolysis and traction force. J Cell Biol 201, 10691084 
Yao J, Lancianese SL, Hovinga KR, Lee J, Lerner AL (2008): Magnetic resonance image analysis of meniscal translation and tibio-menisco-femoral contact in deep knee flexion. J Orthop Res $\underline{26}, 673-684$

Zigmond SH, Hirsch JG (1973): Leukocyte locomotion and chemotaxis. New methods for evaluation, and demonstration of a cell-derived chemotactic factor. J Exp Med 137, 387410 


\section{Danksagungen}

Ich würde mich hiermit gerne bei allen Menschen bedanken, die mich bei dieser Doktorarbeit unterstützt haben.

Dazu gehört an erster Stelle Herr Prof. Dr. N. Miosge als Betreuer, der mich in die Forschungsgruppe einführte und mich jederzeit nach Kräften unterstützte. Ich danke inm ausdrücklich für die Unterstützung und Erklärungsbereitschaft bei fachlichen und methodischen Fragen sowie seine große Diskussionsbereitschaft und seine schnelle und unkomplizierte Ansprechbarkeit.

Des Weiteren möchte ich mich gerne bei allen Mitgliedern der Arbeitsgruppe „Orale Biologie und Geweberegeneration“ für ihre gegenseitige Unterstützung und ihre Freundschaft bedanken. Insbesondere gilt dieser Dank Herrn Dr. med. dent. Boris Schminke, Herrn Dipl.Biol. Gökhan Cingöz, Herrn PhD Hayat Muhammad sowie Frau Christa Bode und Frau Boguslawa Sadowski für ihre große methodische und fachliche Unterstützung sowie ihre generelle Hilfsbereitschaft, ohne die diese Arbeit nicht möglich gewesen wäre. 